
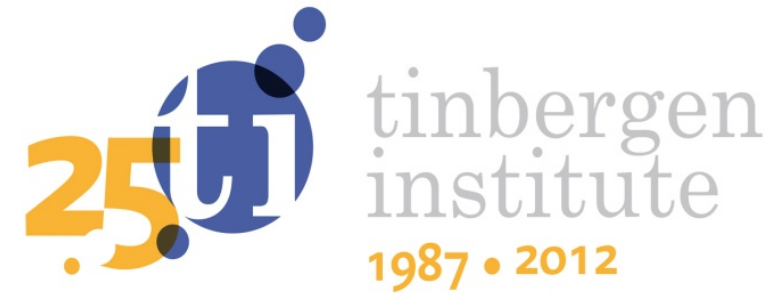

\title{
Search Costs, Demand-Side Economies and the Incentives to Merge under Bertrand Competition
}

José L. Moraga-González',2

Vaiva Petrikaitéz

1 VU University Amsterdam, and Tinbergen Institute;

2 University of Groningen. 
Tinbergen Institute is the graduate school and research institute in economics of Erasmus University Rotterdam, the University of Amsterdam and VU University Amsterdam.

More TI discussion papers can be downloaded at http://www.tinbergen.nl

Tinbergen Institute has two locations:

Tinbergen Institute Amsterdam

Gustav Mahlerplein 117

1082 MS Amsterdam

The Netherlands

Tel.: +31(0)205251600

Tinbergen Institute Rotterdam

Burg. Oudlaan 50

3062 PA Rotterdam

The Netherlands

Tel.: +31(0)10 4088900

Fax: $+31(0) 104089031$

Duisenberg school of finance is a collaboration of the Dutch financial sector and universities, with the ambition to support innovative research and offer top quality academic education in core areas of finance.

DSF research papers can be downloaded at: http://www.dsf.nl/

Duisenberg school of finance

Gustav Mahlerplein 117

1082 MS Amsterdam

The Netherlands

Tel.: +31(0)20 5258579 


\title{
Search Costs, Demand-Side Economies and the Incentives to Merge under Bertrand Competition*
}

\author{
José L. Moraga-González $\quad$ Vaiva Petrikaitė
}

Revised: February 2012

\begin{abstract}
This paper studies the incentives to merge in a Bertrand competition model where firms sell differentiated products and consumers search for satisfactory deals. In the pre-merger symmetric equilibrium, the probability that a firm is the next one to be visited by a consumer is equal across firms not yet visited. However, in the short-run after a merger, because insiders raise their prices more than what the outsiders do, consumers start searching for good deals at the non-merging stores. Only when they do not find any product satisfactory enough, they continue searching at the merging stores. When search costs are sufficiently large, consumer traffic from the non-merging firms to the merged ones is so small that mergers become unprofitable. This new merger paradox, which is more likely the higher the number of non-merging firms, can be overcome in the mediumto long-run if the merging firms choose to stock their shelves with all the products of the constituent firms, which generates sizable search economies. Such demand-side economies can confer the merging firms a prominent position in the marketplace, in which case their price may even be lower than the price of the outsiders. In that case, consumers visit first the merged entity and the firms outside the merger lose out. Search cost economies may render a merger beneficial for consumers and so overall welfare may increase.
\end{abstract}

Keywords: mergers, insiders, outsiders, short-run, long-run, consumer search, demand-side economies, economies of search, order of search, sequential search, prominence

JEL Classification: D40, D83, L13

${ }^{*}$ This paper subsumes our working paper Moraga-González and Petrikaitè (2011). We thank Mark Armstrong, Heski Bar-Isaac, Luis Cabral, Remco van Eijkel, Giulio Federico, Allard van der Made, Evgenia Motchenkova, Marielle Non, Zsolt Sándor, Makoto Watanabe and specially Jidong Zhou and Chris Wilson for observations that helped us improve this paper. The paper has also benefited from presentations at the Dutch Competition Authority (NMa), IESE Business School, University of Amsterdam, University of Bologna, University Pompeu Fabra, the IIOC 2009 in Boston, the EARIE 2009 meetings in Liubljana and the 1st Groningen Workshop on Search and Switching Costs (December 2009). Financial support from the Marie Curie Excellence Grant MEXT-CT-2006-042471 is gratefully acknowledged.

${ }^{\dagger}$ VU University Amsterdam and University of Groningen. E-mail: j.l.moragagonzalez@vu.nl. Moraga is also affiliated with the Tinbergen Institute, the CEPR, and the Public-Private Sector Research Center (IESE, Barcelona).

${ }^{\ddagger}$ University of Groningen, E-mail: v.petrikaite@rug.nl. 


\section{Introduction}

While no one would deny that searching for price and product fit is costly in real-world markets think for example about the time we spend test-driving new cars, acquiring new furniture, touching digital tablets, trying on new clothes and shoes, etc.- there has been little work in the industrial organization literature about the influence of search costs on the incentives to merge and on the aggregate implications of mergers. In this paper we offer three novel insights. First, in markets where search costs are sizable, a merger (of firms selling differentiated products and competing in prices) may result in losses for the merging parties in the short-run. Second, if the merged entity in the long-run chooses to stock the shelves of its shops with all the products of the constituent firms, then search economies unfold and mergers can become profitable and welfare improving. Finally, when search costs are considerable, the outsider firms lose out in the long-run.

We study mergers in a model that could well be referred to as the workhorse model of consumer search for differentiated products. This model was introduced by Wolinsky (1986) and was further studied by Anderson and Renault (1999). ${ }^{1}$ A finite number of firms compete in prices to sell their differentiated products. Consumers search for satisfactory deals sequentially and have perfect recall. In the pre-merger market, all firms look alike and when consumers pick a first shop to visit, they do so in a random way. Those consumers who fail to find a satisfactory product continue searching and once again they pick the next shop to be visited randomly; and so on. When search cost is equal to zero, the model is similar to Perloff and Salop (1985) and the analysis of mergers gives the same results as in Deneckere and Davidson (1985).

However, the existence of search costs makes the order in which consumers visit firms to depend on the prices they charge and on the amount of variety they carry. We distinguish between the short-run and the long-run effects of mergers. In the short-run, firms that merge coordinate their prices and everything else is kept constant. In the long-run, by contrast, the merged entity, after a more or less complex process of business reorganization, stocks its products together, shutting down some of the stores of the parent firms if economical.

Price coordination among the merging firms leads them to charge higher prices than the nonmerging firms' prices. Given this, optimal search leads consumers to search first at the non-merging firms and then, in the event they fail to find a satisfactory product in those firms, continue searching at the merging stores. Therefore, the merging firms, by internalizing the pricing externalities they confer on one another, confer the non-merging firms a prominent position in the marketplace. This puts the merging firms at a disadvantage; in equilibrium, as search costs increase, consumer traffic from the

\footnotetext{
${ }^{1}$ More recently, this model has been used to explain incentives to invest in quality (Wolinsky, 2005), product-design differentiation (Bar-Isaac et al., 2011) and the emergence and effects of market prominence (Armstrong et al., 2009; Armstrong and Zhou, 2011; Haan and Moraga-González, 2011; Zhou, 2009).
} 
non-merging stores to the shops of the merged entity diminishes, which makes merging less profitable. We show that any 2-firm merger is unprofitable if search costs are sufficiently high. Moreover, we show that any arbitrary $k$-firm merger becomes unprofitable if search costs and the number of non-merging firms are sufficiently high. With these results we establish a new merger paradox. What is interesting about this paradox is that it arises when firms sell horizontally differentiated products and compete in prices.

In the long-run, however, the merged entity can counter the detrimental effects of price coordination by choosing to stock in each of its shops all the products of the constituent firms. ${ }^{2}$ By stocking a wider range of products, the merged entity effectively lowers the costs of searching the products of the potentially merging firms. This generates demand-side economies that may give the merged entity a prominent position in the marketplace. We show that when the economies of search are sufficiently strong, in the unique symmetric equilibrium of the post-merger market, the merged entity gains prominence in the marketplace and attracts all consumer first-visits. If unsatisfied with the deals available there, consumers continue searching at the non-merging stores.

In contrast to the paradoxical result found in the short-run, we show that in the long-run merging becomes individually rational provided that search costs are sufficiently high. In addition, and in contrast to most papers on mergers, we find that the outsiders' profits decrease after a merger takes place. These two results together are important since they provide a new theoretical rationale for why merger waves can be observed in the real-world and also for why the outsiders to a merger sometimes oppose consolidation processes of rival firms. We finally show that in the long-run consumers may even benefit from consolidation in the marketplace because the benefits from lower search frictions along with the possibility that the insiders charge lower prices than the outsiders may jointly result in a net positive effect.

The literature on the incentives to merge and the aggregate implications of mergers is quite extensive. For a recent survey of the main theoretical and empirical insights see Whinston (2006). A seminal paper in the literature is Salant et al. (1983), who demonstrated that merging is not very attractive in environments where firms compete in quantities and offer similar products. This result is referred to as the merger paradox. Deneckere and Davidson (1985) showed that price-setting firms selling horizontally differentiated products, other things equal, always have an incentive to merge. In contrast to the Cournot case analyzed by Salant et al. (1983), this result arises because price increases of the merging firms, which favor the coalition partners, are accompanied by price increases of the

\footnotetext{
${ }^{2}$ Hewlett Packard and Compaq, whose merger was cleared in 2002, soon started selling each other products in their separate online shops; in recent days, the merged entity has chosen to downplay the Compaq name in its products. KLM, which merged Air France in a transaction that was cleared subject to conditions in 2004, sells flights operated by Air France in its online shop, and viceversa. Daimler-Benz and Chrysler merged in 1998 but their retail sales largely remained separate; this hindered Chrysler's market penetration in Europe and added to the difficulties experienced by the automobile giant short after merging.
} 
non-merging firms, which also favors them. Our paper puts forward a new merger paradox, which surprisingly arises under price competition with differentiated products. The underlying reason is based on the impact of price coordination on optimal consumer search, something quite different from the merger paradox of Salant et al. (1983), which concerns competition with decision variables that are strategic substitutes.

Since the seminal paper of Williamson (1968), the role of mergers at generating supply-side economies (or cost-synergies) that can more than offset the market power effects of consolidation has been the focus of a considerable amount of research. Perry and Porter (1985), Farrell and Shapiro (1990) and McAfee and Williams (1992) explicitly modelled the cost efficiencies that arise from economies of sharing assets in product markets and stated conditions for an efficiency defense of mergers. Our paper brings out a new efficiency defence argument of mergers, but based on demandrather than on supply-side economies. We show that the economies of search that unfold in the longrun when the merging firms stock wider ranges of products can result in the merging firms becoming prominent in the marketplace, thereby weakening (and sometimes even more than offsetting) their incentives to raise prices above the outsider firms and making a merger welfare-improving.

To the best of our knowledge, the US and EU guidelines do not mention demand-side economies arising from merger activity. By contrast, Section 5.7 of the 2010 Merger Assessment Guidelines of the UK Competition Commission and the Office of Fair Trading acknowledges the importance of demandside efficiencies in merger control. However, the guidelines focus mainly on cases where consumer buy multiple items and product complementarities are significant: "Demand-side efficiencies arise if the attractiveness to customers of the merged firm's products increases as a result of the merger. Common examples of demand-side efficiencies include: network effects, pricing effects and 'one-stop shopping'. ${ }^{3}$ The argument in our paper is clearly different and we hope that it adds to the design of finer merger guidelines. We show that demand-side efficiencies can also unfold when products are substitutes and consumers buy a single product. It is savings in search costs that make visiting first the merged entity a more attractive option than visiting first the outsiders. It is obvious that this mechanism should continue to hold in markets where there are product complementarities or where consumers buy a range of products.

Since in the post-merger market consumers visit merging and non-merging firms in an order that maximizes expected utility, our paper is also related to the recent literature on ordered search. Arbatskaya (2007) studies a market for homogeneous products where the order in which firms are visited

\footnotetext{
${ }^{3}$ Merger Assessment Guidelines (OFT1254, p.57, 2010). With network effects, users place a higher value for a product the more it is used by other consumers. A merger may make networks compatible and so enhance the welfare of consumers. Pricing effects arise when bringing complement products under common ownership, which may results in lower prices for all products. Gains from one-stop shopping arise when consumers have a strong preference for buying a range of products at a single supplier.
} 
is exogenously given. In equilibrium prices must fall as the consumer walks away from the firms visited first. Zhou (2011) considers the case of differentiated products and finds the opposite result. Armstrong, Vickers and Zhou (2009) study the implications of prominence in search markets. In their model, there is a firm that is always visited first and this firm charges lower prices and derives greater profits than the rest of the firms, which are visited randomly after consumers have visited the prominent firm. Zhou (2009) extends the ideas in Armstrong et al. (2009) to the case in which a set of firms, rather than just one, is prominent. In Haan and Moraga-González (2011) firms gain prominence by investing in advertising; they find that firms need not benefit from higher consumer search costs. Armstrong and Zhou (2011) present alternative ways in which firms can become prominent. In our model, the merging stores, by raising their prices to internalize the pricing externalities they exert on one another, confer the non-merging firms a prominent position in the marketplace. This effect is detrimental for the merging firms and we show that it leads to a new merger paradox when search costs are significant. In the long-run, however, the merging firms can choose to stock the wider range of products of the parent firms so as to effectively lower search costs and become prominent in the marketplace.

Our paper is also related to a strand of the consumer search literature dealing with firm's choice of location, entry and choice of product-lines. Our paper and those papers have in common that consumer search economies play a central role. In Stahl (1982) and Wolinsky (1983) savings in search costs can explain the observed geographical concentration of stores selling differentiated products. Fischer and Harrington (1996) go one step further and investigate the role of product heterogeneity in explaining interindustry variation in firm agglomeration. Schulz and Stahl (1996) show that economies of scope in search costs can lead to excessive (price-increasing) entry. Economies of scope in shopping costs also arise when consumers buy multiple products and prefer to concentrate their purchases within a single supplier (one-stop shopping). Klemperer (1992) shows that in these situations firms may prefer head-to-head competition over product-line differentiation. In a subsequent paper, Klemperer and Padilla (1997) show that search cost economies can lead to excessive product-line variety.

The remainder of the paper is organized as follows. Section 2 describes the consumer search model and the benchmark pre-merger market equilibrium. Section 3 presents the analysis of mergers, for both cases, merger effects in the short-run and merger effects in the long-run. Section 4 offers a discussion of the main results. Section 5 concludes. The proofs are placed in the appendix to ease the reading of the paper. 


\section{The model and the pre-merger symmetric equilibrium}

We study the model of consumer search for differentiated products first proposed by Wolinsky (1986) and further studied by Anderson and Renault (1999). On the supply side of the market there are $n$ firms selling horizontally differentiated products. All firms employ the same constant returns to scale technology of production and we normalize unit production costs to zero. Firms compete in prices and they choose them simultaneously. On the demand side of the market, there is a unit mass of consumers. A consumer $m$ has tastes described by an indirect utility function $u^{m i}\left(p_{i}\right)=\varepsilon_{m i}-p_{i}$, if she buys product $i$ at price $p_{i}$. The parameter $\varepsilon_{m i}$ can be thought of as a match value between consumer $m$ and product $i$. We assume that the $\varepsilon_{m i}$ is the realization of a random variable uniformly distributed on $[0,1] .{ }^{4}$ Match values are independently distributed across consumers and products. No firm can observe $\varepsilon_{m i}$ so personalised pricing is not possible. Define $z_{k} \equiv \max \left\{\varepsilon_{1}, \varepsilon_{2}, \ldots, \varepsilon_{k}\right\}$. For later reference, it is useful to calculate the optimal price of a multi-product monopolist selling $k$ varieties, which we denote by $p_{k}^{m}$. This price maximizes the expression $p\left(\operatorname{Pr}\left[z_{k} \geq p\right]\right)$, and is given by $p_{k}^{m}=(1+k)^{-\frac{1}{k}}$. Setting $k=1$ we have the single-product monopolist, whose price is simply denoted by $p^{m}$ and is equal to $1 / 2$.

Consumers search sequentially with costless recall. Each search costs the consumer $s .{ }^{5}$ To avoid that a market equilibrium fails to exist (Diamond, 1971), we assume throughout that $s$ is sufficiently small so as to make a first search always worthwhile for a consumer. The entire paper revolves around the case where search costs are sizable. It is such case that delivers new and interesting results. In fact, when $s=0$ the model is similar to Perloff and Salop (1985) and the effects of mergers in that case are similar to Deneckere and Davidson (1985).

\section{The pre-merger market equilibrium}

As a benchmark case, in this Section we characterize the pre-merger market symmetric equilibrium. ${ }^{6}$ Here we assume that search cost $s \in[0,1 / 8] .^{7}$

Following Wolinsky (1986), let $p^{*}$ denote the price charged by firms other than firm $i$ and consider

\footnotetext{
${ }^{4}$ The uniform distribution is adopted for simplicity, specially in the subsequent analysis of mergers. In an earlier paper Moraga-González and Petrikaitè (2011) we showed that alternative distributions give similar results.

${ }^{5}$ Though we can view this assumption as a standard Nash assumption, rationalizing it requires some sophistication on the part of consumers. In fact, we shall assume that consumers do know the ownership structure of the firms, their prices and the number of products sold in each of the establishments.

${ }^{6}$ We note that asymmetric equilibria can be sustained in this model. The idea is that if consumers believe that firms' prices follow the order, say, $p_{1}<p_{2}<\ldots<p_{n}$, then it is optimal for consumers to visit firms in that order and for firms to price in such a way so as to make consumer beliefs coherent. The unattractive feature of these equilibria is that they are not determined by the underlying characteristics of the market, but by an indeterminacy of beliefs. We will ignore this type of equilibria in our paper. A completely different situation is that studied in Armstrong et al. (2009) and Zhou (2011) where it is assumed that the shops of the firms are arranged in a particular way so consumers have no alternative than to visit them in a pre-specified exogenous order.

${ }^{7}$ We need to make sure that the first search is always worth. The worse case is when consumers expect the firms to charge the monopoly price. Therefore we require that $s \leq \operatorname{Pr}\left[\varepsilon \geq p^{m}\right] E\left[\varepsilon-p^{m} \mid \varepsilon \geq p^{m}\right]$, which is equivalent to $s \leq \bar{s} \equiv\left(1-p^{m}\right)^{2} / 2$. Since $p^{m}=1 / 2, s \leq 1 / 8$ suffices.
} 
the (expected) payoff to a firm $i$ that deviates from the symmetric equilibrium by charging a price $p_{i} \neq p^{*}$. In order to compute firm $i$ 's demand, we need to characterize consumer search behavior. Kohn and Shavell (1974) characterize the solution of the search problem of a consumer who faces a sequence of independently and identically distributed population of options with known distribution. They show that the optimal decision rule is static in nature and has the "reservation value property". Accordingly, let $\bar{x}$ be the solution to

$$
\int_{x}^{1}(\varepsilon-x) d \varepsilon=\frac{1}{2}(1-x)^{2}=s .
$$

The left-hand-side of (1) is the expected benefit from searching one more time if the best option so far is $x$. Searching one more time is worthwhile if and only if these incremental benefits exceed the cost of search $s$. Therefore, $\bar{x}=1-\sqrt{2 s}$ represents the threshold match value above which a consumer will decide not to continue searching for another product. Since $s \in[0,1 / 8]$, we have that $\bar{x} \in[1 / 2,1]$.

We start by computing the probability that a consumer accepts the offer of firm $i$, conditional on the consumer visiting firm $i$ first. Suppose that the purchase option at firm $i$ gives the buyer utility $\varepsilon_{i}-p_{i}$. If $\varepsilon_{i}-p_{i}<0$, the consumer will search again given our assumption $s<\bar{s}$. Suppose $\varepsilon_{i}-p_{i} \geq 0$. The equilibrium requirement that consumer expectations are fulfilled implies that a buyer who contemplates searching again expects to see a price of $p^{*}$ at the next shop to be visited. Therefore, searching one more time, say at firm $j$, yields expected gains equal to $\int_{\varepsilon_{i}-p_{i}+p^{*}}^{1}\left[\varepsilon_{j}-\left(\varepsilon_{i}-p_{i}+p^{*}\right)\right] d \varepsilon_{j}$.

In any equilibrium it must be the case that $\bar{x} \geq p^{*}$ for otherwise no consumer would participate in the market. Therefore, the probability that a buyer stops searching at firm $i$ given that firm $i$ is visited first, is equal to $\operatorname{Pr}\left[\varepsilon_{i}-p_{i}+p^{*}>\bar{x}\right]=1-\bar{x}-p_{i}+p^{*} .^{8}$

Before visiting firm $i$, the consumer may have visited other firm(s). The probability that a consumer goes to firm $i$ in her second search after having visited, say, firm $j$, and decides to acquire the offering of firm $i$ right away is $\operatorname{Pr}\left[\varepsilon_{i}-p_{i}>\bar{x}-p^{*}>\varepsilon_{j}-p^{*}\right]=\bar{x}\left(1-\bar{x}-p_{i}+p^{*}\right)$. Similarly, the probability that a consumer goes to firm $i$ in her $\ell^{\text {th }}$ search and decides to acquire the offering of firm $i$ right away is $\bar{x}^{\ell-1}\left(1-\bar{x}-p_{i}+p^{*}\right)$.

To complete firm $i$ 's payoff calculation, we need to compute the joint probability that a consumer walks away from every single firm in the market and happens to return to firm $i$ to conduct a transaction, that is, $\operatorname{Pr}\left[\max \left\{0, z_{n-1}-p^{*}\right\}<\varepsilon_{i}-p_{i}<\bar{x}-p^{*}\right]$. This probability is independent of the order in which firms are visited. We will denote it as $r_{a}(\cdot)$ to indicate that these sales originate from consumers who return to a firm $i$ after having visited all the firms in the market. We then have:

$$
r_{a}\left(p_{i} ; p^{*}\right) \equiv \int_{p_{i}}^{\bar{x}+p_{i}-p^{*}}\left(\varepsilon_{i}-p_{i}+p^{*}\right)^{n-1} d \varepsilon_{i}=\int_{0}^{\bar{x}-p^{*}}\left(\varepsilon_{i}+p^{*}\right)^{n-1} d \varepsilon_{i}=\frac{1}{n}\left(\bar{x}^{n}-p^{* n}\right) .
$$

${ }^{8}$ This probability is positive provided that the deviating price is not too high, i.e., $p_{i}<1-\bar{x}+p^{*}$ for otherwise every single consumer would walk away from firm $i$. In what follows we derive the payoff of a firm under the assumption that $p_{i}<1-\bar{x}+p^{*}$. When this inequality does not hold, the payoff is slightly different. We deal with this case later (see footnote 9$)$. 
Using the notation introduced above, we can now write firm $i$ 's expected profits:

$$
\pi_{i}\left(p_{i} ; p^{*}\right)=p_{i}\left[\frac{1-\bar{x}^{n}}{n(1-\bar{x})}\left(1-\bar{x}-p_{i}+p^{*}\right)+r_{a}\left(p_{i} ; p^{*}\right)\right] .
$$

We look for a symmetric Nash equilibrium in prices. After applying symmetry, i.e., $p_{i}=p^{*}$, the first-order condition (FOC) is:

$$
1-p^{* n}-p^{*} \frac{1-\bar{x}^{n}}{1-\bar{x}}=0
$$

It is easy to check that (4) has a unique solution that satisfies $\bar{x} \geq p^{*} \geq 1-\bar{x}^{9}$ In addition, one can readily show that the equilibrium price increases in the search cost $s$.

The profits of a typical firm in the pre-merger situation are

$$
\pi^{*}=\frac{1}{n} p^{*}\left(1-p^{* n}\right)
$$

\section{Equilibrium when $k$ firms merge}

This section is divided into two parts. In section 3.1 we study the price implications of mergers and the incentives to merge abstracting from any source of efficiency gains. In this sense, the focus is on the effects of joint (price) decision-making, exactly as in Deneckere and Davidson (1985). In section 3.2 , we study the same questions but from a medium- to long-run perspective where we let the merged entity to stock in each of its shops all the goods of the $k$ parent firms. Anticipating the results, we first show that in the short-run, and provided that search costs are relatively high, firms do not have an incentive to merge. This result is interesting because a merger paradox is established in environments where firms sell differentiated products and compete in prices. In the medium- to long-run when the merged entity stocks all the products of the constituent firms, however, demand-side economies unfold. These economies of search, provided they are sufficiently large, make mergers profitable and welfare improving. This result constitutes a new efficiency defence argument of mergers, but based on demand- rather than on supply-side economies.

\subsection{Short-run effects of mergers}

Consider that $k$ firms merge, with $2 \leq k \leq n-1$. We assume here that $s \in\left[0,\left(1-(1+k)^{-1 / k}\right)^{2} / 2\right]{ }^{10}$

\footnotetext{
${ }^{9}$ The equilibrium price $p^{*}$ is indeed an equilibrium if no firm has an incentive to deviate from it. So far we have checked that "small" deviations are not profitable. Suppose now that the deviant firm charges a price so high that consumers always walk away from it and therefore this firm only sells to those consumers who come back to it after having visited all other firms. In that case the deviant profits become $\pi_{i}\left(p_{i} ; p^{*}\right)=p_{i} \int_{p_{i}}^{1}\left(\varepsilon-p_{i}+p^{*}\right)^{n-1} d \varepsilon$. Because of log-concavity of the uniform density function, this profits expression is quasi-concave in own price (Caplin and Nalebuff, 1991). Taking the derivative of the deviating profits with respect to $p_{i}$, and setting $p_{i}=p^{*}$, we get $d \pi_{i} /\left.d p_{i}\right|_{p_{i}=p^{*}}=\left(1-p^{* n}-n p^{*}\right) / n<0$, where the inequality follows from the fact that $p^{*}$ solves (4). Since deviating profits are quasi-concave and they decrease at $p_{i}=p^{*}$, we conclude they are even lower at prices $p_{i}$ such that $\bar{x}+p_{i}-p^{*}>1$.

${ }^{10}$ Again, we need that consumers find it worthwhile to make a first search even if they expect firms to charge the monopoly price. The monopoly price of a firm controlling $k$ stores is $p_{k}^{m}=(1+k)^{-1 / k}$, which increases in $k$. Therefore we require $s \leq \operatorname{Pr}\left[\varepsilon \geq p_{k}^{m}\right] E\left[\varepsilon-p_{k}^{m} \mid \varepsilon \geq p_{k}^{m}\right]$.
} 
As before we focus on symmetric equilibria in the sense that all non-merging firms will be assumed to charge a price denoted by $\tilde{p}^{*}$, and all merging firms will be supposed to charge a price denoted by $\hat{p}^{*}{ }^{11}$ Since a non-merging firm controls the price of a single variety, we let $\tilde{p}^{*} \in\left[0, p^{m}\right]$; the merged entity, by contrast, controls the price of $k$ varieties and correspondingly we let $\hat{p}^{*} \in\left[0, p_{k}^{m}\right]$. As it is expected, suppose also that the merging firms charge higher prices than the non-merging firms, i.e., $\tilde{p}^{*}<\hat{p}^{*}$. A priori, this is a reasonable conjecture because the internalization of the pricing externalities the merging firms confer on one another typically lead these firms to charge higher prices than the non-merging ones. In Section 4, however, we study whether an alternative symmetric equilibrium where the merging firms charge a price lower than the non-merging firms, i.e. $\tilde{p}^{*}>\hat{p}^{*}$, exists.

Given that $\tilde{p}^{*}<\hat{p}^{*}$, consumers do now face a problem of search where the options have known, independent but non-identical utility distributions. Weitzman (1979) shows that also in this case the optimal decision rule is static in nature and has the "reservation value property". In particular, he proves that consumers should search as follows: at every step in the search process, a consumer should consider visiting next the (not-yet-visited) shop for which reservation utility is highest; moreover, at every step in the search process a consumer should terminate her search whenever the maximum sampled reward obtained so far is above the reservation utility at the shop to be visited next.

Let $\bar{x}$ be given by (1). The number $\bar{x}-\hat{p}^{*}$ defines the reservation utility for searching the product of a merging firm. Likewise, $\bar{x}-\tilde{p}^{*}$ is the reservation utility for searching the product of a non-merging store. Since $\tilde{p}^{*}<\hat{p}^{*}$, Weitzman's results prescribe consumers to start searching for a satisfactory product at the non-merging firms and then, if no alternative is found to be good enough in those firms, continue searching at the merging ones. This implies that the post-merger demands of the two types of stores (merging and non-merging) are similar to the demands derived by Zhou (2009) in his paper dealing with competition between prominent firms -which are visited first- and non-prominent ones - which are visited later-.${ }^{12}$

To calculate the post-merger equilibrium prices, we proceed by computing the payoff that merging and non-merging firms would obtain when deviating from the equilibrium prices. While deriving the payoffs of the two types of (deviating) firms, we require consumer expectations about the prices charged by firms not yet visited to be correct. In what follows, a typical merging firm will be indexed by $i$, while a typical non-merging store will be indexed by $j$.

\footnotetext{
${ }^{11} \mathrm{As}$ in the pre-merger market, it may be possible to sustain asymmetric equilibria in the sense that distinct nonmerging and/or distinct merging firms may charge different prices. Again, these asymmetries are not based on any underlying characteristic of the market and can only be sustained because of the indeterminacy of consumer beliefs discussed in the previous section (cf. footnote 6). We will abstract from these types of asymmetric equilibria.

${ }^{12}$ To be sure, the payoff of a non-merging (deviating) firm is exactly identical to the payoff of a prominent (deviating) firm in Zhou's (2009) paper. However, since all the prices of the merged firms are under the control of a single manager in our paper, the payoff of the (deviating) merging firms is different from the payoff of a non-prominent firm in Zhou's paper.
} 


\section{Payoff to a deviant non-merging store.}

Consider a non-merging store $j$ that deviates from $\tilde{p}^{*}$ by charging a price $\tilde{p} \neq \tilde{p}^{*}$. As all non-merging firms are expected to charge the same price $\tilde{p}^{*}$, consumers visit them randomly. Therefore, the deviant firm may be visited in first place, second place and so on till the $(n-k)^{t h}$ place. As any other nonmerging store, the deviant has a probability $1 /(n-k)$ of being visited in each of these positions. When the consumer visits the deviant in the 1st, $2 \mathrm{nd}, \ldots,(n-k-1)^{t h}$ place, the decision whether to continue searching or not takes into account that the next shop to be visited is also a non-merging store. By contrast, when the deviant firm is the last non-merging store visited by the consumer, i.e. the $(n-k)^{t h}$, the decision of the consumer is slightly different because the next shop to be visited is a merging store and such a store charges a price different from the price of a non-merging store. Since the consumer stopping rule at any of the first $n-k-1$ non-merging stores is different from that at the last non-merging store, it is convenient to distinguish among those two cases.

Consider then first the situation in which a consumer visits the deviant non-merging firm $j$ in $h^{\text {th }}$ place, with $h=1,2, \ldots, n-k-1$. Suppose the deal a consumer observes upon entering the deviant's shop is $\varepsilon_{j}-\tilde{p}$. There are three circumstances in which the consumer will buy the product of the deviant.

- First, the consumer may stop searching at this shop and buy there right away. This occurs when $\varepsilon_{j} \geq \bar{x}-\tilde{p}^{*}+\tilde{p}$. Therefore, the joint probability a consumer visits the deviant in $h^{\text {th }}$ place and buys there directly is ${ }^{13}$

$$
\operatorname{Pr}\left[z_{h-1}-\tilde{p}^{*}<\bar{x}-\tilde{p}^{*}<\varepsilon_{j}-\tilde{p}\right]=\bar{x}^{h-1}\left(1-\bar{x}+\tilde{p}^{*}-\tilde{p}\right)
$$

- Second, the consumer may walk away from the firm visited in $h^{\text {th }}$ place and come back to it after visiting all non-merging stores. ${ }^{14}$ This occurs when

$$
\operatorname{Pr}\left[\max \left\{z_{n-k-1}-\tilde{p}^{*}, \bar{x}-\hat{p}^{*}\right\}<\tilde{\varepsilon}_{j}-\tilde{p}<\bar{x}-\tilde{p}^{*}\right]
$$

and this gives the following demand from "returning" consumers:

$$
\tilde{r}_{n m}(\cdot) \equiv \int_{\bar{x}-\hat{p}^{*}+\tilde{p}}^{\bar{x}-\tilde{p}^{*}+\tilde{p}}\left(\varepsilon_{j}-\tilde{p}+\tilde{p}^{*}\right)^{n-k-1} d \varepsilon_{j}=\frac{1}{n-k}\left[\bar{x}^{n-k}-\left(\bar{x}-\hat{p}^{*}+\tilde{p}^{*}\right)^{n-k}\right]
$$

where the subindex " $n m$ " refers to the fact that consumers return to the deviant firm after having visited all the non-merging stores.

\footnotetext{
${ }^{13}$ Here we are again assuming "small" deviations in the sense that $\tilde{p}<1-\bar{x}+\tilde{p}^{*}$. Like in footnote 9 , we need to make sure that deviating to larger prices is not profitable either. We prove this in the appendix.

${ }^{14}$ To see this, note that optimal search implies that the consumer would walk away from the last non-merging store and visit one of the merging firms if $z_{n-k} \leq \bar{x}-\hat{p}^{*}+\tilde{p}^{*}$. Moreover, if the consumer happens to arrive to the $(n-k)^{t h}$ non-merging store, it must be the case that $z_{n-k-1} \leq \bar{x}$. Since $\hat{p}^{*}>\tilde{p}^{*}$, it is clear that the condition to leave the last non-merging store and continue searching among the merging stores is more stringent than that to continue searching among the non-merging stores. For this reason, the consumer may return to the deviant firm after having visited all non-merging firms and buy there.
} 
- Finally, the consumer may walk away from the deviant non-merging firm and come back to it after having visited all the firms in the market. This occurs when

$$
\operatorname{Pr}\left[\max \left\{z_{n-k-1}-\tilde{p}^{*}, z_{k}-\hat{p}^{*}, 0\right\}<\tilde{\varepsilon}_{j}-\tilde{p}<\bar{x}-\hat{p}^{*}\right]
$$

and this gives the following demand from consumers "coming-back" to the deviant:

$$
\tilde{r}_{a}(\cdot) \equiv \int_{0}^{\bar{x}-\hat{p}^{*}}\left(\varepsilon_{j}+\tilde{p}^{*}\right)^{n-k-1}\left(\varepsilon_{j}+\hat{p}^{*}\right)^{k} d \varepsilon_{j}
$$

where the subindex " $a$ " refers to the fact that consumers return to the deviant firm after having visited all the stores in the market.

We now consider the case in which the consumer visits the deviant firm in $(n-k)^{t h}$ place. There are two situations in which the consumer will buy the deviant's product:

- First, the consumer may stop searching at its shop and buy there right away. This occurs with probability

$$
\operatorname{Pr}\left[\varepsilon_{j}-\tilde{p} \geq \max \left\{z_{n-k-1}-\tilde{p}^{*}, \bar{x}-\hat{p}^{*}\right\} \text { and } z_{n-k-1}<\bar{x}\right]
$$

and this gives a demand

$$
\bar{x}^{n-k-1}\left(1-\bar{x}+\tilde{p}^{*}-\tilde{p}\right)+\frac{1}{n-k}\left[\bar{x}^{n-k}-\left(\bar{x}-\hat{p}^{*}+\tilde{p}^{*}\right)^{n-k}\right]
$$

- Second, the consumer may walk away from this firm and come back to it after visiting all the firms in the market. In this second case we have exactly the same expression for returning consumers as in (6).

As a result, taking into account the different positions in which the deviant firm may be visited by a consumer, we get the profits of a deviant non-merging firm:

$$
\tilde{\pi}\left(\tilde{p} ; \tilde{p}^{*}, \hat{p}^{*}\right)=\tilde{p}\left[\frac{1}{n-k} \frac{1-\bar{x}^{n-k}}{1-\bar{x}}\left(1-\bar{x}+\tilde{p}^{*}-\tilde{p}\right)+\tilde{r}_{n m}\left(\tilde{p}^{*}, \hat{p}^{*}\right)+\tilde{r}_{a}\left(\tilde{p}^{*}, \hat{p}^{*}\right)\right]
$$

\section{Payoff to a deviant merged entity.}

We now compute the joint payoff of the (deviating) merging stores. Since consumers expect that $\tilde{p}^{*}<\hat{p}^{*}$, they contemplate visiting the stores of the merged entity only after they have visited all the non-merging firms. Suppose that the merging firms deviate by charging $\hat{p} \neq \hat{p}^{*}$ and consider a consumer who walks away from the last non-merging store and observes a deal $\varepsilon_{i}-\hat{p}$ at the first merging store she visits. Such a consumer will never return to any of the non-merged firms without first visiting all the other merging stores. This is because the utilities from all non-merged firms are lower than $\bar{x}-\hat{p}^{*}$, which is the reservation utility at any of the merging shops. We now ask whether 
the consumer will continue searching after she visits the first merging shop. Clearly, she will continue searching when her best deal so far does not give her positive utility. She will do the same when the highest utility so far is obtained at one of the non-merging stores, that is, when $z_{n-k}-\tilde{p}^{*}>\varepsilon_{i}-\hat{p}>0$. Finally, when the best deal is the one at the merging store where she currently is, the consumer will continue searching when $\varepsilon_{i}-\hat{p}<\bar{x}-\hat{p}^{*}{ }^{15}$ As a result, the probability that the consumer arrives at the first merging store and buys there right away is ${ }^{16}$

$$
\operatorname{Pr}\left[\varepsilon_{i}-\hat{p} \geq \bar{x}-\hat{p}^{*} \geq \max \left\{z_{n-k}-\tilde{p}^{*}\right\}\right]=\left(\bar{x}-\hat{p}^{*}+\tilde{p}^{*}\right)^{n-k}\left(1-\bar{x}+\hat{p}^{*}-\hat{p}\right)
$$

Suppose now that the consumer walks into the $h^{\text {th }}$ merged store, $h=2, \ldots, k$. The probability this consumer buys at that shop right away is

$$
\operatorname{Pr}\left[\max \left\{z_{h-1}-\hat{p}, z_{n-k}-\tilde{p}^{*}\right\}<\bar{x}-\hat{p}^{*}<\varepsilon_{i}-\hat{p}\right]
$$

This gives a demand $\left(\bar{x}-\hat{p}^{*}+\hat{p}\right)^{h-1}\left(\bar{x}-\hat{p}^{*}+\tilde{p}^{*}\right)^{n-k}\left(1-\bar{x}+\hat{p}^{*}-\hat{p}\right)$.

Taking into account the different positions in which a merging firm may be visited, $h=1,2, \ldots, k$, we have a demand equal to

$$
\sum_{h=1}^{k}\left(\bar{x}-\hat{p}^{*}+\hat{p}\right)^{h-1}\left(\bar{x}-\hat{p}^{*}+\tilde{p}^{*}\right)^{n-k}\left(1-\bar{x}+\hat{p}^{*}-\hat{p}\right)=\left(\bar{x}-\hat{p}^{*}+\tilde{p}^{*}\right)^{n-k}\left[1-\left(\bar{x}-\hat{p}^{*}+\hat{p}\right)^{k}\right]
$$

Some consumers visit all shops in the market and decide to return to one of the merging stores to conduct a purchase. This occurs with probability $\operatorname{Pr}\left[\varepsilon_{i} \geq \max \left\{z_{k-1}, z_{n-k}+\hat{p}-\tilde{p}^{*}, \hat{p}\right\}\right.$ and $\left.\varepsilon_{i}<\bar{x}-\hat{p}^{*}+\hat{p}\right]$. Taking into account that consumers can return to any of the merging stores, we obtain the following demand from "coming-back" consumers:

$$
\hat{r}_{a}\left(\hat{p} ; \tilde{p}^{*}, \hat{p}^{*}\right) \equiv k \int_{0}^{\bar{x}-\hat{p}^{*}}\left(\varepsilon_{i}+\tilde{p}^{*}\right)^{n-k}\left(\varepsilon_{i}+\hat{p}\right)^{k-1} d \varepsilon_{i}
$$

where again the sub-index " $a$ " refers to consumers having visited all the stores in the market.

The payoff to a deviating merged entity is then:

$$
\hat{\pi}\left(\hat{p} ; \tilde{p}^{*}, \hat{p}^{*}\right)=\hat{p}\left\{\left(\bar{x}-\hat{p}^{*}+\tilde{p}^{*}\right)^{n-k}\left[1-\left(\bar{x}-\hat{p}^{*}+\hat{p}\right)^{k}\right]+\hat{r}_{a}(\cdot)\right\}
$$

\footnotetext{
${ }^{15}$ We assume that a buyer who observes a deviation price $\hat{p}$ at one of the merging stores does not change the expectation that the other merged firms charge $\hat{p}^{*}$. This assumption can easily be justified by a trembling-hand argument if we think that prices are decided by the headquarters of the merged entity but price tags are set by the managers of the individual merged shops and the latter can independently "tremble" with a small but positive probability (we thank an anonymous referee for this line of argumentation). If consumers did know the merging firm deviates jointly in all its stores, then they would update their expectations correspondingly and this would lead to a kink in the demand function of the merging firms. In this situation, downward deviations lead to exactly the same payoff as here. However, upward deviations lead to a different payoff function, which suggests the existence of multiple equilibria. Our results, however, do not depend on this. Details can be obtained from the authors upon request.

${ }^{16}$ We assume here that $\hat{p}<1-\bar{x}+\hat{p}^{*}$. We check that "large" deviations are not profitable either in the appendix.
} 


\section{Results}

We first study the existence of equilibrium. Taking the first order derivative of the payoff in (7) with respect to the deviation price $\tilde{p}$ and applying symmetry yields the following FOC for the non-merging firms:

$$
1-\frac{1-\bar{x}^{n-k}}{1-\bar{x}} \tilde{p}^{*}-\left(\bar{x}-\hat{p}^{*}+\tilde{p}^{*}\right)^{n-k}+(n-k) \int_{0}^{\bar{x}-\hat{p}^{*}}\left(\varepsilon+\tilde{p}^{*}\right)^{n-k-1}\left(\varepsilon+\hat{p}^{*}\right)^{k} d \varepsilon=0
$$

Likewise, taking the first order derivative of the payoff in (9) with respect to $\hat{p}$ and using the equilibrium requirement that consumer beliefs are correct, i.e., $\hat{p}=\hat{p}^{*}$ yields the FOC for the merged entity:

$$
\left(\bar{x}-\hat{p}^{*}+\tilde{p}^{*}\right)^{n-k}\left(1-\bar{x}^{k}-k \hat{p}^{*} \bar{x}^{k-1}\right)+k \int_{0}^{\bar{x}-\hat{p}^{*}}\left(\varepsilon+\tilde{p}^{*}\right)^{n-k}\left(\varepsilon+\hat{p}^{*}\right)^{k-2}\left(\varepsilon+k \hat{p}^{*}\right) d \varepsilon=0
$$

Proposition 1 Assume that $k$ firms merge. Then, in the short-run, there exists a Nash equilibrium in the post-merger market where:

- Consumers start searching at the non-merging stores and then, if they wish so, they proceed by searching at the merged ones.

- Merging firms charge a price $\hat{p}^{*}$ and the non-merging stores charge a price $\tilde{p}^{*}$; these prices are given by the unique solution to the system of FOCs (10)-(11) and the price ranking is consistent with consumer search behavior, that is, $\hat{p}^{*}>\tilde{p}^{*}$.

This equilibrium exists for any $s \in\left[0,\left(1-(1+k)^{-\frac{1}{k}}\right)^{2} / 2\right]$.

The proof of this Proposition has the following steps. We first show that there is a unique pair of prices $\left\{\hat{p}^{*}, \tilde{p}^{*}\right\}$ that satisfies the FOCs (10)-(11). We then show that these prices satisfy the inequality $\hat{p}^{*}>\tilde{p}^{*}$, which immediately implies that the hypothesized consumer search behavior is optimal. The equilibrium of Proposition 1 exists for all admissible search costs.

When the potentially merging firms do indeed merge, two effects take place. On the one hand, since consumers expect the insiders to charge higher prices than the outsiders, consumers push the merging firms all the way back in the queue they follow when they search for satisfactory products. On the other hand, there is an internalization-of-pricing-externalities effect, as usual when firms merge. These effects take place simultaneously but it is illustrative to separate them in a graph.

As in Deneckere and Davidson (1985), because the prices of similar firms are identical, the effects of a merger can be shown in a two-dimensional graph. In Figure 1a, the crossing point between the two blue curves gives the pre-merger equilibrium. The line $r_{k}^{p r e}\left(r_{n-k}^{p r e}\right)$ is the joint reaction of the potential insiders (outsiders) to a price $\tilde{p}(\hat{p})$ charged by the outsiders (insiders), given consumer beliefs that the equilibrium price is $p^{*}$. The curves cross on the 45 degrees line at $p^{*}$ so both types of firms charge $p^{*}$ and consumers' expectations are fulfilled. 
By the search-order effect, outsiders are visited first and insiders later. The pricing problem when some firms are visited first and the rest later has been studied by Zhou (2009). In his paper, the so-called prominent firms are first in line and when consumers do not find there a satisfactory product they continue by searching the so-called non-prominent firms. ${ }^{17}$ The line $r_{k}\left(r_{n-k}\right)$ in Figure 1a is the joint reaction of the non-prominent (prominent) firms to a price $\tilde{p}(\hat{p})$ charged by the prominent (non-prominent) ones, given consumer beliefs that the equilibrium prices are Zhou's equilibrium ones. As we can see, by the search-order effect, the joint reaction curve of the insiders (outsiders) shifts upwards (leftwards) from $r_{k}^{\text {pre }}\left(r_{n-k}^{\text {pre }}\right)$ to $r_{k}\left(r_{n-k}\right)$. These moves capture the fact that, relative to the pre-merger situation, the insiders' demand becomes more inelastic while the outsiders' demand turns more elastic. The crossing point between the curves $r_{k}$ and $r_{n-k},\left\{\tilde{p}_{1}^{*}, \hat{p}_{1}^{*}\right\}$, gives Zhou's equilibrium of the pricing game when $n-k$ firms are visited first and the rest $k$ of the firms later.

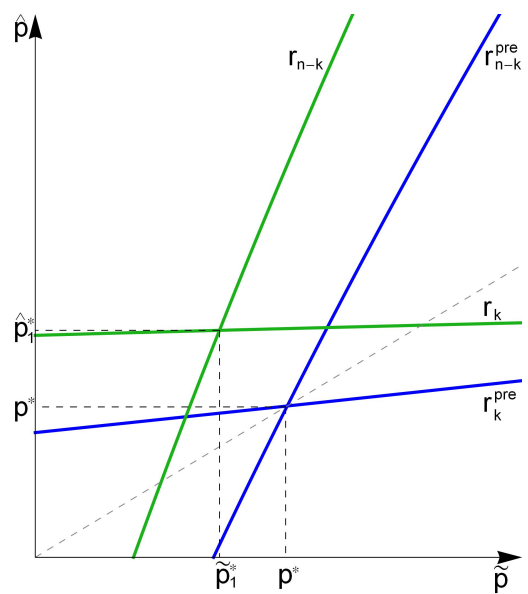

(a) Search-order effect

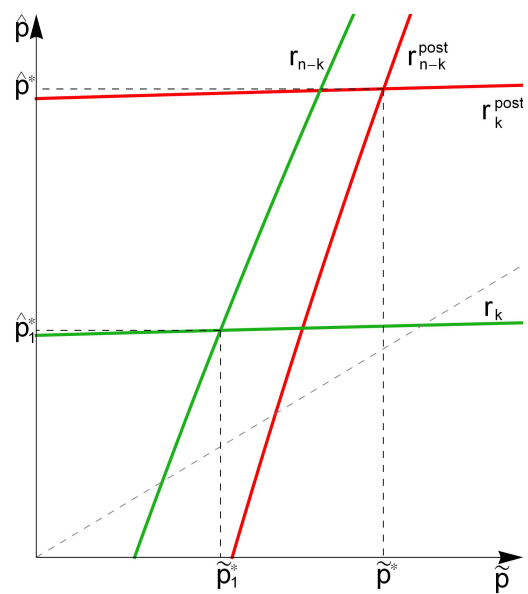

(b) Internalization of pricing externalities

Figure 1: Short-run pre- and post-merger equilibria $(n=3, k=2)$.

The effects of price coordination among the insiders are shown in Figure 1b. The line $r_{k}^{\text {post }}\left(r_{n-k}^{\text {post }}\right)$ is the joint reaction of the insiders (outsiders) to a price $\tilde{p}(\hat{p})$ charged by the outsiders (insiders), given consumer beliefs that the equilibrium prices are $\hat{p}^{*}$ and $\tilde{p}^{*}$. The internalization-of-pricing-externalities effect is captured by the shift from $r_{k}\left(r_{n-k}\right)$ to $r_{k}^{\text {post }}\left(r_{n-k}^{\text {post }}\right)$. The post-merger equilibrium is given by the crossing point of the two red curves, where consumer expectations are also fulfilled. ${ }^{18}$

We explore next the relationship between the post-merger equilibrium prices and the pre-merger equilibrium price. Whether the post-merger equilibrium prices are higher or lower than the pre-merger equilibrium price is a priori ambiguous. Consider the price charged by the non-merging firms. The fact

\footnotetext{
${ }^{17}$ When there is just one prominent firm, Armstrong et al. (2009) show that the price of the prominent firm will be lower than the price the firms would charge in a symmetric situation. Zhou (2009) qualifies this result demonstrating that when the number of prominent firms in the market is higher than 1, the price of prominent firms may be higher than the price firms would charge if they were all symmetric.

${ }^{18}$ We note that the reaction function of the outsiders also changes because of the change in consumer expectations.
} 
that the potentially merging stores by actually merging confer the non-merging stores a "prominent" position in the marketplace causes a direct downward pressure on the price of the non-merging firms. As said before, this is because when a firm becomes prominent its pool of consumers becomes more elastic. In addition there are two indirect effects. The first is that, since the merging firms are relegated to the last positions of the queue consumers follow when they search, they tend to raise their prices. This is because for the non-prominent firms it holds the opposite, namely, that their demand becomes less elastic. By strategic complementarity, the latter effect weakens competition in the marketplace and the non-merging firms tend to raise their prices as well. The second effect follows from the fact that the merging firms internalize the pricing externalities they confer on one another. This also tends to raise their price, and indirectly, by strategic complementarity again, the prices of the non-merging firms. Similar considerations apply to the price of the merging firms. Our next proposition shows that when the search-order effects are not very strong then all prices increase after a merger. ${ }^{19}$

Proposition 2 In the short-run post-merger equilibrium of Proposition 1, the ranking of pre- and post-merger equilibrium prices is $p^{*}<\tilde{p}^{*}<\hat{p}^{*}$ whenever one of the following conditions holds: (a) the search cost is sufficiently low, (b) the search cost is sufficiently high, (c) the number of firms $n=3$.

We study next the issue of merger profitability. As expected, the case in which search cost is small reproduces naturally the situation in Deneckere and Davidson (1985). However, as search costs increase, fewer consumers walk away from the non-merging stores and visit the merged ones. This fall in consumer traffic from the outsiders to the insiders turns out to be fatal for the latter.

\section{Proposition 3 In the short-run post-merger equilibrium of Proposition 1:}

1. Any 2-firm merger is not profitable if the search cost is sufficiently high.

2. Any arbitrary $k$-firm merger is not profitable if the search cost and the number of competitors are sufficiently high.

3. If search costs are sufficiently small, any arbitrary $k$-firm merger is profitable.

Proposition 3 shows that, unless there are many firms in the industry and the merger comprises almost all of them, eventually as the search cost becomes relatively high merging is not individually rational for the merging firms. The interest of this Proposition is that it puts forward a new merger paradox, which arises under price competition with differentiated products. The underlying reason is based on search costs, something quite different from the merger paradox of Salant et al. (1983), which concerns competition with decision variables that are strategic substitutes. ${ }^{20}$

\footnotetext{
${ }^{19}$ We note, however, that solving numerically the model we have found no example in which this does not happen.

${ }^{20} \mathrm{We}$ are implicitly assuming that the non-merging firms can absorb the (possibly large) post-merger increase in consumer traffic toward their stores. If firms were capacity constrained, this result would have to be qualified. In
} 
Propositions 2 and 3 are illustrated in Figure 2, where we plot the post-merger equilibrium prices, $\hat{p}^{*}$ and $\tilde{p}^{*}$, against search costs. For comparison purposes, we also plot the pre-merger price, $p^{*}$. All prices are increasing in search costs. ${ }^{21}$ As searching for price and product fit becomes more costly, firms have more market power over the consumers who pay them a visit and this results in higher prices for all the firms. As the graph reveals, post-merger prices, whether from merging or non-merging firms, happen to be higher than the pre-merger price.

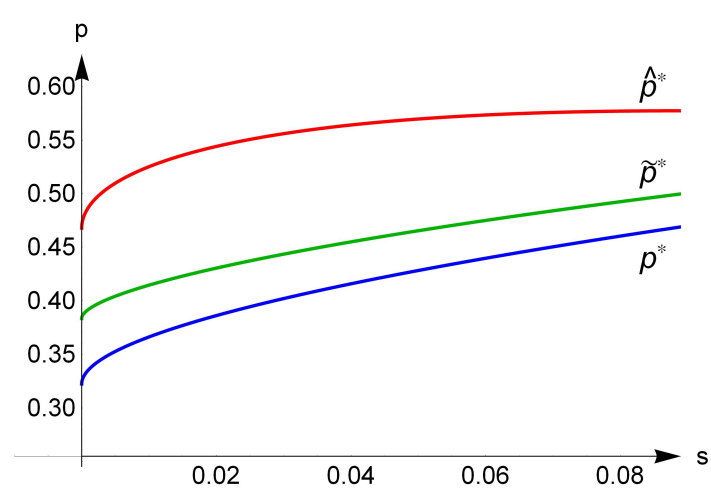

(a) Prices

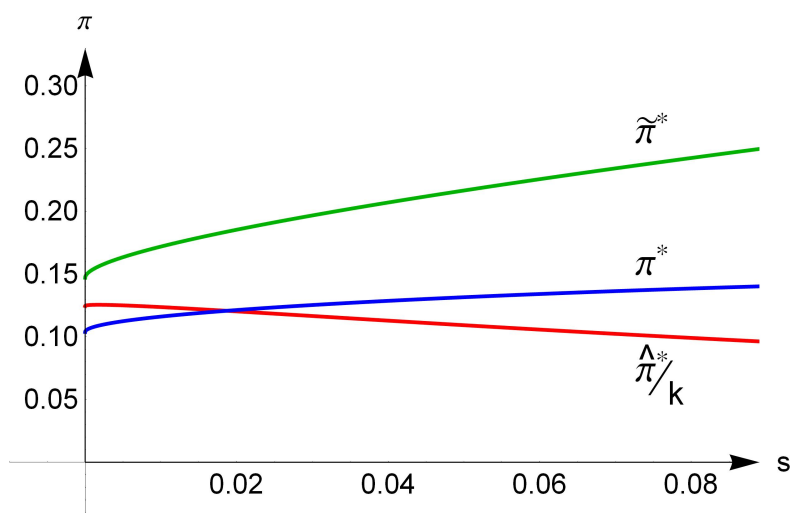

(b) Profits

Figure 2: Pre- and post-merger prices, and merger profitability $(n=3, k=2)$.

Figure $2 \mathrm{~b}$ shows how the profits of a merging firm and a non-merging firm, $\hat{\pi}^{*} / k$ and $\tilde{\pi}^{*}$, vary with search costs. In addition, the figure gives the pre-merger profits, $\pi^{*}$, so we can readily assess whether consolidation is worthwhile for the merging parties. Profits of a merging firm decline as search cost goes up. The reason is that, as the search cost increases, fewer consumers walk away from the non-merging firm and visit the shops of the merged entity. This has a major implication on merger profitability: for search costs approximately above 0.018 (3.6\% of the average value of a firm's product), merging is not individually rational for the merging firms. The graph also reveals that the non-merging firm "gets a free ride" and that "this ride is freer" the higher the search cost.

\section{$3.2 \quad$ Long-run effects of mergers}

In this section we take a medium- to long-term view of mergers and assume that, after a more or less complex process of business reorganization, the merged entity starts selling the $k$ products of the $k$ mother firms in all its shops. Alternatively, we can assume that the merged entity shuts down all its shops but one, where it stocks the $k$ varieties stemming from the $k$ original merging firms. Irrespective of the precise reorganization, we assume that consumers know about it so they can take it into account

addition, as mentioned above, we are abstracting from any cost-synergies. If, as in Farrel and Shapiro (1990), the insiders did lower their costs of production as a result of the merger and consequently lowered their prices below those of the outsiders, then the situation would be quite the opposite.

${ }^{21}$ For a proof of this, see our working paper Moraga-González and Petrikaitè (2011). 
when deciding which type of firm to visit first. ${ }^{22}$

In this section we maintain the assumption that ${ }^{23}$

$$
s \in\left[0, \min \left\{\frac{1}{8}, \frac{k}{k+1}\left[1-(k+2)(k+1)^{-\frac{k+1}{k}}\right]\right\}\right]
$$

As before, let $\tilde{p}^{*}$ and $\hat{p}^{*}$ denote the equilibrium prices of the non-merging and merging firms, respectively. To characterize the post-merger equilibrium we need to write out the payoffs of the different types of firms. These payoffs in turn depend on the optimal consumer search behavior, which, of course, has to be consistent with equilibrium pricing.

We then proceed by first specifying the order in which consumers will visit the two types of firms, then calculating equilibrium prices and finally checking back the consistency of the search rule. The trade-off for a consumer is clear: relative to the deal offered by a non-merging firm, at the merged entity the consumer encounters more variety but probably, though not surely, at higher prices. ${ }^{24}$

To characterize the order of search, we invoke again Weitzman's (1979) results. Let $\overline{\bar{x}}$ be the solution to

$$
\int_{x}^{1}(\varepsilon-x) k \varepsilon^{k-1} d \varepsilon-s=0
$$

As in (1), $\overline{\bar{x}}$ represents a threshold match value above which a consumer will decide not to continue searching the products of the merged entity. Correspondingly, the number $\overline{\bar{x}}-\hat{p}^{*}$ defines the reservation utility for searching the $k$ products of the merged entity. Likewise, $\bar{x}-\tilde{p}^{*}$ is the reservation utility for searching the product of a non-merging store, where $\bar{x}$, is again given by (1).

Momentarily, assume $\overline{\bar{x}}-\hat{p}^{*}>\bar{x}-\tilde{p}^{*}$; given this, Weitzman's optimal search rule prescribes consumers to visit first the merged entity. To calculate the post-merger equilibrium prices, we proceed by computing the payoffs the (merging and non-merging) firms would obtain when deviating from the equilibrium prices. Then we derive the FOCs and solve for equilibrium prices. After this we look for conditions under which the inequality $\overline{\bar{x}}-\hat{p}^{*}>\bar{x}-\tilde{p}^{*}$ indeed holds. Later in Section 4 we prove that the symmetric equilibrium we derive here is the unique symmetric equilibrium provided that search costs are sufficiently large.

\footnotetext{
${ }^{22}$ Absent any form of fixed costs of keeping shops open, these two alternative business organizations yield exactly the same payoff. In fact, the demand of a merging store in the first case is equal to the demand of the unique merging store in the second case divided by $k$. The reason is simply that the decision to walk away from a merging store and visit a non-merging store, or the other way around, is exactly the same in the two settings.

${ }^{23}$ One more time we need to make sure that the first search is always worth. If a consumer contemplates to visit first a non-merging firm, the condition $s \leq 1 / 8$ suffices. However, if the consumer contemplates to go first to the merged entity, we need that $s \leq \operatorname{Pr}\left[z_{k} \geq p_{k}^{m}\right] E\left[z_{k}-p_{k}^{m} \mid z_{k} \geq p_{k}^{m}\right]$. Using the facts that $p_{k}^{m}=(k+1)^{-1 / k}$ and the distribution of $z_{k}$ is $\varepsilon^{k}$ we obtain the bound $\frac{k}{k+1}\left[1-(k+2)(k+1)^{-(k+1) / k}\right]$.

${ }^{24}$ To be sure, the price of the merged entity need not be higher than the price of the non-merging firms. While merging firms internalize pricing externalities and this pushes prices up (relative to the non-merging stores), if the merged entity is visited first then, as mentioned above, market prominence pushes prices down (Armstrong et al., 2009; Haan and Moraga-González, 2011; Zhou, 2009). As we will see later, if the merged entity is visited first by the consumers in an equilibrium, it can very well be the case that it charges a lower price than that of the non-merging stores.
} 


\section{Payoff to a deviant merging store.}

Since consumers expect the price set by the merged entity to be $\hat{p}^{*}$, and since we have assumed search costs to be low enough, consumers will surely make a first search. Upon arrival at the merged entity, they may be surprised by a deviation price, denoted by $\hat{p} \neq \hat{p}^{*}$.

Let $z_{k}-\hat{p}$ be the deal observed by the consumer at the merged entity. A consumer stops there and buys right away if the expected gains from further search are lower than the search cost. Since consumers believe the non-merging firms to be charging $\tilde{p}^{*}$, the probability that a buyer stops searching at the merged entity is equal to $1-\left(\bar{x}-\tilde{p}^{*}+\hat{p}\right)^{k}$ provided, again, that the deviating price is not too high. $^{25}$

The merged entity also receives demand from consumers who decide to walk away from it, visit all the non-merging firms and finally return to it because the deal offered by the merged entity is in the end the best in the market. This happens with probability:

$$
\operatorname{Pr}\left[z_{k}-\hat{p}<\bar{x}-\tilde{p}^{*} \text { and } z_{k}-\hat{p}>\max \left\{z_{n-k}-\tilde{p}^{*}, 0\right\}\right]
$$

which gives a demand from "coming-back" consumers equal to

$$
\hat{c}_{a}\left(\hat{p} ; \tilde{p}^{*}, \hat{p}^{*}\right)=\int_{\hat{p}}^{\bar{x}-\tilde{p}^{*}+\hat{p}}\left(\varepsilon-\hat{p}+\tilde{p}^{*}\right)^{n-k} d \varepsilon^{k}=k \int_{0}^{\bar{x}-\tilde{p}^{*}}\left(\varepsilon+\tilde{p}^{*}\right)^{n-k}(\varepsilon+\hat{p})^{k-1} d \varepsilon
$$

where the subindex " $a$ " refers to the fact that consumers come back to the merging firm after having visited all firms in the market.

The total profit of the merged entity therefore equals:

$$
\hat{\pi}\left(\hat{p} ; \tilde{p}^{*}, \hat{p}^{*}\right)=\hat{p}\left[1-\left(\bar{x}-\tilde{p}^{*}+\hat{p}\right)^{k}+\hat{c}_{a}\left(\hat{p} ; \tilde{p}^{*}, \hat{p}^{*}\right)\right]
$$

\section{Payoff to a deviant non-merging store.}

We now compute the payoff of a non-merging store that deviates from $\tilde{p}^{*}$ by charging $\tilde{p} \neq \tilde{p}^{*}$. As all non-merging firms are expected to charge $\tilde{p}^{*}$, consumers are supposed to visit them randomly. Therefore the deviant firm may be visited in first place after the merged entity, in second place and so on till the $n-k^{\text {th }}$ place.

Consider that the deviant non-merging firm is visited by a consumer in her $h^{\text {th }}$ search after walking away from the merged entity, with $h=1,2, \ldots, n-k \cdot{ }^{26}$ Suppose the deal the consumer observes upon entering the deviant's shop is $\varepsilon_{j}-\tilde{p}$. There are two situations in which the deviant sells to this consumer. First, the consumer may stop searching at this shop and buy there right away. Using the

\footnotetext{
${ }^{25}$ In the appendix we deal with the case of "large" deviations, i.e. deviations where $\hat{p}>1-\bar{x}+\tilde{p}^{*}$ and correspondingly all consumers walk away from the merged entity.

${ }^{26}$ We note that when the consumer visits the deviant immediately after leaving the merged firm, $h=1$, the consumer, even if surprised by a deviation, never wants to return to the merged entity without searching further. If fact, this event has probability $\operatorname{Pr}\left[z_{k}-\hat{p}^{*}<\bar{x}-\tilde{p}^{*}\right.$ and $\varepsilon-\tilde{p}>\bar{x}-\tilde{p}^{*}$ and $\left.z_{k}-\hat{p}^{*}>\varepsilon-\tilde{p}\right]=0$.
} 
search logic described above, conditional on the consumer visiting the non-merging firm $j$ in her $h^{\text {th }}$ search, this occurs when $\varepsilon_{j} \geq \bar{x}-\tilde{p}^{*}+\tilde{p}$. The probability the deviant is visited in $h^{\text {th }}$ place is $1 /(n-k)$. Therefore, the joint probability a consumer visits the deviant in $h^{\text {th }}$ place and buys there directly is

$$
\frac{1}{n-k} \operatorname{Pr}\left[z_{k}-\hat{p}^{*}<\bar{x}-\tilde{p}^{*} \text { and } z_{h-1}<\bar{x} \text { and } \varepsilon_{j}-\tilde{p}>\bar{x}-\tilde{p}^{*}\right]
$$

Taking into account that the deviant may be visited by the consumer in positions $h=1,2, \ldots, n-k$, total demand in this case is equal to ${ }^{27}$

$$
\frac{1}{n-k} \sum_{h=1}^{n-k}\left(\bar{x}-\tilde{p}^{*}+\hat{p}^{*}\right)^{k} \bar{x}^{h-1}\left(1-\bar{x}+\tilde{p}^{*}-\tilde{p}\right)
$$

Second, the consumer may walk away from the deviant firm and come back to it after checking the products of all stores. This occurs when

$\operatorname{Pr}\left[z_{k}-\hat{p}^{*}<\bar{x}-\tilde{p}^{*}\right.$ and $z_{n-k-1}<\bar{x}$ and $\varepsilon_{j}-\tilde{p}<\bar{x}-\tilde{p}^{*}$ and $\left.\varepsilon_{j}-\tilde{p}>\max \left\{z_{k}-\hat{p}^{*}, z_{n-k-1}-\tilde{p}^{*}, 0\right\}\right]$,

After manipulation, this gives a demand from come-back consumers equal to

$$
\tilde{c}_{a}\left(\tilde{p} ; \tilde{p}^{*} \hat{p}^{*}\right) \equiv \int_{\tilde{p}}^{\bar{x}-\tilde{p}^{*}+\tilde{p}}\left(\varepsilon+\hat{p}^{*}-\tilde{p}\right)^{k}\left(\varepsilon+\tilde{p}^{*}-\tilde{p}\right)^{n-k-1} d \varepsilon=\int_{0}^{\bar{x}-\tilde{p}^{*}}\left(\varepsilon+\hat{p}^{*}\right)^{k}\left(\varepsilon+\tilde{p}^{*}\right)^{n-k-1} d \varepsilon
$$

Again the subindex " $a$ " denotes that this demand stems from consumers who visit all the shops. Note that this probability does not depend on $h$.

Taking into account (16) and (17) we obtain the profits of a non-merging firm:

$$
\tilde{\pi}\left(\tilde{p}, \tilde{p}^{*} \hat{p}^{*}\right)=\tilde{p}\left[\frac{1}{n-k} \frac{1-\bar{x}^{n-k}}{1-\bar{x}}\left(\bar{x}-\tilde{p}^{*}+\hat{p}^{*}\right)^{k}\left(1-\bar{x}+\tilde{p}^{*}-\tilde{p}\right)+\tilde{c}_{a}(\cdot)\right]
$$

\section{Results}

Taking the first order derivative in (15) and requiring that consumer beliefs coincide with the actual price of the merged entity, i.e. $\hat{p}=\hat{p}^{*}$, we obtain the following FOC:

$$
1-\left(\bar{x}-\tilde{p}^{*}+\hat{p}^{*}\right)^{k-1}\left(\bar{x}-\tilde{p}^{*}+(k+1) \hat{p}^{*}\right)+k \int_{0}^{\bar{x}-\tilde{p}^{*}}\left(\varepsilon+\tilde{p}^{*}\right)^{n-k}\left(\varepsilon+\hat{p}^{*}\right)^{k-2}\left(\varepsilon+k \hat{p}^{*}\right) d \varepsilon=0
$$

Likewise, taking the FOC in (18) and imposing symmetry among the prices of the non-merging firms, i.e. $\tilde{p}=\tilde{p}^{*}$, gives:

$$
\frac{1}{n-k}\left(\bar{x}-\tilde{p}^{*}+\hat{p}^{*}\right)^{k} \frac{1-\bar{x}^{n-k}}{1-\bar{x}}\left(1-\bar{x}-\tilde{p}^{*}\right)+\int_{0}^{\bar{x}-\tilde{p}^{*}}\left(\varepsilon+\tilde{p}^{*}\right)^{n-k-1}\left(\varepsilon+\hat{p}^{*}\right)^{k} d \varepsilon=0
$$

Proposition 4 Assume that $k \leq 10$ firms merge. Then in the long-run after the merged entity stocks all the products of the parent firms there exists a Nash equilibrium in the post-merger market where:

\footnotetext{
${ }^{27}$ Once more we are assuming here that the deviation is "small". Deviations to prices $\tilde{p}>1-\bar{x}+\tilde{p}^{*}$ are dealt with in the appendix.
} 
- Consumers prefer start searching at the merged entity and then, if they wish so, continue searching at the non-merging firms.

- The merged entity charges a price $\hat{p}^{*}$ and the non-merging stores charge a price $\tilde{p}^{*}$; these prices solve the system of FOCs (19)-(20).

This equilibrium exists if the search cost $s$ is sufficiently large, in which case $\overline{\bar{x}}-\hat{p}^{*} \geq \bar{x}-\tilde{p}^{*}$ and $\hat{p}^{*} \geq \tilde{p}^{*}$.

The proof has three steps. We first prove that there exists at least one solution to the system of FOCs (19)-(20). We then show that this solution is unique. Finally, we show that when the search cost is large, consumer putative search order (i.e. first visit the merged entity and then the non-merging firms) is consistent with equilibrium pricing. ${ }^{28}$

As we did in the previous subsection, it is illustrative to look at the behavior of the reaction functions of the different types of firm once a merger takes place. We illustrate the main effects in Figure 3. As before, the crossing point between the two blue reaction functions gives the pre-merger equilibrium. Again, when the potentially merging firms do indeed merge a search-order effect and a internalization-of-pricing-externalities effect take place.

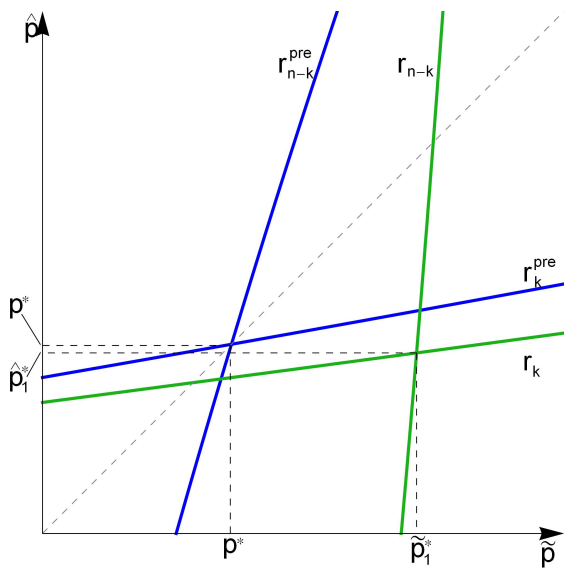

(a) Search-order effect

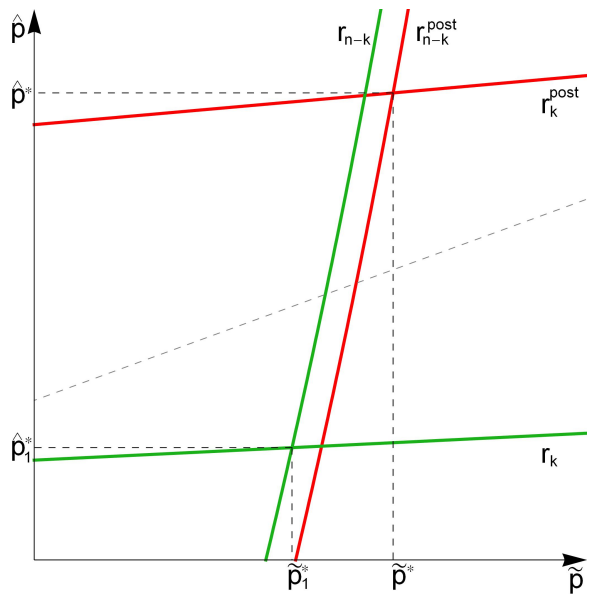

(b) Internalization of pricing externalities

Figure 3: Long-run pre- and post-merger equilibria $(n=3, k=2)$.

The search-order effect stems from the demand-side economies that unfold when the merging stores start carrying all the products of the parent firms. By this effect, the reaction curve of the outsiders (insiders) shifts rightwards (downwards) from $r_{n-k}^{p r e}\left(r_{k}^{p r e}\right)$ to $r_{n-k}\left(r_{k}\right)$. This move is driven by the

\footnotetext{
${ }^{28}$ The restriction $k \leq 10$ is adopted for convenience. If $k$ is larger than 11 the search cost bound in (12) is a complicated function of $k$ and this makes the calculations cumbersome. Since mergers are relevant in relatively concentrated markets and often take place between 2 firms at most, the restriction $k \leq 10$ implies little loss of generality. Obviously, the restriction $n \leq 10$ is equivalent.
} 
fact that the demand of a non-merging firm becomes more inelastic after the search-order changes. The crossing point between $r_{n-k}$ and $r_{k}$ determines the price implications of the search-order effect. The usual internalization-of-pricing-externalities effect shifts the joint reaction function of the insiders (outsiders) further from $r_{k}\left(r_{n-k}\right)$ to $r_{k}^{\text {post }}\left(r_{n-k}^{\text {post }}\right)$. At the post-merger equilibrium, all prices, whether from outsiders or insiders, increase. Proposition 4 shows that when search costs are sufficiently large, the merged entity charges a higher price than the price of the non-merging firms. This means that the internalization-of-pricing-externalities effect dominates the search-order effect. Still, the trade-off consumers face turns out to be favorable for the merging firms: consumers prefer to start searching at the merged entity despite the fact that this firm has a higher price. Economies of search are at the heart of this result.

Before turning to a discussion of the aggregate implications of mergers, we make two remarks in connection with Proposition 4. The first observation is that, even though the proof of the proposition uses the case where the search cost converges to its maximum value, the result is true for much lower search costs. This can be seen in Figure 4a, where we plot the reservation utilities $\overline{\bar{x}}-\hat{p}^{*}$ and $\bar{x}-\tilde{p}^{*}$ against search costs for the $n=3$ case. The equilibrium of Proposition 4 exists for search costs to the right of the point where the two reservation utility curves intersect (approximately 0.015 , i.e., $3 \%$ of the average value of a firm's good). In Figure $4 \mathrm{~b}$ we see that the price of the merged entity is higher than the price of the non-merging firm no matter the level of search costs.

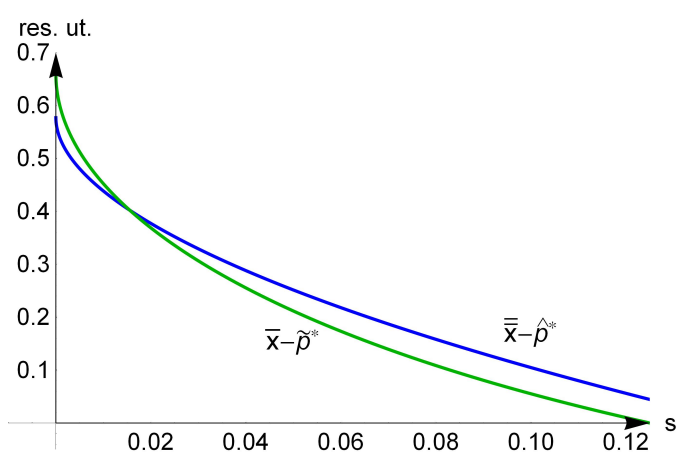

(a) Reservation utilities

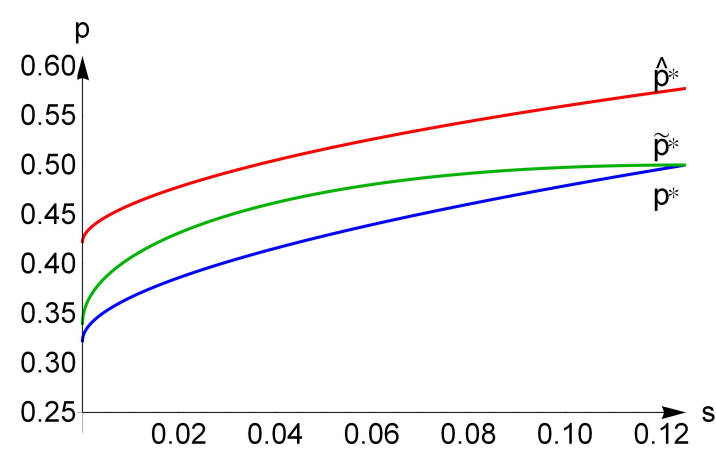

(b) Prices

Figure 4: Reservation utilities, prices and search $\operatorname{costs}(n=3, k=2)$.

However, our second observation is that the ranking of merging and non-merging firm prices given in Proposition 4 need not hold for all parameters. In fact, it is indeed possible that the search-order effect more than offsets the internalization-of-pricing-externalities effect, in which case the merged entity charges a price lower than the non-merging stores. This occurs when the search cost is relatively small and the number of merging firms relative to the total number of firms in the market is also small. In the graphs of Figure 5, the number of merging firms is set equal to 2 and the search cost is very 
small $(s=0.005)$. Figure 5a plots the post-merger equilibrium prices and shows that the merged entity charges a price lower than that of the non-merging firms when $n \geq 7$. Figure $5 \mathrm{~b}$ plots consumer reservation utilities for searching the two types of firms and shows that consumer search order is consistent with equilibrium pricing for all $n \geq 4$.

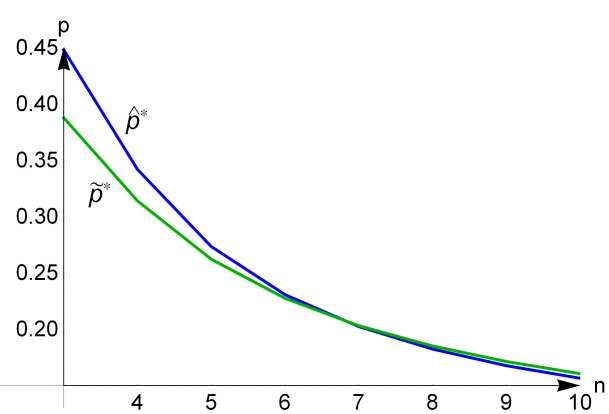

(a) Prices

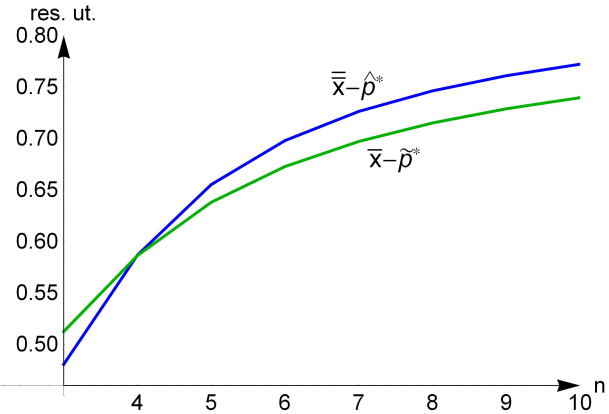

(b) Reservation utilities

Figure 5: Post-merger prices and reservation utilities $(\bar{x}=0.9, k=2)$.

We now turn to the impact of merging activity on the profits of insiders and outsiders to a merger.

\section{Proposition 5 In the long-run post-merger equilibrium of Proposition 4:}

1. Any $k$-firm merger is individually rational for the merging firms, that is, $\hat{\pi}^{*} / k>\pi^{*}$.

2. If search cost is sufficiently large, in any $k$-firm merger the non-merging firms obtain lower profits than the merging firms, that is, $\hat{\pi}^{*} / k>\tilde{\pi}^{*}$.

In the short-run equilibrium of Proposition 3 firms did not have an incentive to merge when the search costs are high. The reason is that, everything else equal, the merging firms are pushed to the end of consumers' search order. In the long-run, by contrast, firms that merge gain a prominent position in the marketplace because their shops are stocked with a larger array of products. This clearly makes merging profitable in the long-run and, in addition, has a serious impact on the profits of the non-merging firms. In fact, Proposition 5 shows that, when search frictions are high, the nonmerging firms obtain lower profits than the merged entity. The non-merging firms, being relegated to the end of the optimal search order consumers follow when they search for satisfactory deals, receive little custom when search costs are high and, correspondingly, lose out relative to the merging firms. This result is in contrast with the standard "free-riding effect" by which outsiders to a merger benefit more than the insiders. To the extent that the free-riding effect is at odds with observed merger waves, our result is more comforting.

Figure 6 illustrates these results on profits. It can be seen that the merged entity's profits (red curve) are clearly above pre-merger levels (blue curve). As explained before, this is the outcome of 


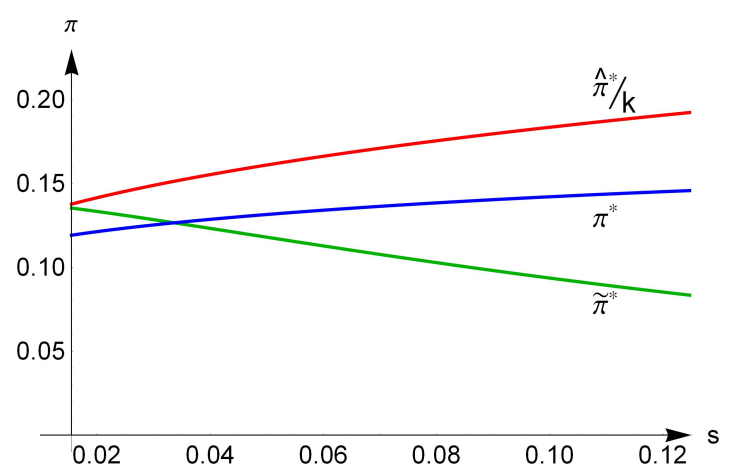

Figure 6: Long-run pre- and post-merger equilibrium profits $(n=3, k=2)$.

two forces: one the one hand, the merged entity benefits from the market prominence it gains by stocking all the products from the parent firms in the merged entity; on the other hand, the merged entity profits from increased market power. The figure also shows that, unless search costs are very low, outsiders lose out (red curve). Finally, it is also worth mentioning the asymmetry in the way search costs affect the profits of the different firms after a merger. As search costs increase, the profits of the merged entity go up while the profits of the non-merging firms typically fall. This is due to the fact that as search costs increase consumer traffic from the merged entity to the non-merging firms decreases.

Our final result pertains to the aggregate implications of mergers. As usual, we evaluate the effects of a merger on welfare grounds by comparing the pre- and post-merger un-weighted sum of consumer surplus and firms' profits. We now compute the expected surplus consumers derive in the post-merger market. Consider first those consumers who buy from the merged entity. As explained above, these consumers either buy there directly upon arrival or after having visited all the non-merging firms. Let $\widehat{C S}$ denote the gross-of-search-costs expected surplus of the clientele of the merged entity:

$$
\widehat{C S}=\int_{\bar{x}-\tilde{p}^{*}+\hat{p}^{*}}^{1}\left(\varepsilon-\hat{p}^{*}\right) d \varepsilon^{k}+\int_{\hat{p}^{*}}^{\bar{x}-\tilde{p}^{*}+\hat{p}^{*}}\left(\varepsilon-\hat{p}^{*}+\tilde{p}^{*}\right)^{n-k}\left(\varepsilon-\hat{p}^{*}\right) d \varepsilon^{k}
$$

Consider now those consumers who buy from the non-merging firms. Similarly to the consumers who buy from the merged entity, these consumers may buy directly upon arrival or after visiting all the firms in the market. Let $\widetilde{C S}$ denote the gross-of-search-costs expected surplus of the clientele of the non-merging firms:

$$
\widetilde{C S}=\left(\bar{x}-\tilde{p}^{*}+\hat{p}^{*}\right)^{k} \frac{1-\bar{x}^{n-k}}{1-\bar{x}} \int_{\bar{x}}^{1}\left(\varepsilon-\tilde{p}^{*}\right) d \varepsilon+(n-k) \int_{\tilde{p}^{*}}^{\bar{x}} \varepsilon^{n-k-1}\left(\varepsilon-\tilde{p}^{*}+\hat{p}^{*}\right)^{k}\left(\varepsilon-\tilde{p}^{*}\right) d \varepsilon .
$$

In the long-run post-merger equilibrium search economies play an important role. Consumers who buy directly at the merged entity search only one time. Those who walk away and stop at the first non-merging store they visit search only two times. And so on and so forth. Denoting by $N S$ the 
total number of searches we have:

$$
N S=1-\left(\bar{x}-\tilde{p}^{*}+\hat{p}^{*}\right)^{k}+\left(\bar{x}-\tilde{p}^{*}+\hat{p}^{*}\right)^{k}(1-\bar{x}) \sum_{j=1}^{n-k}(j+1) \bar{x}^{j-1}+\left(\bar{x}-\tilde{p}^{*}+\hat{p}^{*}\right)^{k} \bar{x}^{n-k}(n-k+1)
$$

Denoting the total search costs incurred by consumers by $S c$, after simplification, we obtain

$$
S c=\frac{1}{2}(1-\bar{x})\left[1-\bar{x}+\left(\bar{x}-\tilde{p}^{*}+\hat{p}^{*}\right)^{k}\left(1-\bar{x}^{n-k}\right)\right],
$$

which, keeping prices fixed, clearly decreases in $k .{ }^{29}$ The total net-of-search-costs expected consumer surplus is therefore $C S=\widehat{C S}+\widetilde{C S}-S c$. Adding the profits of the firms, we obtain a measure of expected social welfare $S W=C S+\hat{\pi}+(n-k) \tilde{\pi}$.

Proposition 6 In the long-run post-merger equilibrium of Proposition 4, if search cost is high enough:

\section{Any $k$-firm merger results in an increase in industry profits.}

2. Consumer surplus increases after a $k$-firm merger.

As a result, social welfare increases after a merger has taken place.

The aggregate implications of a merger are illustrated in Figure 7. In Figure 7a we compare preand post-merger collective profits. Collectively firms obtain greater profits post-merger (red curve) than pre-merger (blue curve).

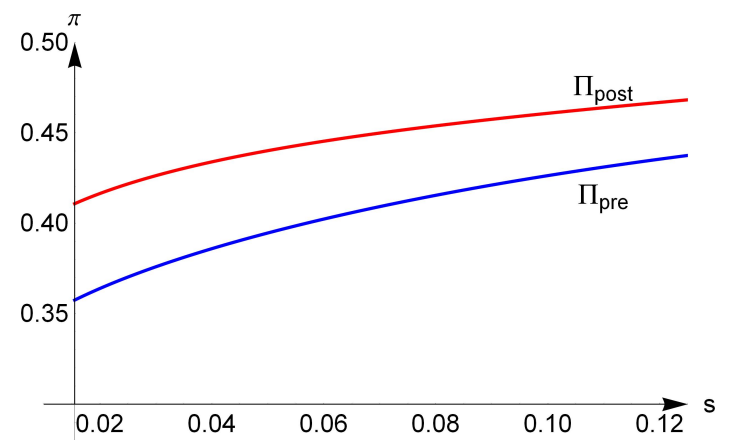

(a) Industry profits

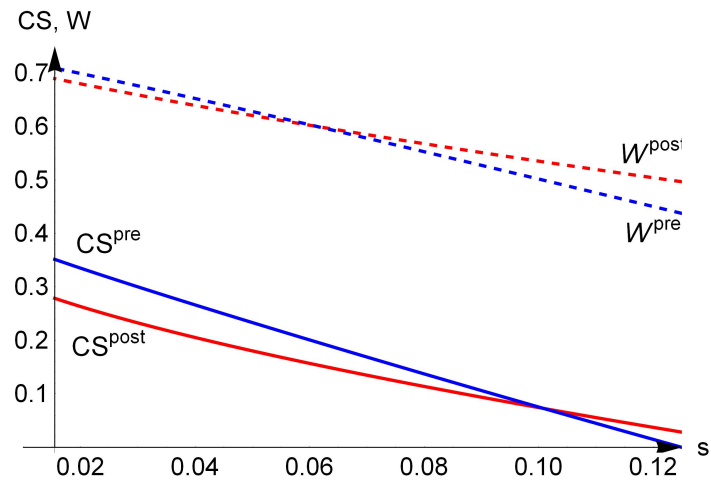

(b) Consumer surplus

Figure 7: Long-run pre- and post-merger profits and consumer surplus $(n=3, k=2)$.

Figure 7b depicts pre- and post-merger consumer surplus and social welfare. The graph illustrates our result in Proposition 6 that when search cost is relatively high, consumer search economies more than offset the negative price effects of consolidation thereby increasing the welfare of consumers. When search costs are intermediate, the price effects are stronger than the search economies and

\footnotetext{
${ }^{29}$ In fact, numerical calculations show that the total search costs also decrease in $k$ when we take into account how prices change with $k$.
} 
consumers lose out; however, their loss is not so large because of the savings in search costs so overall welfare increases. When search costs converge to zero, the usual negative price effects associated to consolidation lead to welfare losses as in Deneckere and Davidson (1985).

\section{Discussion}

The most important results of the paper are about situations in which search costs are relatively high for otherwise the model is similar to the perfect information case of Deneckere and Davidson (1985). In particular, in Section 3.1 on the short-run effects of mergers, we have shown that mergers are not individually rational when search costs are relatively high. Likewise, in Section 3.2 on the long-run effects of mergers, we have proven that demand-side economies can make mergers welfare improving when search costs are relatively high. The purpose of this Section is to argue that when search costs are high, the equilibria given in Propositions 1 and 4 are the only symmetric equilibria.

\section{The short-run}

The discussion in Section 3.1 centered around a symmetric equilibrium with the merging firms charging a higher price than the non-merging firms and, correspondingly, consumers starting their search for satisfactory products at the non-merging stores. This equilibrium is the natural extension of the equilibrium that arises under perfect information (Deneckere and Davidson, 1985) because, due to the internalization-of-pricing externalities effect, we expect the merging firms to charge higher, rather than lower, prices than the non-merging firms. As shown in Proposition 1, this equilibrium exists for all admissible levels of the search cost.

However, as we mentioned above when we discussed the potential problems associated with the indeterminacy of consumer beliefs about which type of firms charge the lowest prices, another symmetric equilibrium can be proposed. In such alternative symmetric equilibrium, consumers hold the belief that the merging stores charge lower prices than those of the non-merging firms and, correspondingly, they start their search for satisfactory products at the former; firms respond by setting prices in such a way that consumer beliefs are fulfilled. This could very well occur if the merger process looms so large in consumer minds that the merging firms capture consumer attention and become prominent in the market. In that case, the power of consumer beliefs at dictating the prices of the firms must be sufficiently strong so as to more than offset the internalization-of-pricing externalities effect. In this Section we focus attention on such an alternative equilibrium.

Since in this alternative equilibrium consumers start their search for satisfactory products by visiting the shops of the merged entity, we can borrow the payoffs of the different types of firms from the analysis in Section 3.2. The only difference between the situation described there and the new one here in that in Section 3.2 the merged entity stocks all the products of the parent firms in each of its 
shops. But this difference turns out to be inconsequential for the payoffs of both firms. Let us explain why.

Here, the demand of a non-merging firm $j$ is made of consumers who walk away from all the merging stores, happen to stop by firm $j$ and buy right away there; or, else, by consumers returning to firm $j$ after having visited all shops. The decision to walk away from the very last merging store is based on the comparison between $z_{k}-\hat{p}^{*}$ and $\bar{x}-\tilde{p}^{*}$. This condition is exactly the same as that in Section 3.2 for consumers to leave the merged entity and visit one of the non-merging stores. As a result, the payoff of a (deviant) non-merging firm here is exactly the same as (18).

We now examine the joint demand of the merging stores. We can assume without loss of generality that the merging stores are visited in a particular order, say, first the merging store 1, then the merging store 2 and so on all the way till the merging store $k$. Consider a consumer who starts searching and visits the first merging store. If the match value encountered there is less than $\bar{x}-\hat{p}^{*}+\hat{p}$, the consumer will continue searching and visit a second merging firm. Otherwise, the buyer will acquire the product sold there right away. In the second shop, and all the way till the $(k-1)^{t h}$ store the trade-off faced by the consumer is exactly the same. Therefore, the direct demand obtained by the first $k-1$ merged stores is

$$
\sum_{i=1}^{k-1}\left(\bar{x}-\hat{p}^{*}+\hat{p}\right)^{i-1}\left(1-\bar{x}+\hat{p}^{*}-\hat{p}\right)=1-\left(\bar{x}-\hat{p}^{*}+\hat{p}\right)^{k-1}
$$

When a consumer arrives at the $k^{\text {th }}$ merging firm, the situation a consumer faces is different because the firm to be visited next is a non-merging firm and this type of firm charges a different price, namely $\tilde{p}^{*}$. As a result, the consumer may take one of three decisions. First, the consumer may terminate her search at the last merging store. This occurs when the match value there is higher than at the other merging stores and it is not worth to continue searching further at the non-merging stores, i.e., with probability $\operatorname{Pr}\left[\varepsilon_{k}-\hat{p}>\max \left\{\bar{x}-\tilde{p}^{*} ; z_{k-1}-\hat{p}\right\}\right]$, and this gives a demand equal to

$$
\left(\bar{x}-\hat{p}^{*}+\hat{p}\right)^{k-1}\left(1-\left(\bar{x}-\hat{p}^{*}+\hat{p}\right)\right)+\frac{1}{k}\left[\left(\bar{x}-\hat{p}^{*}+\hat{p}\right)^{k}-\left(\bar{x}-\tilde{p}^{*}+\hat{p}\right)^{k}\right]
$$

Second, the consumer may return to one of the previously visited merging stores. This can occur because, since $\hat{p}^{*}<\tilde{p}^{*}$ by assumption, the decision to walk away from the previously visited shops, i.e., $z_{k-1}-\hat{p}<\bar{x}-\hat{p}^{*}$ does not necessarily imply the consumer will continue searching after getting a bad deal at the last merging store. The probability the consumer returns to a given previously visited merging store is $\operatorname{Pr}\left[\bar{x}-\hat{p}^{*}>z_{k-1}-\hat{p}>\max \left\{\bar{x}-\tilde{p}^{*} ; \varepsilon_{k}-\hat{p}\right\}\right]$. Since there are $k-1$ such stores, the fraction of consumers who return to a previously visited merging store without visiting all shops in the market is

$$
\hat{r}_{m}\left(\hat{p} ; \tilde{p}^{*}, \hat{p}^{*}\right) \equiv \frac{k-1}{k}\left[\left(\bar{x}-\hat{p}^{*}+\hat{p}\right)^{k}-\left(\bar{x}-\tilde{p}^{*}+\hat{p}\right)^{k}\right]
$$


where the sub-index $m$ refers to the fact that these consumers return to a merging store after visiting only the merging stores.

Finally, the consumer may walk away from the last merging store, continue to visit the rest of the (non-merging) stores and return to one of the merging stores to conduct a purchase. This fraction of consumers, which we denote $\hat{r}_{a}$ to refer to the situation that consumers come back to one of the merging stores after visiting all firms in the market, is given by $\operatorname{Pr}\left[\bar{x}-\tilde{p}^{*}>z_{k}-\hat{p}>\max \left\{0 ; z_{n-k}-\tilde{p}^{*}\right\}\right]$, that is

$$
\hat{r}_{a}\left(\hat{p} ; \tilde{p}^{*}, \hat{p}^{*}\right) \equiv k \int_{0}^{\bar{x}-\tilde{p}^{*}}(\varepsilon+\hat{p})^{k-1}\left(\varepsilon+\tilde{p}^{*}\right)^{n-k} d \varepsilon
$$

Putting these demands together, we obtain a payoff for the (deviant) merging store that is exactly the same as that given by (15).

But can such an equilibrium exist for all parameters? From the received theory we know that when the search cost is exactly equal to zero (Deneckere and Davidson, 1985), such price ranking is impossible. By continuity' we expect this alternative equilibrium to fail to exist when the search cost is positive but small. This is indeed what our next result shows. In addition, we can prove that the same is true when the search cost is very high or for example when the number of firms is 3 or very large.

Proposition 7 Assume that $k$ firms merge. Then, in the short-run, a symmetric Nash equilibrium where $\hat{p}^{*}<\tilde{p}^{*}$ so that consumers start searching at the stores of the merged entity and then proceed by searching at the non-merging stores does not exist whenever one of the following conditions holds: (a) the search cost is sufficiently low, (b) the search cost is sufficiently high, (c) $n=3$, (d) the number of competitors is sufficiently large.

The intuition behind this result is as follows. The price ranking of the firms is the outcome of the tension between the search-order effect, which pushes merging firms that are visited first to lower prices relative to the non-merging firms, and the internalization-of-pricing-externalities effect, which works in the opposite direction. The magnitude of the search cost and the number of non-merging firms affect the outcome of this tension. In fact, note that the search-order effect is practically non-existent when the search cost is arbitrarily close to zero, while the internalization-of-pricing-externalities effect is the strongest. In this case, the second effect has a dominating influence and this explains the first part of the result in Proposition 7. When the search cost increases, the search-order effect gains importance, while the internalization-of-pricing-externalities effect loses strength. For intermediate levels of the search cost, the alternative equilibrium where the merging firms charge lower prices and are visited first may exist (though not necessarily as demonstrated for the case $n=3$ ). Finally, when search costs are very high, prices, whether from merging or not merging firms, are close to monopoly prices 
and the search-order effect loses again against the internalization-of-pricing-externalities effect. ${ }^{30}$ The number of firms affects the tension between the search-order effect and the internalization-of-pricingexternalities effect in a similar way.

Proposition 7 implies that the alternative equilibrium where merging firms charge lower prices and are visited first can only exist for intermediate levels of the search cost and the number of firms. This casts doubts about the appeal of such equilibrium. At the very least, taking such an alternative equilibrium seriously requires consumer beliefs to be discontinuous in parameters such as search costs and the number of firms. We find such requirement on beliefs difficult to justify.

\section{The long-run}

In Section 3.2 we have characterized an equilibrium where the potentially merging firms gain market prominence if they indeed merge. This gain in prominence arises because the merging firms choose to sell all their products under the same roof. If this is so, and provided search costs are sufficiently large, consumers find it optimal to first search the products of the merged entity to continue later, if desired, searching the products of the non-merging firms.

The reader may ask whether other symmetric equilibria are possible. In this section we argue that the equilibrium in Proposition 4 is unique when search costs are indeed relatively high. We prove this by contradiction. Suppose that consumers find it optimal to start searching for a satisfactory good at the non-merging firms. If this is so, then the reservation utility at the merged entity, $\overline{\bar{x}}-\hat{p}^{*}$, must be lower than the reservation utility at the non-merging firms, $\bar{x}-\tilde{p}^{*}$ (where $\bar{x}$ and $\overline{\bar{x}}$, as before, solve (1) and (13), respectively) (cf. Weitzman, 1979).

Since consumers visit first the non-merging firms, we can borrow from the analysis in Section 3.1 to write out here the payoff functions of the different firms. In what follows we argue that the payoff functions of merged and non-merged firms here have exactly the same form as those in (7) and (9). The only difference comes from the fact that the reservation value for visiting the merged entity is now $\overline{\bar{x}}-\hat{p}^{*}$ instead of $\bar{x}-\hat{p}^{*}$.

Consider the payoff of the merged entity when it deviates to $\hat{p} \neq \hat{p}^{*}$. Consumers will walk away from the last non-merging store and arrive at the merged entity if the best of the non-merging firms' deals is lower than $\overline{\bar{x}}-\hat{p}^{*}$. Therefore, the merged entity will only receive demand when its offer is the best of all offers in the market, that is, with probability $\operatorname{Pr}\left[z_{n-k}-\tilde{p}^{*}<\overline{\bar{x}}-\hat{p}^{*}\right.$ and $\left.z_{k}-\hat{p}>\max \left\{0 ; z_{n-k}-\tilde{p}^{*}\right\}\right]$.

\footnotetext{
${ }^{30}$ We have explored alternative ways to affect the trade-off between the search-order effect and the internalizationof-pricing-externalities effect and rule out the alternative equilibrium where the merging firms charge lower prices and are visited first. What is important is to weaken the power consumer beliefs have at dictating equilibrium prices. For example, one can show that this equilibrium fails to exist when there is a sufficiently large number of consumers who have perfect information (see Moraga-González and Petrikaitè, 2011). The equilibrium in Proposition 1 by contrast survives this modification as well as our merger paradox result in Proposition 3.
} 
This gives a payoff for the merged entity equal to

$$
\hat{\pi}\left(\hat{p} ; \tilde{p}^{*}, \hat{p}^{*}\right)=\hat{p}\left\{\left(\overline{\bar{x}}-\hat{p}^{*}+\tilde{p}^{*}\right)^{n-k}\left[1-\left(\overline{\bar{x}}-\hat{p}^{*}+\hat{p}\right)^{k}\right]+k \int_{0}^{\overline{\bar{x}}-\hat{p}^{*}}\left(\varepsilon+\tilde{p}^{*}\right)^{n-k}(\varepsilon+\hat{p})^{k-1} d \varepsilon\right\}
$$

which is exactly identical to (9) except in that $\bar{x}$ is here replaced by $\overline{\bar{x}}$.

We now look at the payoff of a (deviant) non-merging firm. We only need to modify the payoff in (7) by properly taking into account that the decision to walk away from the last non-merging firm and visit the merged entity depends on whether the best of the non-merging firms' deals is lower than $\overline{\bar{x}}-\hat{p}^{*}$. This affects, on the one hand, the probability consumers return to the deviant merging firm after having visited all the non-merging firms, which becomes $\operatorname{Pr}\left[\max \left\{z_{n-k-1}-\tilde{p}^{*}, \bar{x}-\hat{p}^{*}\right\}<\tilde{\varepsilon}_{j}-\tilde{p}<\bar{x}-\tilde{p}^{*}\right]$ and therefore $\tilde{r}_{n m}(\cdot)$ is modified to

$$
\tilde{d}_{n m}(\cdot) \equiv \frac{1}{n-k}\left[\bar{x}^{n-k}-\left(\overline{\bar{x}}-\hat{p}^{*}+\tilde{p}^{*}\right)^{n-k}\right]
$$

and, on the other hand, the probability consumers return to the deviant merging firm after having visited all the firms in the market, which becomes $\operatorname{Pr}\left[\max \left\{z_{n-k-1}-\tilde{p}^{*}, z_{k}-\hat{p}^{*}, 0\right\}<\tilde{\varepsilon}_{j}-\tilde{p}<\overline{\bar{x}}-\hat{p}^{*}\right]$ and therefore $\tilde{r}_{a}(\cdot)$ becomes

$$
\tilde{d}_{a}(\cdot) \equiv \int_{0}^{\overline{\bar{x}}-\hat{p}^{*}}\left(\varepsilon_{j}+\tilde{p}^{*}\right)^{n-k-1}\left(\varepsilon_{j}+\hat{p}^{*}\right)^{k} d \varepsilon_{j}
$$

As a result, the total payoff of a deviating non-merging firm equals:

$$
\tilde{\pi}\left(\tilde{p} ; \tilde{p}^{*}, \hat{p}^{*}\right)=\tilde{p}\left[\frac{1}{n-k} \frac{1-\bar{x}^{n-k}}{1-\bar{x}}\left(1-\bar{x}+\tilde{p}^{*}-\tilde{p}\right)+\tilde{d}_{n m}(\cdot)+\tilde{d}_{a}(\cdot)\right],
$$

which is similar to $(7)$.

Proposition 8 Assume that $k \leq 10$ firms merge and that the search cost is sufficiently high. Then in the long-run after the merged entity stocks all the products of parent firms in each of its stores, an equilibrium where consumers prefer to search first the products of the non-merging firms and then, if they wish so, the products of the merged entity does not exist.

\section{Concluding remarks}

This paper has studied the aggregate consequences of mergers in environments where consumers have to search in order to find satisfactory goods. We have used a model where firms compete in prices to sell differentiated products and consumers search sequentially to find price and product fit information. When the search cost is equal to zero, the model collapses to Perloff and Salop (1985) and merger analysis gives results similar to those in Deneckere and Davidson (1985). However, when search costs are sizable, the price divergence between merging and non-merging firms has implications for the order in which consumers visit firms when they search for good deals. 
We have distinguished between the short-run and the long-run effects of mergers. In the short-run, the merging firms coordinate their prices while everything else stays the same. We have shown that when search costs are relatively high, the unique post-merger symmetric equilibrium has the merging stores charging higher prices than the non-merging ones and consumers, correspondingly, visiting first the non-merging stores and then, if necessary, the stores of the merged entity. In such environment, we have proven that merging may be unprofitable. The paper has thus shown that a merger paradox may also arise when firms compete in prices to sell differentiated products. The paradox may arise because the insiders of a merger by actually merging put themselves at a disadvantage in the marketplace: consumers visit first the outsider and cheaper firms and then, if unsatisfied with the products available there, proceed by visiting the insider and more expensive firms.

In the long-run, however, we have argued that the merged entity can choose to sell all the products of the parent firms in each of its stores; alternatively, the merged entity may stock the shelves of a single shop with all the products of the parent firms and shut down the rest of the shops if economical. When search costs are significant, this business reorganization generates substantial demand-side economies because, everything else equal, consumers do not need to search as intensively as in the pre-merger situation to find satisfactory products. In contrast to a large literature on cost synergies and supplyside economies, this paper has emphasized the importance of these demand-side economies for the aggregate implications of merger activity. We have shown that firms that merge may gain a prominent position in the marketplace, in which case their incentives to raise prices are seriously dampened. In that case, consumers prefer to start searching for satisfactory products at the merged entity. In equilibrium, insider firms gain customers and increase their profits, while outsider firms lose out because they are pushed all the way back in the optimal search order consumers follow when they search for products. Importantly, we have shown that consolidation may create sufficiently large search economies so as to generate rents for consumers too.

We believe the arguments in this paper are novel and useful to further understand the effects of consolidation processes. Our merger paradox arises in a market where strategic variables are complement and our merger defence result is based on demand-side economies arising from sources other than complementarities (network externalities, complement products, one-stop shopping of an array of products, etc.) Moreover, because the main mechanisms at play are intuitive and powerful, they are expected to play a role in more general market settings provided search costs are significant. Ultimately, we hope this paper adds to a finer design of merger policy.

Efficiency gains arising from mergers may take a relatively long time to materialize. Our theory points out that after-merger business reorganization may lead to important search economies that in the long-run may even result in price decreases relative to the short-run. Whether supply- or demandside economies are at the heart of after-merger potential welfare gains remains an empirical question. 
Developing methods to quantify the importance of economies of search and cost synergies seems a fascinating area for future empirical research. 


\section{Appendix}

Proof of Proposition 1. The proof is organized in three Claims. Claim 1 shows that there is a pair of prices $\left\{\hat{p}^{*}, \tilde{p}^{*}\right\}$ that satisfies the FOCs (10) and (11). Claim 2 shows that such a pair of prices is unique. Finally, Claim 3 demonstrates that $\tilde{p}^{*}<\hat{p}^{*}$. Finally, we check that "large" deviations are not profitable either. In what follows, we drop the “*” super-indexes to shorten the expressions.

Claim 1 There is at least one pair of prices $\left\{\hat{p}^{*}, \tilde{p}^{*}\right\}$ that satisfies (10) and (11).

Proof. We first rewrite the FOC (11) as $G(\hat{p}, \tilde{p})=0$, where

$$
G(\hat{p}, \tilde{p}) \equiv \frac{1-\bar{x}^{k}}{k \bar{x}^{k-1}}-\hat{p}+g(\hat{p}, \tilde{p})
$$

and

$$
g(\hat{p}, \tilde{p}) \equiv \frac{\int_{0}^{\bar{x}-\hat{p}}(\varepsilon+\hat{p})^{k-2}(\varepsilon+\tilde{p})^{n-k}(\varepsilon+k \hat{p}) d \varepsilon}{(\bar{x}-\hat{p}+\tilde{p})^{n-k} \bar{x}^{k-1}}
$$

Since $G$ is continuously differentiable, the FOC $G(\hat{p}, \tilde{p})=0$ defines an implicit relationship between $\hat{p}$ and $\tilde{p}$. Let the function $\eta_{1}(\tilde{p})$ define this relationship. This function is represented in Figure 8 below. By the implicit function theorem we have

$$
\frac{\partial \eta_{1}(\tilde{p})}{\partial \tilde{p}}=-\frac{\partial G / \partial \tilde{p}}{\partial G / \partial \hat{p}}=-\frac{\partial g / \partial \tilde{p}}{\partial g / \partial \hat{p}-1},
$$

The numerator of (25) is positive. This is because

$$
\frac{\partial g}{\partial \tilde{p}}=\frac{n-k}{\bar{x}^{k-1}(\bar{x}-\hat{p}+\tilde{p})^{n-k+1}} \int_{0}^{\bar{x}-\hat{p}}(\varepsilon+\hat{p})^{k-2}(\varepsilon+k \hat{p})(\varepsilon+\tilde{p})^{n-k-1}(\bar{x}-\hat{p}-\varepsilon) d \varepsilon>0
$$

The denominator of (25) is however negative. To see this, we note first that

$$
\begin{aligned}
\bar{x}^{k-1}(\bar{x}-\hat{p}+\tilde{p})^{n-k+1}\left[\frac{\partial g}{\partial \hat{p}}-1\right] & =(n-k) \int_{0}^{\bar{x}-\hat{p}}(\varepsilon+\hat{p})^{k-2}(\varepsilon+\tilde{p})^{n-k}(\varepsilon+k \hat{p}) d \varepsilon \\
& +(\bar{x}-\hat{p}+\tilde{p})(k-1) \int_{0}^{\bar{x}-\hat{p}}(\varepsilon+\hat{p})^{k-3}(\varepsilon+\tilde{p})^{n-k}(2 \varepsilon+k \hat{p}) d \varepsilon \\
& -(\bar{x}-\hat{p}+\tilde{p})^{n-k+1} \bar{x}^{k-2}[2 \bar{x}+(k-1) \hat{p}] .
\end{aligned}
$$

Assuming $k>2$, let us take the derivative of the RHS of (26) with respect to $\bar{x}$. After simplifying it, we obtain:

$$
-\bar{x}^{k-2}(\bar{x}-\hat{p}+\tilde{p})^{n-k}[\bar{x}(n-k+2)+(k-1) \hat{p}]+(k-1) \int_{0}^{\bar{x}-\hat{p}}(\varepsilon+\hat{p})^{k-3}(\varepsilon+\tilde{p})^{n-k}(2 \varepsilon+k \hat{p}) d \varepsilon
$$

If we now take the derivative of $(27)$ with respect to $\bar{x}$ and simplify it we get

$$
-(n-k) \bar{x}^{k-2}(\bar{x}-\hat{p}+\tilde{p})^{n-k-1}[\bar{x}(n+1)+\tilde{p}(k-1)]<0 .
$$

This implies that the derivative of the RHS of (26) with respect to $\bar{x}$, given in equation (27), is decreasing in $\bar{x}$. Setting $\bar{x}$ equal to its lowest value, $\hat{p}$, in (27) gives

$$
-\hat{p}^{k-2} \tilde{p}^{n-k}[\hat{p}(n-k+2)+(k-1) \hat{p}]<0 .
$$

As a result, the RHS of (26) is also decreasing in $\bar{x}$. If we set now $\bar{x}=\hat{p}$ in the RHS of (26), we obtain $-\tilde{p}^{* n-k+1} \hat{p}^{k-1}(k+1)<0$. From this we conclude that $(26)$ is negative. As a result, since the 
numerator of $\partial \eta_{1}(\tilde{p}) / \partial \tilde{p}$ is positive and the denominator is negative, we infer that the function $\eta_{1}(\tilde{p})$ increases in $\tilde{p}^{31}$

Now consider the other equilibrium condition. Let us denote the LHS of (10) as $H(\hat{p}, \tilde{p})$. The condition $H(\hat{p}, \tilde{p})=0$ also defines an implicit relationship between $\hat{p}$ and $\tilde{p}$. Let the function $\eta_{2}(\tilde{p})$ define such relationship. This function is represented in Figure 8 below. By the implicit function theorem we have

$$
\frac{\partial \eta_{2}(\tilde{p})}{\partial \tilde{p}}=-\frac{\partial H / \partial \tilde{p}}{\partial H / \partial \hat{p}}
$$

We note that $H$ increases in $\hat{p}$. In fact,

$$
\frac{\partial H}{\partial \hat{p}}=(n-k)(\bar{x}-\hat{p}+\tilde{p})^{n-k-1}\left(1-\bar{x}^{k}\right)+(n-k) k \int_{0}^{\bar{x}-\hat{p}}(\varepsilon+\tilde{p})^{n-k-1}(\varepsilon+\hat{p})^{k-1} d \varepsilon>0
$$

Moreover, $H$ decreases in $\tilde{p}$. In fact, for $k<n-1$ we have

$$
\begin{aligned}
\frac{\partial H}{\partial \tilde{p}} & =-\frac{1-\bar{x}^{n-k}}{1-\bar{x}}-(n-k)(\bar{x}-\hat{p}+\tilde{p})^{n-k-1}+(n-k)(n-k-1) \int_{0}^{\bar{x}-\hat{p}}(\varepsilon+\tilde{p})^{n-k-2}(\varepsilon+\hat{p})^{k} d \varepsilon \\
& <-\frac{1-\bar{x}^{n-k}}{1-\bar{x}}-(n-k)(\bar{x}-\hat{p}+\tilde{p})^{n-k-1}\left(1-\bar{x}^{k}\right)-(n-k) \bar{x}^{k} \tilde{p}^{n-k-1}<0,
\end{aligned}
$$

while for $k=n-1$ we get $\partial H / \partial \tilde{p}=-2<0$. As a result, we conclude that the function $\eta_{2}$ is increasing in $\tilde{p}$.

Therefore both $\eta_{1}$ and $\eta_{2}$ increase in $\tilde{p}$. To show that at least one pair of prices $\left\{\hat{p}^{*}, \tilde{p}^{*}\right\}$ exists that satisfies the system of FOCs (11) and (10), we need to show that the functions $\eta_{1}$ and $\eta_{2}$ cross at least once in the space $[0 ; 1 / 2] \times\left[0, p_{k}^{m}\right]$. As shown in Figure 8 we observe that $\eta_{1}(0)>0$. To demonstrate this, note that

$$
G(\hat{p}, 0)=\frac{1-\bar{x}^{k}}{k \bar{x}^{k-1}}-\hat{p}+\frac{1}{\bar{x}^{k-1}(\bar{x}-\hat{p})^{n-k}} \int_{0}^{\bar{x}-\hat{p}}(\varepsilon+\hat{p})^{k-2}(\varepsilon+k \hat{p}) \varepsilon^{n-k} d \varepsilon .
$$

Since $G$ decreases in $\hat{p}$ and since

$$
G(0,0)=\frac{1-\bar{x}^{k}}{k \bar{x}^{k-1}}+\frac{1}{\bar{x}^{n-1}} \int_{0}^{\bar{x}} \varepsilon^{n-1} d \varepsilon>0,
$$

${ }^{31}$ When $k=2$, equation (26) changes slightly. Therefore, we treat this case separately. If $k=2$ then

$$
g(\hat{p}, \tilde{p})=\frac{\int_{0}^{\bar{x}-\hat{p}^{*}}(\varepsilon+\tilde{p})^{n-2}(\varepsilon+2 \hat{p}) d \varepsilon}{(\bar{x}-\hat{p}+\tilde{p})^{n-2} \bar{x}}
$$

and

$$
\frac{\partial g(\hat{p}, \tilde{p})}{\partial \hat{p}}=\frac{(n-2) \int_{0}^{\bar{x}-\hat{p}^{*}}(\varepsilon+\tilde{p})^{n-2}(\varepsilon+2 \hat{p}) d \varepsilon}{(\bar{x}-\hat{p}+\tilde{p})^{n-1} \bar{x}}+\frac{2 \int_{0}^{\bar{x}-\hat{p}^{*}}(\varepsilon+\tilde{p})^{n-2} d \varepsilon}{(\bar{x}-\hat{p}+\tilde{p})^{n-2} \bar{x}}-\frac{\bar{x}+\hat{p}}{\bar{x}} .
$$

Then equation (26) is

$$
\begin{aligned}
\bar{x}(\bar{x}-\hat{p}+\tilde{p})^{n-1}\left[\frac{\partial g}{\partial \hat{p}}-1\right] & =(n-2) \int_{0}^{\bar{x}-\hat{p}}(\varepsilon+\tilde{p})^{n-2}(\varepsilon+2 \hat{p}) d \varepsilon \\
& +\frac{2}{n-1}(\bar{x}-\hat{p}+\tilde{p})^{n}-\frac{2}{n-1} \tilde{p}^{n-1}(\bar{x}-\hat{p}+\tilde{p})-(2 \bar{x}+\hat{p})(\bar{x}-\hat{p}+\tilde{p})^{n-1}
\end{aligned}
$$

The derivative of the RHS of (28) with respect to $\bar{x}$ is negative

$$
\begin{array}{r}
-(\bar{x}-\hat{p}+\tilde{p})^{n-2}\left[\bar{x} \frac{n^{2}-n-2}{n-1}+\hat{p} \frac{n+1}{n-1}-\frac{2}{n-1} \tilde{p}\right]-\frac{2}{n-1} \tilde{p}^{n-1}< \\
-(\bar{x}-\hat{p}+\tilde{p})^{n-2}\left[\bar{x} \frac{n^{2}-n-2}{n-1}+\hat{p} \frac{n+1}{n-1}-\frac{2}{n-1} \bar{x}\right]-\frac{2}{n-1} \tilde{p}^{n-1}= \\
-(\bar{x}-\hat{p}+\tilde{p})^{n-2}\left[\bar{x} \frac{n^{2}-n-4}{n-1}+\hat{p} \frac{n+1}{n-1}\right]-\frac{2}{n-1} \tilde{p}^{n-1}<0
\end{array}
$$

Since this expression is negative, the same arguments can be used to conclude that $\partial G / \partial \tilde{p}$ is positive also when $k=2$, which implies that $\eta_{1}(\tilde{p})$ increases in $\tilde{p}$. 
we conclude that $\eta_{1}(0)>0$.

On the contrary, we now observe that $\eta_{2}(0)<0$ (see Figure 8 ). This is because

$$
H(\hat{p}, 0)=1-(\bar{x}-\hat{p})^{n-k}+(n-k) \int_{0}^{\bar{x}-\hat{p}} \varepsilon^{n-k-1}(\varepsilon+\hat{p})^{k} d \varepsilon
$$

is increasing in $\hat{p}$ and $H(0,0)=1-\bar{x}^{n-k}+(n-k) \int_{0}^{\bar{x}} \varepsilon^{n-1} d \varepsilon>0$.

Secondly, as depicted in Figure 8, we show that $\eta_{1}(1 / 2)<p_{k}^{m}<\eta_{2}(1 / 2)$, which ensures that the functions $\eta_{1}$ and $\eta_{2}$ cross at least once in the area $[0 ; 1 / 2] \times\left[0 ; p_{k}^{m}\right]$. To see that $\eta_{2}(1 / 2)>p_{k}^{m}$, we show that $H\left(p_{k}^{m}, 1 / 2\right)<0$ where

$$
H\left(p_{k}^{m}, \frac{1}{2}\right)=1-\frac{1-\bar{x}^{n-k}}{1-\bar{x}} \frac{1}{2}-\left(\bar{x}-p_{k}^{m}+\frac{1}{2}\right)^{n-k}+(n-k) \int_{0}^{\bar{x}-p_{k}^{m}}\left(\varepsilon+\frac{1}{2}\right)^{n-k-1}\left(\varepsilon+p_{k}^{m}\right)^{k} d \varepsilon .
$$

Taking the derivative of $H\left(p_{k}^{m}, 1 / 2\right)$ with respect to $\bar{x}$ gives

$$
-\frac{1-(n-k) \bar{x}^{n-k-1}+(n-k-1) \bar{x}^{n-k}}{2(1-\bar{x})^{2}}-(n-k)\left(\bar{x}-p_{k}^{m}+\frac{1}{2}\right)^{n-k-1}\left(1-\bar{x}^{k}\right)<0,
$$

so $H\left(p_{k}^{m}, 1 / 2\right)$ is decreasing in $\bar{x} \cdot{ }^{32}$ Setting $\bar{x}$ equal to its lowest possible value, $p_{k}^{m}$, we get

$$
\left.H\left(p_{k}^{m}, \frac{1}{2}\right)\right|_{\bar{x}=p_{k}^{m}}=1-\frac{1}{2^{n-k}}-\frac{1-\left(p_{k}^{m}\right)^{n-k}}{2\left(1-p_{k}^{m}\right)}
$$

This expression is decreasing in $n$. In fact, its derivative with respect to $n$ can be written as

$$
\frac{2^{n-k-1}\left(p_{k}^{m}\right)^{n-k} \ln p_{k}^{m}+\left(1-p_{k}^{m}\right) \ln 2}{2^{n-k}\left(1-p_{k}^{m}\right)}<\frac{1}{2^{n-k}\left(1-p_{k}^{m}\right)}\left[p_{k}^{m} \ln p_{k}^{m}+\left(1-p_{k}^{m}\right) \ln 2\right]<0
$$

The last inequatility follows from the fact that $p_{k}^{m} \ln p_{k}^{m}+\left(1-p_{k}^{m}\right) \ln 2<0 .{ }^{33}$ Since $\left.H\left(p_{k}^{m}, 1 / 2\right)\right|_{\bar{x}=p_{k}^{m}}$ is decreasing in $n$, if we set $n$ equal to its lowest possible value, $k+1$, in (30) we obtain

$$
\left.H\left(p_{k}^{m}, \frac{1}{2}\right)\right|_{\bar{x}=p_{k}^{m}} \leq\left. H\left(p_{k}^{m}, \frac{1}{2}\right)\right|_{\bar{x}=p_{k}^{m} ; n=k+1}=1-\frac{1}{2^{k+1-k}}-\frac{1-\left(p_{k}^{m}\right)^{k+1-k}}{2\left(1-p_{k}^{m}\right)}=1-\frac{1}{2}-\frac{1}{2}=0
$$

Therefore, since $H\left(p_{k}^{m}, 1 / 2\right)$ is decreasing in $\bar{x}$, we conclude that $H\left(p_{k}^{m}, 1 / 2\right)$ is always negative. And because $H$ is increasing in $\hat{p}$, we obtain the result that $\eta_{2}(1 / 2)>p_{k}^{m}$.

We now show that $\eta_{1}(1 / 2)<p_{k}^{m}$. Since $G$ is decreasing in $\hat{p}$, it suffices to demonstrate that

$$
G\left(p_{k}^{m}, \frac{1}{2}\right)=\frac{1-\bar{x}^{k}}{k \bar{x}^{k-1}}-p_{k}^{m}+\frac{\int_{0}^{\bar{x}-p_{k}^{m}}\left(\varepsilon+p_{k}^{m}\right)^{k-2}\left(\varepsilon+\frac{1}{2}\right)^{n-k}\left(\varepsilon+k p_{k}^{m}\right) d \varepsilon}{\left(\bar{x}-p_{k}^{m}+\frac{1}{2}\right)^{n-k} \bar{x}^{k-1}}<0 .
$$

Taking the derivative of $G\left(p_{k}^{m}, 1 / 2\right)$ with respect to $n$ gives

$$
\left(\bar{x}-p_{k}^{m}+\frac{1}{2}\right)^{n-k} \bar{x}^{k-1} \frac{\partial G\left(p_{k}^{m}, \frac{1}{2}\right)}{\partial n}=\int_{0}^{\bar{x}-p_{k}^{m}}\left(\varepsilon+\frac{1}{2}\right)^{n-k}\left(\varepsilon+p_{k}^{m}\right)^{k-2}\left(\varepsilon+k p_{k}^{m}\right) \ln \left(\frac{\varepsilon+1 / 2}{\bar{x}-p_{k}^{m}+1 / 2}\right) d \varepsilon<0
$$

\footnotetext{
${ }^{32}$ The inequality follows from noting that the expression $1-(n-k) \bar{x}^{n-k-1}+(n-k-1) \bar{x}^{n-k}$ decreases in $\bar{x}$ and therefore it is higher than when we set $\bar{x}=1$, that is, $1-(n-k) \bar{x}^{n-k-1}+(n-k-1) \bar{x}^{n-k} \geq 1-(n-k)+(n-k-1)=0$.

${ }^{33}$ Taking the derivative of $p_{k}^{m} \ln p_{k}^{m}+\left(1-p_{k}^{m}\right) \ln 2$ with respect to $k$ gives $\left(\partial p_{k}^{m} / \partial k\right)\left(1-\ln 2+\ln p_{k}^{m}\right)$. The sign of this depends on the sign of $1-\ln 2+\ln p_{k}^{m}$, which is monotonically increasing in $k$, first negative and then positive. As a result, $p_{k}^{m} \ln p_{k}^{m}+\ln 2\left(1-p_{k}^{m}\right)$ first decreases and then increases in $k$. At $k=2$ it takes on a negative value while at $k \rightarrow \infty$ it is equal to zero. Therefore it is always negative.
} 
Since $G\left(p_{k}^{m}, 1 / 2\right)$ decreases in $n$, we can set $n$ equal to its lowest value and write

$$
G\left(p_{k}^{m}, \frac{1}{2}\right)<\left.G\left(p_{k}^{m}, \frac{1}{2}\right)\right|_{n=k+1}=\frac{1}{k \bar{x}^{k-1}\left(\bar{x}-p_{k}^{m}+\frac{1}{2}\right)} T(\bar{x})
$$

where

$$
T(\bar{x})=\left(\bar{x}-p_{k}^{m}+\frac{1}{2}\right)\left(1-\bar{x}^{k}-k \bar{x}^{k-1} p_{k}^{m}\right)+k \int_{0}^{\bar{x}-p_{k}^{m}}\left(\varepsilon+p_{k}^{m}\right)^{k-2}\left(\varepsilon+\frac{1}{2}\right)\left(\varepsilon+k p_{k}^{m}\right) d \varepsilon
$$

Note that $\left[k \bar{x}^{k-1}\left(\bar{x}-p_{k}^{m}+1 / 2\right)\right]^{-1}>0$. Thus, $\left.G\left(p_{k}^{m}, 1 / 2\right)\right|_{n=k+1}$ is negative if $T(\bar{x})<0 . T(\bar{x})$ decreases in $\bar{x}$ because $\partial T(\bar{x}) / \partial \bar{x}=1-\bar{x}^{k}-k \bar{x}^{k-1} p_{k}^{m}$ and this expression decreases in $\bar{x}$. Therefore, using $\bar{x}=p_{k}^{m}$, we can write

$$
\frac{\partial T(\bar{x})}{\partial \bar{x}}<\left.\frac{\partial T(\bar{x})}{\partial \bar{x}}\right|_{\bar{x}=p_{k}^{m}}=1-\left(p_{k}^{m}\right)^{k}-k\left(p_{k}^{m}\right)^{k-1} p_{k}^{m}=0 .
$$

Since $T(\bar{x})$ decreases in $\bar{x}$, we conclude that $T(\bar{x})<T\left(p_{k}^{m}\right)=0$. As a result the functions $\eta_{1}$ and $\eta_{2}$ cross at least once in the area $[0 ; 1 / 2] \times\left[0 ; p_{k}^{m}\right]$.

Claim 2 The pair of prices $\left\{\hat{p}^{*}, \tilde{p}^{*}\right\}$ that satisfies (10) and (11) is unique.

Proof. To show this, it is enough to show that $\eta_{1}$ increases in $\tilde{p}$ at a rate less than 1 , while $\eta_{2}$ does so at a rate greater than 1 . From $(25)$, since $\partial G / \partial \hat{p}<0$, we know that $\eta_{1}$ increases in $\tilde{p}$ at a rate less than 1 if and only if $\partial G / \partial \hat{p}+\partial G / \partial \tilde{p}<0$. For the case $k>2$, we can then write

$$
\begin{aligned}
& \bar{x}^{k-1}(\bar{x}-\hat{p}+\tilde{p})^{n-k}\left[\frac{\partial G(\hat{p}, \tilde{p})}{\partial \tilde{p}}+\frac{\partial G(\hat{p}, \tilde{p})}{\partial \hat{p}}\right]=(n-k) \int_{0}^{\bar{x}-\hat{p}}(\varepsilon+\hat{p})^{k-2}(\varepsilon+k \hat{p})(\varepsilon+\tilde{p})^{n-k-1} d \varepsilon \\
& +(k-1) \int_{0}^{\bar{x}-\hat{p}}(\varepsilon+\hat{p})^{k-3}(\varepsilon+\tilde{p})^{n-k}(2 \varepsilon+k \hat{p}) d \varepsilon-(\bar{x}-\hat{p}+\tilde{p})^{n-k} \bar{x}^{k-2}[2 \bar{x}+(k-1) \hat{p}] .
\end{aligned}
$$

We now notice that the RHS of (31) decreases in $\bar{x}$. In fact its derivative, after rearranging, is equal to $-(n-k) \bar{x}^{k-1}(\bar{x}-\hat{p}+\tilde{p})^{n-k-1}<0$. Therefore, if (31) is negative when setting $\bar{x}=\hat{p}$, then it is always negative. Checking this, we obtain: ${ }^{34}$

$$
\bar{x}^{k-1}(\bar{x}-\hat{p}+\tilde{p})^{n-k}\left[\frac{\partial G(\hat{p}, \tilde{p})}{\partial \tilde{p}}+\frac{\partial G(\hat{p}, \tilde{p})}{\partial \hat{p}}\right]<-\tilde{p}^{n-k} \hat{p}^{k-1}(k+1)<0 .
$$

Similarly, using (29), since $\partial H / \partial \hat{p}>0$, we know that $\partial \eta_{2} / \partial \tilde{p}>1$ if and only if $\partial H / \partial \hat{p}+\partial H / \partial \tilde{p}<0$. For the case $k<n-1$, using the expressions above, we then compute

$$
\begin{aligned}
\frac{\partial H}{\partial \tilde{p}}+\frac{\partial H}{\partial \hat{p}} & =-\frac{1-\bar{x}^{n-k}}{1-\bar{x}}+(n-k)(n-k-1) \int_{0}^{\bar{x}-\hat{p}}(\varepsilon+\tilde{p})^{n-k-2}(\varepsilon+\hat{p})^{k} d \varepsilon \\
& -(n-k)(\bar{x}-\hat{p}+\tilde{p})^{n-k-1} \bar{x}^{k}+(n-k) k \int_{0}^{\bar{x}-\hat{p}}(\varepsilon+\tilde{p})^{n-k-1}(\varepsilon+\hat{p})^{k-1} d \varepsilon
\end{aligned}
$$

${ }^{34}$ The same holds for the case when $k=2$. We have

$$
\begin{aligned}
\bar{x}(\bar{x}-\hat{p}+\tilde{p})^{n-2}\left[\frac{\partial G(\hat{p}, \tilde{p})}{\partial \tilde{p}}+\frac{\partial G(\hat{p}, \tilde{p})}{\partial \hat{p}}\right] & =(n-2) \int_{0}^{\bar{x}-\hat{p}}(\varepsilon+\tilde{p})^{n-3}(\varepsilon+2 \hat{p}) d \varepsilon \\
+ & \frac{2}{n-1}(\bar{x}-\hat{p}+\tilde{p})^{n-1}-\frac{2}{n-1} \tilde{p}^{n-1}-(2 \bar{x}+\hat{p})(\bar{x}-\hat{p}+\tilde{p})^{n-2}
\end{aligned}
$$

After simplifying, the derivative of (32) with respect to $\bar{x}$ is $-\bar{x}(n-2)(\bar{x}-\hat{p}+\tilde{p})^{n-3}$, which is clearly negative. Then

$$
\bar{x}(\bar{x}-\hat{p}+\tilde{p})^{n-2}\left[\frac{\partial G(\hat{p}, \tilde{p})}{\partial \tilde{p}}+\frac{\partial G(\hat{p}, \tilde{p})}{\partial \hat{p}}\right]<-3 \hat{p} \tilde{p}^{n-2}<0
$$


This expression decreases in $\bar{x}$ because its partial derivative with respect to $\bar{x}$, after rearranging, is equal to

$$
-\frac{1-(n-k) \bar{x}^{n-k-1}+(n-k-1) \bar{x}^{n-k}}{(1-\bar{x})^{2}}
$$

and we have already shown above that the numerator of this expression is positive. Thus, using $\bar{x}=\hat{p}$ in (33) we can write ${ }^{35}$

$$
\frac{\partial H}{\partial \tilde{p}}+\frac{\partial H}{\partial \hat{p}}<-\frac{1-\hat{p}^{n-k}}{1-\hat{p}}-(n-k) \tilde{p}^{n-k-1} \hat{p}^{k}<0 .
$$

The result then follows.

Claim 3 The price of the merging stores is higher than the price of the non-merging ones, i.e., $\hat{p}^{*}>\tilde{p}^{*}$.

Proof. Let $\tilde{p}_{1}$ be the price at which the function $\eta_{1}$ crosses the 45 degrees line, i.e., $\eta_{1}\left(\tilde{p}_{1}\right)=\tilde{p}_{1}$; likewise, let $\tilde{p}_{2}$ be such that $\eta_{2}\left(\tilde{p}_{2}\right)=\tilde{p}_{2}\left(\tilde{p}_{1}\right.$ and $\tilde{p}_{2}$ are represented in Figure 8$)$. Given the properties of $\eta_{1}$ and $\eta_{2}$, if we show that $\tilde{p}_{1}>\tilde{p}_{2}$ then we can conclude that $\hat{p}^{*}>\tilde{p}^{*}$.

If we set $\tilde{p}=\tilde{p}_{1}$ in the FOC $G(\hat{p}, \tilde{p})=0$ we obtain:

$$
\tilde{p}_{1}=\frac{1-\bar{x}^{k}}{k \bar{x}^{k-1}}+\frac{\int_{0}^{\bar{x}-\tilde{p}_{1}}\left(\varepsilon+\tilde{p}_{1}\right)^{n-2}\left(\varepsilon+k \tilde{p}_{1}\right) d \varepsilon}{\bar{x}^{n-1}}
$$

Similarly, when $\tilde{p}=\tilde{p}_{2}$ the FOC $H(\hat{p}, \tilde{p})=0$ gives:

$$
\tilde{p}_{2}=1-\bar{x}+\frac{1-\bar{x}}{1-\bar{x}^{n-k}}(n-k) \int_{0}^{\bar{x}-\tilde{p}_{2}}\left(\varepsilon+\tilde{p}_{2}\right)^{n-1} d \varepsilon
$$

For a contradiction, suppose that $\tilde{p}_{2}>\tilde{p}_{1}$. Then the difference between the RHS of (34) and the RHS of (35) must be negative. Let us denote this difference as $V$ and note that

$$
\begin{aligned}
V & \equiv \frac{\int_{0}^{\bar{x}-\tilde{p}_{1}}\left(\varepsilon+\tilde{p}_{1}\right)^{n-2}\left(\varepsilon+k \tilde{p}_{1}\right) d \varepsilon}{\bar{x}^{n-1}}+\frac{1+(k-1) \bar{x}^{k}-k \bar{x}^{k-1}}{k \bar{x}^{k-1}}-\frac{1-\bar{x}}{1-\bar{x}^{n-k}}(n-k) \int_{0}^{\bar{x}-\tilde{p}_{2}}\left(\varepsilon+\tilde{p}_{2}\right)^{n-1} d \varepsilon \\
& >\frac{\int_{0}^{\bar{x}-\tilde{p}_{1}}\left(\varepsilon+\tilde{p}_{1}\right)^{n-1} d \varepsilon}{\bar{x}^{n-1}}+\frac{1+(k-1) \bar{x}^{k}-k \bar{x}^{k-1}}{k \bar{x}^{k-1}}-\frac{1-\bar{x}}{1-\bar{x}^{n-k}}(n-k) \int_{0}^{\bar{x}-\tilde{p}_{2}}\left(\varepsilon+\tilde{p}_{2}\right)^{n-1} d \varepsilon
\end{aligned}
$$

where the inequality follows from replacing $\varepsilon+k \tilde{p}_{1}$ by $\varepsilon+\tilde{p}_{1}$ in the first integral.

Since the second integral in (36) is equal to $\left[\bar{x}^{n}-\left(\tilde{p}_{2}\right)^{n}\right] / n$, the whole expression in (36) increases in $\tilde{p}_{2}$. Therefore, (36) must be higher than when we replace $\tilde{p}_{2}$ by $\tilde{p}_{1}$. That is, (36) is higher than

$$
\begin{aligned}
& \frac{1}{\bar{x}^{n-1}} \int_{0}^{\bar{x}-\tilde{p}_{1}}\left(\varepsilon+\tilde{p}_{1}\right)^{n-1} d \varepsilon+\frac{1-(k-1) \bar{x}^{k}-k \bar{x}^{k-1}}{k \bar{x}^{k-1}}-\frac{1-\bar{x}}{1-\bar{x}^{n-k}}(n-k) \int_{0}^{\bar{x}-\tilde{p}_{1}}\left(\varepsilon+\tilde{p}_{1}\right)^{n-1} d \varepsilon \\
& =\frac{\bar{x}^{n}-\tilde{p}_{1}^{n}}{n\left(1-\bar{x}^{n-k}\right)}\left[\frac{1-\bar{x}^{n-k}-(n-k) \bar{x}^{n-1}(1-\bar{x})}{\bar{x}^{n-1}}\right]+\frac{1+(k-1) \bar{x}^{k}-k \bar{x}^{k-1}}{k \bar{x}^{k-1}}
\end{aligned}
$$

This last expression is positive, which establishes a contradiction. ${ }^{36}$ As a result, $\hat{p}^{*}>\tilde{p}^{*}$.

The very last thing we check is whether "large" deviations are profitable. We start with the nonmerging firms. A non-merging firm may choose a price $\tilde{p}$ such that $1-\bar{x}+\tilde{p}^{*}<\tilde{p}<1-\bar{x}+\hat{p}^{*}$. Given this, all consumers walk away from the deviant non-merging store and therefore its demand is made

\footnotetext{
${ }^{35}$ If $k=n-1$ then $\frac{\partial H}{\partial \tilde{p}}+\frac{\partial H}{\partial \hat{p}}=-2+\left(1-\bar{x}^{n-1}\right)+(n-1) \int_{0}^{\bar{x}-\hat{p}}(\varepsilon+\hat{p})^{n-2} d \varepsilon=-1-\hat{p}^{n-1}<0$.

${ }^{36}$ The term in squared brackets is positive. To see this, note that it is concave in $k$. Therefore, if it is positive for $k=2$ and $k=n-1$, then it is positive for all $k$. Setting $k=2$ gives $1-\bar{x}^{n-2}-(n-2) \bar{x}^{n-1}(1-\bar{x})$, which decreases in $\bar{x}$ since its derivative is $-(n-2) \bar{x}^{n-3}(1-\bar{x})[(1+\bar{x})+(n-1) \bar{x}]<0$. If we set $\bar{x}=1$ in the value for $k=2$ gives zero. Therefore it is positive for all $\bar{x}$ and $k=2$. Setting now $k=n-1$ gives $(1-\bar{x})\left(\bar{x}^{n-1}\right)>0$.
} 


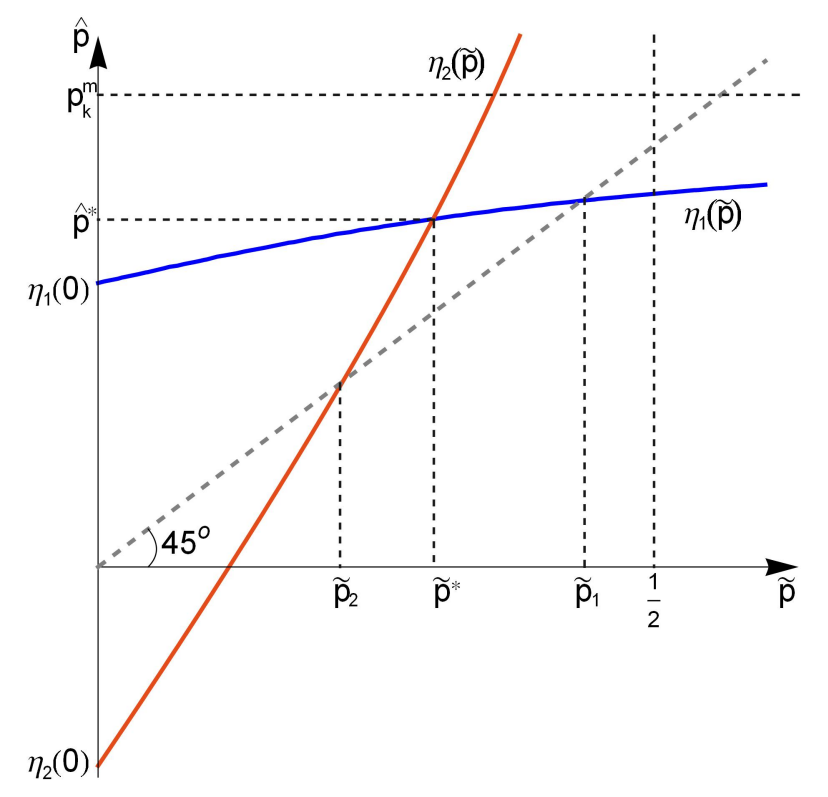

Figure 8: Existence and uniqueness of symmetric equilibrium

of consumers who return to it, either after visiting all non-merging stores or after visiting all stores in the market. Then, the payoff function of the deviant is

$$
\tilde{\pi}=\tilde{p}\left[\int_{\bar{x}-\hat{p}^{*}}^{1-\tilde{p}}\left(\varepsilon+\tilde{p}^{*}\right)^{n-k-1} d \varepsilon+\int_{0}^{\bar{x}-\hat{p}^{*}}\left(\varepsilon+\tilde{p}^{*}\right)^{n-k-1}\left(\varepsilon+\hat{p}^{*}\right)^{k} d \varepsilon\right]
$$

Taking the FOC gives:

$$
\int_{\bar{x}-\hat{p}^{*}}^{1-\tilde{p}}\left(\varepsilon+\tilde{p}^{*}\right)^{n-k-1} d \varepsilon+\int_{0}^{\bar{x}-\hat{p}^{*}}\left(\varepsilon+\tilde{p}^{*}\right)^{n-k-1}\left(\varepsilon+\hat{p}^{*}\right)^{k} d \varepsilon-\tilde{p}\left(1-\tilde{p}+\tilde{p}^{*}\right)^{n-k-1}=0
$$

which can be rewritten as

$$
\begin{aligned}
\left(1-\tilde{p}+\tilde{p}^{*}\right)^{n-k}-\left(\bar{x}-\hat{p}^{*}+\tilde{p}^{*}\right)^{n-k}+(n-k) & \int_{0}^{\bar{x}-\hat{p}^{*}}\left(\varepsilon+\tilde{p}^{*}\right)^{n-k-1}\left(\varepsilon+\hat{p}^{*}\right)^{k} d \varepsilon \\
& -(n-k) \tilde{p}\left(1-\tilde{p}+\tilde{p}^{*}\right)^{n-k-1}=0
\end{aligned}
$$

From (10), we obtain the relationship

$$
(n-k) \int_{0}^{\bar{x}-\hat{p}^{*}}\left(\varepsilon+\tilde{p}^{*}\right)^{n-k-1}\left(\varepsilon+\hat{p}^{*}\right)^{k} d \varepsilon=\frac{1-\bar{x}^{n-k}}{1-\bar{x}} \tilde{p}^{*}-1+\left(\bar{x}-\hat{p}^{*}+\tilde{p}^{*}\right)^{n-k}
$$

and use it in (38) to get

$$
\left(1-\tilde{p}+\tilde{p}^{*}\right)^{n-k}-1+\frac{1-\bar{x}^{n-k}}{1-\bar{x}} \tilde{p}^{*}-\tilde{p}\left(1-\tilde{p}+\tilde{p}^{*}\right)^{n-k-1}(n-k)=0
$$

or

$$
\left(1-\tilde{p}+\tilde{p}^{*}\right)^{n-k-1}\left[1+\tilde{p}^{*}-(n-k+1) \tilde{p}-\frac{1}{\left(1-\tilde{p}+\tilde{p}^{*}\right)^{n-k-1}}\left(1-\frac{1-\bar{x}^{n-k}}{1-\bar{x}} \tilde{p}^{*}\right)\right]=0 .
$$

We now argue that the LHS of (39) is always negative. Denote the term in squared brackets by $\phi\left(\tilde{p}, \tilde{p}^{*}\right)$. Taking its derivative with respecto to $\tilde{p}$ gives

$$
\frac{\partial \phi}{\partial \tilde{p}}=-(n-k+1)-\frac{n-k-1}{\left(1-\tilde{p}+\tilde{p}^{*}\right)^{n-k}}\left(1-\frac{1-\bar{x}^{n-k}}{1-\bar{x}} \tilde{p}^{*}\right)
$$


which is negative because

$$
\begin{aligned}
\frac{1-\bar{x}^{n-k}}{1-\bar{x}} \tilde{p}^{*}-1 & =-\left(\bar{x}-\hat{p}^{*}+\tilde{p}^{*}\right)^{n-k}+(n-k) \int_{0}^{\bar{x}-\hat{p}^{*}}\left(\varepsilon+\tilde{p}^{*}\right)^{n-k-1}\left(\varepsilon+\hat{p}^{*}\right)^{k} d \varepsilon \\
& <-\left(\bar{x}-\hat{p}^{*}+\tilde{p}^{*}\right)^{n-k}+\bar{x}^{k}(n-k) \int_{0}^{\bar{x}-\hat{p}^{*}}\left(\varepsilon+\tilde{p}^{*}\right)^{n-k-1} d \varepsilon \\
& =\left(\bar{x}-\hat{p}^{*}+\tilde{p}^{*}\right)^{n-k}\left(\bar{x}^{k}-1\right)-\bar{x}^{k} \tilde{p}^{*}<0
\end{aligned}
$$

Since $\phi\left(\tilde{p}, \tilde{p}^{*}\right)$ decreases in $\tilde{p}$ and

$$
\begin{aligned}
\phi\left(\tilde{p}, \tilde{p}^{*}\right)<\phi\left(\tilde{p}^{*}, \tilde{p}^{*}\right) & =1+\tilde{p}^{*}-(n-k+1) \tilde{p}^{*}-\left(1-\frac{1-\bar{x}^{n-k}}{1-\bar{x}} \tilde{p}^{*}\right) \\
& <1-(n-k) \tilde{p}^{*}-\left(1-(n-k) \tilde{p}^{*}\right)=0,
\end{aligned}
$$

we conclude that the LHS of (39) is always negative, which implies that the profit function is decreasing in $\tilde{p}$. As a result, the deviation is not profitable.

A non-merging firm may also deviate to a price $\tilde{p}$ such that $1-\bar{x}+\hat{p}^{*}<\tilde{p}<1 / 2$, in which case its payoff would be

$$
\tilde{\pi}=\tilde{p} \int_{\tilde{p}}^{1}\left(\varepsilon-\tilde{p}+\tilde{p}^{*}\right)^{n-k-1}\left(\varepsilon-\tilde{p}+\hat{p}^{*}\right)^{k} d \varepsilon=\tilde{p} \int_{0}^{1-\tilde{p}}\left(\varepsilon+\tilde{p}^{*}\right)^{n-k-1}\left(\varepsilon+\hat{p}^{*}\right)^{k} d \varepsilon .
$$

Taking the FOC and rewriting it gives

$$
\int_{0}^{1-\tilde{p}} \frac{\left(\varepsilon+\tilde{p}^{*}\right)^{n-k-1}\left(\varepsilon+\hat{p}^{*}\right)^{k}}{\left(1-\tilde{p}+\tilde{p}^{*}\right)^{n-k-1}\left(1-\tilde{p}+\hat{p}^{*}\right)^{k}} d \varepsilon-\tilde{p}=0
$$

The integrand of this expression increases in $k$. In fact its derivative is equal to

$$
\frac{\left(\varepsilon+\tilde{p}^{*}\right)^{n-k-1}}{\left(1-\tilde{p}+\tilde{p}^{*}\right)^{n-k-1}} \frac{\left(\varepsilon+\hat{p}^{*}\right)^{k}}{\left(1-\tilde{p}+\hat{p}^{*}\right)^{k}} \ln \frac{\left(\varepsilon+\hat{p}^{*}\right)\left(1-\tilde{p}+\tilde{p}^{*}\right)}{\left(1-\tilde{p}+\hat{p}^{*}\right)\left(\varepsilon+\tilde{p}^{*}\right)}>0,
$$

where the inequality follows from the observation that

$$
\frac{\left(\varepsilon+\hat{p}^{*}\right)\left(1-\tilde{p}+\tilde{p}^{*}\right)}{\left(1-\tilde{p}+\hat{p}^{*}\right)\left(\varepsilon+\tilde{p}^{*}\right)}>\frac{\left(\varepsilon+\hat{p}^{*}\right)\left(1-\tilde{p}+\hat{p}^{*}\right)}{\left(1-\tilde{p}+\hat{p}^{*}\right)\left(\varepsilon+\hat{p}^{*}\right)}=1
$$

Hence, we can write

$$
\begin{aligned}
& \int_{0}^{1-\tilde{p}} \frac{\left(\varepsilon+\tilde{p}^{*}\right)^{n-k-1}\left(\varepsilon+\hat{p}^{*}\right)^{k}}{\left(1-\tilde{p}+\tilde{p}^{*}\right)^{n-k-1}\left(1-\tilde{p}+\hat{p}^{*}\right)^{k}} d \varepsilon-\tilde{p} \leq \int_{0}^{1-\tilde{p}} \frac{\left(\varepsilon+\tilde{p}^{*}\right)^{n-n+1-1}\left(\varepsilon+\hat{p}^{*}\right)^{n-1}}{\left(1-\tilde{p}+\tilde{p}^{*}\right)^{n-n+1-1}\left(1-\tilde{p}+\hat{p}^{*}\right)^{n-1}} d \varepsilon-\tilde{p} \\
& \quad=\int_{0}^{1-\tilde{p}} \frac{\left(\varepsilon+\hat{p}^{*}\right)^{n-1}}{\left(1-\tilde{p}+\hat{p}^{*}\right)^{n-1}} d \varepsilon-\tilde{p}<\int_{0}^{1-\tilde{p}} \frac{(\varepsilon+\tilde{p})^{n-1}}{(1-\tilde{p}+\tilde{p})^{n-1}} d \varepsilon-\tilde{p}=\frac{1}{n}\left(1-\tilde{p}^{n}-n \tilde{p}\right)<0,
\end{aligned}
$$

where the last inequality follows from the fact that $\tilde{p}>\hat{p}^{*}$ and $\hat{p}^{*}>p^{*}$ (see the proof of Proposition 2 ) and the expression $1-\tilde{p}^{n}-n \tilde{p}$ decreases in $\tilde{p}$ so $1-\tilde{p}^{n}-n \tilde{p}<1-p^{* n}-n p^{*} \leq 0$ (see the FOC (4)). We then conclude that the LHS of (40) is negative and therefore the deviation is not profitable either.

We finish by checking that the merged entity does not find it profitable to deviate to a price $\hat{p}>1-\bar{x}+\hat{p}^{*}$. In such a case, its payoff would be

$$
\widehat{\pi}=\hat{p} \int_{\hat{p}}^{1}\left(\varepsilon-\hat{p}+\tilde{p}^{*}\right)^{n-k} k \varepsilon^{k-1} d \varepsilon=\hat{p} \int_{0}^{1-\hat{p}}\left(\varepsilon+\tilde{p}^{*}\right)^{n-k} k(\varepsilon+\hat{p})^{k-1} d \varepsilon
$$


and the corresponding FOC:

$$
\frac{\int_{0}^{1-\hat{p}}\left(\varepsilon+\tilde{p}^{*}\right)^{n-k}(\varepsilon+\hat{p})^{k-2}(\varepsilon+k \hat{p}) d \varepsilon}{\left(1-\hat{p}+\tilde{p}^{*}\right)^{n-k}}-\hat{p}=0 .
$$

We note that this FOC is identical to (19) when $s \rightarrow 0$. We already proved that (41) decreases in $\hat{p}$. Therefore, the deviating profits are highest when $\hat{p}=1-\bar{x}+\hat{p}^{*}$, which implies that the deviation is not profitable because $\widehat{\pi}^{*}>\left.\widehat{\pi}\right|_{\hat{p}=1-\bar{x}+\hat{p}^{*}}$.

Proof of Proposition 2. From Proposition $1 \hat{p}^{*}>\tilde{p}^{*}$. Let us now show that $\tilde{p}^{*}>p^{*}$.

(1) For a contradiction, assume that $\tilde{p}^{*}<p^{*}$ when $\bar{x} \rightarrow 1$. Denote the quantity sold by a nonmerged firm by $\tilde{q}^{*}$, that sold by all the merging firms together by $\hat{q}^{*}$ and the aggregate quantity sold in the market by all firms by $Q$. We note that $Q=1-\hat{p}^{* k} \tilde{p}^{* n-k} \cdot{ }^{37}$ Using the FOCs we can write that

$$
Y\left(\tilde{p}^{*}, \hat{p}^{*}\right) \equiv Q-(n-k) \tilde{q}^{*}-\hat{q}^{*}=0
$$

where

$$
\begin{gathered}
(n-k) \tilde{q}^{*}=\frac{1-\bar{x}^{n-k}}{1-\bar{x}} \tilde{p}^{*} \\
\hat{q}^{*}=k \hat{p}^{*} \bar{x}^{k-1}\left(\bar{x}-\hat{p}^{*}+\tilde{p}^{*}\right)^{n-k}-k(k-1) \hat{p}^{*} \int_{0}^{\bar{x}-\hat{p}^{*}}\left(\varepsilon+\hat{p}^{*}\right)^{k-2}\left(\varepsilon+\tilde{p}^{*}\right)^{n-k} d \varepsilon .
\end{gathered}
$$

We now argue that $Y\left(\tilde{p}^{*}, \hat{p}^{*}\right)$ is decreasing in $\tilde{p}^{*}$. This is because $\partial Q / \partial \tilde{p}^{*}<0, \partial \tilde{q}^{*} / \partial \tilde{p}^{*}>0$ and

$$
\begin{aligned}
\frac{1}{k(n-k) \hat{p}^{*}} \frac{\partial \hat{q}^{*}}{\partial \tilde{p}^{*}} & =\bar{x}^{k-1}\left(\bar{x}-\hat{p}^{*}+\tilde{p}^{*}\right)^{n-k-1}-(k-1) \int_{0}^{\bar{x}-\hat{p}^{*}}\left(\varepsilon+\hat{p}^{*}\right)^{k-2}\left(\varepsilon+\tilde{p}^{*}\right)^{n-k-1} d \varepsilon \\
& >\bar{x}^{k-1}\left(\bar{x}-\hat{p}^{*}+\tilde{p}^{*}\right)^{n-k-1}-(k-1)\left(\bar{x}-\hat{p}^{*}+\tilde{p}^{*}\right)^{n-k-1} \int_{0}^{\bar{x}-\hat{p}^{*}}\left(\varepsilon+\hat{p}^{*}\right)^{k-2} d \varepsilon \\
& =\left(\bar{x}-\hat{p}^{*}+\tilde{p}^{*}\right)^{n-k-1} \hat{p}^{* k-1}>0
\end{aligned}
$$

Next, since $Y$ is decreasing in $\tilde{p}^{*}$ and by assumption $\tilde{p}^{*}<p^{*}$ we must have $Y\left(p^{*}, \hat{p}^{*}\right)<0$. In other words, it must be the case that

$$
\begin{aligned}
\lim _{\bar{x} \rightarrow 1} Y\left(p^{*}, \hat{p}^{*}\right) & =1-\hat{p}^{* k} p^{* n-k}-(n-k) p^{*}-k \hat{p}^{*}\left(1-\hat{p}^{*}+p^{*}\right)^{n-k} \\
& +k(k-1) \hat{p}^{*} \int_{0}^{1-\hat{p}^{*}}\left(\varepsilon+\hat{p}^{*}\right)^{k-2}\left(\varepsilon+p^{*}\right)^{n-k} d \varepsilon<0
\end{aligned}
$$

Now we invoke the FOC of the merged entity, denoted above by $G\left(\hat{p}^{*}, \tilde{p}^{*}\right)$. The function $G\left(\hat{p}^{*}, \tilde{p}^{*}\right)$ was shown to be increasing in $\tilde{p}^{*}$ so when $\tilde{p}^{*}<p^{*}$ we must have $G\left(\hat{p}^{*}, p^{*}\right)>G\left(\hat{p}^{*}, \tilde{p}^{*}\right)=0$. Therefore:

$$
\begin{aligned}
\lim _{\bar{x} \rightarrow 1} G\left(\hat{p}^{*}, p^{*}\right) & =-\hat{p}^{*}+\frac{(k-1)}{\left(1-\hat{p}^{*}+\tilde{p}^{*}\right)^{n-k}} \hat{p}^{*} \int_{0}^{1-\hat{p}^{*}}\left(\varepsilon+\hat{p}^{*}\right)^{k-2}\left(\varepsilon+p^{*}\right)^{n-k} d \varepsilon \\
& +\frac{1}{\left(1-\hat{p}^{*}+\tilde{p}^{*}\right)^{n-k}} \int_{0}^{1-\hat{p}^{*}}\left(\varepsilon+\hat{p}^{*}\right)^{k-1}\left(\varepsilon+p^{*}\right)^{n-k} d \varepsilon
\end{aligned}
$$

must be positive, which implies that it must be the case that

$$
-\hat{p}^{*}\left(1-\hat{p}^{*}+p^{*}\right)^{n-k}+(k-1) \hat{p}^{*} \int_{0}^{1-\hat{p}^{*}}\left(\varepsilon+\hat{p}^{*}\right)^{k-2}\left(\varepsilon+p^{*}\right)^{n-k} d \varepsilon>-\int_{0}^{1-\hat{p}^{*}}\left(\varepsilon+\hat{p}^{*}\right)^{k-1}\left(\varepsilon+p^{*}\right)^{n-k} d \varepsilon .
$$

Using this inequality in (42), we get that

$$
\lim _{\bar{x} \rightarrow 1} Y\left(p^{*}, \hat{p}^{*}\right)>1-\hat{p}^{* k} p^{* n-k}-(n-k) p^{*}-k \int_{0}^{1-\hat{p}^{*}}\left(\varepsilon+\hat{p}^{*}\right)^{k-1}\left(\varepsilon+p^{*}\right)^{n-k} d \varepsilon
$$

\footnotetext{
${ }^{37} \mathrm{~A}$ consumer does not buy at all when the match value drawn at every firm is lower than its corresponding price.
} 
This last expression is increasing in $\hat{p}^{*}$. This is because the sign of its derivative with respect to $\hat{p}^{*}$ is the same as the sign of the following expression

$$
\begin{aligned}
& -\hat{p}^{* k-1} p^{* n-k}-(k-1) \int_{0}^{1-\hat{p}^{*}}\left(\varepsilon+\hat{p}^{*}\right)^{k-2}\left(\varepsilon+p^{*}\right)^{n-k} d \varepsilon+\left(1-\hat{p}^{*}+p^{*}\right)^{n-k} \\
& >-\hat{p}^{* k-1} p^{* n-k}-(k-1)\left(1-\hat{p}^{*}+p^{*}\right)^{n-k} \int_{0}^{1-\hat{p}^{*}}\left(\varepsilon+\hat{p}^{*}\right)^{k-2} d \varepsilon+\left(1-\hat{p}^{*}+p^{*}\right)^{n-k} \\
& =-\hat{p}^{* k-1} p^{* n-k}+\left(1-\hat{p}^{*}+p^{*}\right)^{n-k} \hat{p}^{* k-1}>0
\end{aligned}
$$

We now argue that $\hat{p}^{*} \geq p^{*}$. To show this, we first invoke the result in Proposition 3 of Zhou (2009) that the equilibrium price of firms visited last is higher than $p^{*}$. In our model, in addition to the search-order effect of Zhou, the firms visited last internalize the pricing externalities they confer on one another and this leads the firms to raise further their prices. As a result, here it must also be the case that $\hat{p}^{*} \geq p^{*}$. Given this, (43) is greater than after setting $\hat{p}^{*}=p^{*}$, that is, $\lim _{\bar{x} \rightarrow 1} Y\left(p^{*}, \hat{p}^{*}\right)$ is larger than

$$
1-\left(p^{*}\right)^{n}-(n-k) p^{*}-k\left[\frac{1}{n}-\frac{1}{n}\left(p^{*}\right)^{n}\right]=n p^{*}-(n-k) p^{*}-k p^{*}=0,
$$

where for the last equality we have used the FOC of a typical firm in the pre-merger market (when $\bar{x} \rightarrow 1$ the FOC of a firm in a pre-merger market becomes $\left.1-n p^{*}-\left(p^{*}\right)^{n}=0\right)$. Consequently, if $\tilde{p}^{*}>p^{*}$ then we have $\lim _{\bar{x} \rightarrow 1} Y\left(p^{*}, \hat{p}^{*}\right)>0$, which establishes a contradiction.

(2) Let us take the limit of the LHS of (11) and (10) when $\bar{x} \rightarrow p_{k}^{m}$ and let $\tilde{p}_{l} \equiv \lim _{\bar{x} \rightarrow p_{k}^{m}} \tilde{p}^{*}$ and $p_{k}^{m} \equiv \lim _{\bar{x} \rightarrow p_{k}^{m}} \hat{p}^{*}$. Then we get the following expressions

$$
\begin{aligned}
\left(\tilde{p}_{l}\right)^{n-k}\left[1-(k+1)\left(p_{k}^{m}\right)^{k}\right] & =0 \\
\left(1-p_{k}^{m}\right)\left(1-\left(\tilde{p}_{l}\right)^{n-k}\right)-\tilde{p}_{l}\left[1-\left(p_{k}^{m}\right)^{n-k}\right] & =0 .
\end{aligned}
$$

The first equation is indeed zero given the definition of $p_{k}^{m}$ and the second equation therefore gives the value of $\tilde{p}^{*}$ when $\bar{x} \rightarrow p_{k}^{m}$. We note that $\tilde{p}_{l}<p^{m}=1 / 2$ because, as shown in the proof of proposition $1, H\left(p_{k}^{m}, 1 / 2\right) \leq 0$.

Let $p_{l} \equiv \lim _{\bar{x} \rightarrow p_{k}^{m}} p^{*}$. We now argue that $\tilde{p}_{l}>p_{l}$. To show this, we take the limit when $\bar{x} \rightarrow p_{k}^{m}$ of the FOC that determines $p_{l}$. This gives $\left(1-p_{k}^{m}\right)\left(1-\left(p_{l}\right)^{n}\right)-p_{l}\left[1-\left(p_{k}^{m}\right)^{n}\right]=0$. The solution of this equation, $p_{l}$, decreases in $n$. Comparing this equation with (44), since $n-k<n$, it is immediately clear that $\tilde{p}_{l}>p_{l}$.

(3) If $n=3$ then the FOC of a merging firm may be rearranged as follows

$$
\hat{p}^{* 3}-\hat{p}^{*} \bar{x}^{2}-\tilde{p}^{*}\left(3 \hat{p}^{* 2}-1\right)=\frac{\bar{x}^{3}}{3}-\frac{\hat{p}^{* 3}}{3}-\bar{x}+\hat{p}^{*} .
$$

The FOC of a non-merging firm gives us the relation $\bar{x}^{3} / 3-\hat{p}^{* 3} / 3-\bar{x}+\hat{p}^{*}=2 \tilde{p}^{*}-1$. Using this expression in (45) we have $\hat{p}^{* 3}-\hat{p}^{*} \bar{x}^{2}-3 \tilde{p}^{*} \hat{p}^{* 2}-\tilde{p}^{*}+1=0$, or

$$
\tilde{p}^{*}=\frac{1+\hat{p}^{* 3}-\hat{p}^{*} \bar{x}^{2}}{1+3 \hat{p}^{* 2}} .
$$

From the FOC in the pre-merger market we know that

$$
p^{*}=\frac{1-p^{* 3}}{1+\bar{x}+\bar{x}^{2}} .
$$

Since, by strategic complementarity, $\tilde{p}^{*}$ increases in $\hat{p}^{*}$ and since $\hat{p}^{*}>p^{*}$, the difference $\tilde{p}^{*}-p^{*}$ is greater than when we replace $\hat{p}^{*}$ by $p^{*}$. Therefore

$$
\tilde{p}^{*}-p^{*}=\frac{1+\hat{p}^{* 3}-\hat{p}^{*} \bar{x}^{2}}{1+3 \hat{p}^{* 2}}-\frac{1-p^{* 3}}{1+\bar{x}+\bar{x}^{2}}>\frac{1+p^{* 3}-p^{*} \bar{x}^{2}}{1+3 p^{* 2}}-\frac{1-p^{* 3}}{1+\bar{x}+\bar{x}^{2}}
$$


The RHS of this expression is concave in $\bar{x}$ because its second derivative with respect to $\bar{x}$ is negative:

$$
-\frac{2 p^{*}}{1+3 p^{* 2}}-\frac{6\left(1-p^{* 3}\right) \bar{x}(1+\bar{x})}{\left(1+\bar{x}+\bar{x}^{2}\right)^{3}}<0
$$

Hence, if the RHS of (46) is positive with the highest and the lowest possible values of $\bar{x}$ then it is positive for all possible $\bar{x}$ values. Setting $\bar{x}=1$ in the RHS of (46) gives

$$
\frac{2-3 p^{*}-3 p^{* 2}+4 p^{* 3}+3 p^{* 5}}{3\left(1+3 p^{* 2}\right)} \text {. }
$$

which, as shown in Figure 9, is always positive for all $p^{*} \in[0,1 / 2]$. Setting $\bar{x}=p^{*}$ in (46) gives

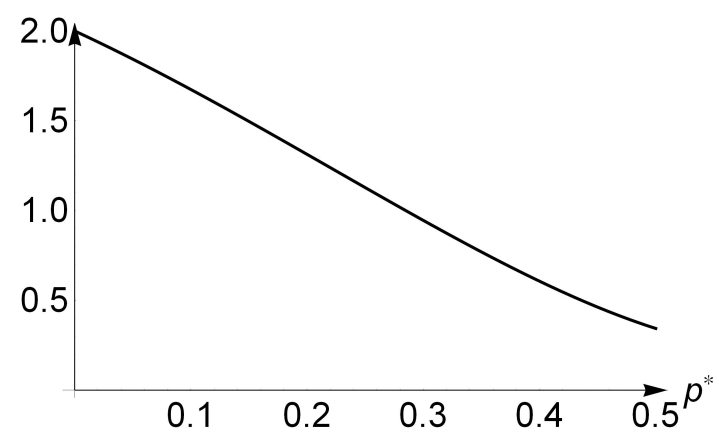

Figure 9: Plot of expression 47

$$
\frac{p\left(1-3 p^{*}+3 p^{* 2}\right)}{1+3 p^{* 2}}>0
$$

Thus, $\tilde{p}^{*}>p^{*}$.

Proof of Proposition 3. (1) To prove this we set $k=2$ in the profits difference $\hat{\pi}^{*} / k-\pi^{*}$ and study its sign when $\bar{x} \rightarrow p_{2}^{m}(=1 / \sqrt{3})$. For the profit of a merging firm we have

$$
\lim _{\bar{x} \rightarrow 1 / \sqrt{3}} \frac{\hat{\pi}^{*}}{2}=\frac{\left(\tilde{p}_{l}\right)^{n-2}}{3 \sqrt{3}}
$$

where, as in the proof of Proposition 2, $\tilde{p}_{l} \equiv \lim _{\bar{x} \rightarrow p_{k}^{m}} \tilde{p}^{*}$. We have shown above that $\tilde{p}_{l}<p^{m}=1 / 2$. Therefore,

$$
\lim _{\bar{x} \rightarrow 1 / \sqrt{3}} \frac{\hat{\pi}^{*}}{2}<\frac{\left(p^{m}\right)^{n-2}}{3 \sqrt{3}}
$$

which implies that

$$
\lim _{\bar{x} \rightarrow 1 / \sqrt{3}}\left[\frac{\hat{\pi}^{*}}{2}-\pi^{*}\right]<\frac{(1 / 2)^{n-2}}{3 \sqrt{3}}-\frac{\left(p_{l}\right)^{2}\left[1-\left(p_{2}^{m}\right)^{n}\right]}{n\left(1-p_{2}^{m}\right)}
$$

where, again as in the proof of Proposition $2, p_{l} \equiv \lim _{\bar{x} \rightarrow p_{k}^{m}} p^{*}$. If we demonstrate that (48) is negative, then the result follows. For this we need that

$$
p_{l}>\sqrt{\frac{n\left(1-3^{-1 / 2}\right)(1 / 2)^{n-2}}{3 \sqrt{3}\left(1-3^{-n / 2}\right)}}
$$

To show that (49) indeed holds, we now invoke the FOC in the pre-merger market; when $\bar{x} \rightarrow 1 / \sqrt{3}$ the FOC writes

$$
1-\left(p_{l}\right)^{n}-p_{l} \frac{1-3^{-n / 2}}{1-3^{-1 / 2}}=0 .
$$


Now, using (50), if we replace $p_{l}$ by $\left[\frac{n\left(1-3^{-1 / 2}\right)}{2^{n-2} 3 \sqrt{3}\left(1-3^{-n / 2}\right)}\right]^{\frac{1}{2}}$ in this expression we get

$$
1-\left[\frac{n\left(1-3^{-1 / 2}\right)}{2^{n-2} 3 \sqrt{3}\left(1-3^{-n / 2}\right)}\right]^{\frac{n}{2}}-\sqrt{\frac{n\left(1-3^{-1 / 2}\right)}{2^{n-2} 3 \sqrt{3}\left(1-3^{-n / 2}\right)}} \frac{\left(1-3^{-n / 2}\right)}{1-3^{-1 / 2}} .
$$

This last expression, as shown in Figure 10, is always positive for $n \geq 3$.

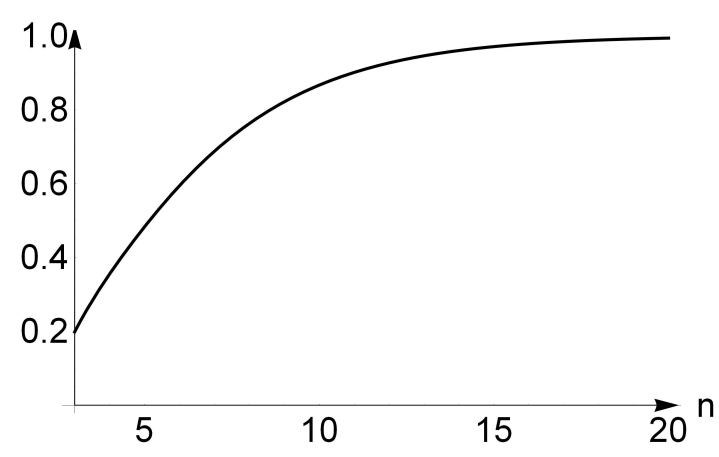

Figure 10: Plot of expression (51).

Since (50) is decreasing in $p_{l}$, then (49) must hold.

(2) Using the definition of $p_{k}^{m}$, we have that $1-\left(p_{k}^{m}\right)^{k}=k\left(p_{k}^{m}\right)^{k}$. Therefore we can write

$$
\begin{aligned}
\lim _{\bar{x} \rightarrow p_{k}^{m} ; n \rightarrow \infty}\left[\frac{\hat{\pi}^{*}}{k}-\pi^{*}\right] & =\lim _{n \rightarrow \infty}\left[p_{k}^{m}\left(\tilde{p}_{l}\right)^{n-k}\left(1-\left(p_{k}^{m}\right)^{k}\right)-\frac{\left(p_{l}\right)^{2}\left(1-\left(p_{k}^{m}\right)^{n}\right)}{n\left(1-p_{k}^{m}\right)}\right] \\
& <\lim _{n \rightarrow \infty}\left[\frac{\left(p_{k}^{m}\right)^{k+1}}{2^{n-k}}-\frac{\left(p_{l}\right)^{2}\left(1-\left(p_{k}^{m}\right)^{n}\right)}{n\left(1-p_{k}^{m}\right)}\right]
\end{aligned}
$$

where the inequality follows from the fact that $\tilde{p}_{l}<p^{m}=1 / 2$. Note that $1-\left(p_{k}^{m}\right)^{n}>1-\left(p_{k}^{m}\right)^{k}=$ $k\left(p_{k}^{m}\right)^{k}$. Thus,

$$
\lim _{n \rightarrow \infty}\left[\frac{\left(p_{k}^{m}\right)^{k+1}}{2^{n-k}}-\frac{\left(p_{l}\right)^{2}\left(1-\left(p_{k}^{m}\right)^{n}\right)}{n\left(1-p_{k}^{m}\right)}\right]<\frac{\left(p_{k}^{m}\right)^{k}}{1-p_{k}^{m}} \lim _{n \rightarrow \infty}\left[\frac{p_{k}^{m}\left(1-p_{k}^{m}\right)}{2^{n-k}}-\frac{\left(p_{l}\right)^{2} k}{n}\right]=0,
$$

which shows that for any $k$, merging is not profitable whenever search costs and the number of competitors is sufficiently high.

(3) To prove this, we show that $\lim _{\bar{x} \rightarrow 1}\left[\hat{\pi}^{*}-k \pi^{*}\right]>0$. Notice that

$$
\lim _{\bar{x} \rightarrow 1} \hat{\pi}^{*}=\hat{p}_{1}^{*} k \int_{0}^{1-\hat{p}_{1}^{*}}\left(\varepsilon+\tilde{p}_{1}^{*}\right)^{n-k}\left(\varepsilon+\hat{p}_{1}^{*}\right)^{k-1} d \varepsilon
$$

where $\hat{p}_{1}^{*} \equiv \lim _{\bar{x} \rightarrow 1} \hat{p}^{*}$ and $\tilde{p}_{1}^{*} \equiv \lim _{\bar{x} \rightarrow 1} \tilde{p}_{1}^{*}$. Since $\hat{p}_{1}^{*}$ solves the FOC (11), we can replace $\hat{p}_{1}^{*}$ in $(52)$ and write

$$
\lim _{\bar{x} \rightarrow 1} \hat{\pi}^{*}>\tilde{p}_{1}^{*} k \int_{0}^{1-\tilde{p}_{1}^{*}}\left(\varepsilon+\tilde{p}_{1}^{*}\right)^{n-k}\left(\varepsilon+\tilde{p}_{1}^{*}\right)^{k-1} d \varepsilon=\frac{k \tilde{p}_{1}^{*}}{n}\left(1-\tilde{p}_{1}^{* n}\right) .
$$

We note note that the polynomial $y\left(1-y^{n}\right)$ is increasing in $y$ for all $y \leq(n+1)^{-1 / n}$. Therefore, because $\tilde{p}_{1}^{*}>p_{1}^{*}$ we can write that $\lim _{\bar{x} \rightarrow 1} \hat{\pi}^{*}>\frac{k p_{1}^{*}}{n}\left(1-p_{1}^{* n}\right)=k \lim _{\bar{x} \rightarrow 1} \pi^{*}$, where $p_{1}^{*} \equiv \lim _{\bar{x} \rightarrow 1} p_{1}^{*}$.

Proof of Proposition 4. The proof is similar to the proof of Proposition 1. We first claim that there is a pair of prices $\left\{\hat{p}^{*}, \tilde{p}^{*}\right\}$ that satisfies the FOCs (19) and (20) and then argue that such a pair 
of prices is unique. After this, we show that the putative order of search is optimal when the search cost is sufficiently large. Finally, we check whether "large" deviations are profitable.

Let $G\left(\hat{p}^{*}, \tilde{p}^{*}\right)$ and $H\left(\hat{p}^{*}, \tilde{p}^{*}\right)$ denote the LHS of the FOCs (19) and (20), respectively. In what follows, we drop the "*" super-indexes to shorten the expressions.

Claim 4 There is a pair of prices $\hat{p}$ and $\tilde{p}$ that satisfy the first-order conditions $G(\hat{p}, \tilde{p})=0$ and $H(\hat{p}, \tilde{p})=0$.

Proof. The function $G$ is differentiable and takes on real values for all $(\hat{p}, \tilde{p}) \in\left[0, p_{k}^{m}\right] \times\left[0, p^{m}\right]$. Therefore, the FOC $G(\tilde{p}, \hat{p})=0$ defines an implicit relation between $\hat{p}$ and $\tilde{p}$. Let us denote such relationship by $\tilde{p}=v_{1}(\hat{p})$. We now argue that $v_{1}$ is increasing. By the implicit function theorem

$$
\frac{\partial v_{1}}{\partial \hat{p}}=\frac{-\partial G / \partial \hat{p}}{\partial G / \partial \tilde{p}}
$$

We next note that $G$ is decreasing in $\hat{p}$ and increasing in $\tilde{p}$. To see this, compute first

$$
\begin{aligned}
\frac{\partial G}{\partial \hat{p}} & =\left[-(k-1)(\bar{x}-\tilde{p}+\hat{p})^{k-2}(\bar{x}-\tilde{p}+(k+1) \hat{p})-(k+1)(\bar{x}-\tilde{p}+\hat{p})^{k-1}\right. \\
& \left.+k(k-1) \int_{0}^{\bar{x}-\tilde{p}}(\varepsilon+\tilde{p})^{n-k}(\varepsilon+\hat{p})^{k-3}(2 \varepsilon+k \hat{p}) d \varepsilon\right] \\
& =-k(\bar{x}-\tilde{p}+\hat{p})^{k-2}(2 \bar{x}-2 \tilde{p}+(k+1) \hat{p}) \\
& +k(k-1) \int_{0}^{\bar{x}-\tilde{p}}(\varepsilon+\tilde{p})^{n-k}(\varepsilon+\hat{p})^{k-3}(2 \varepsilon+k \hat{p}) d \varepsilon
\end{aligned}
$$

Note next that $\partial G / \partial \hat{p}$ decreases in $\bar{x}$. This is because

$$
\begin{aligned}
\frac{1}{k} \frac{\partial^{2} G}{\partial \bar{x} \partial \hat{p}} & =-(k-2)(\bar{x}-\tilde{p}+\hat{p})^{k-3}(2 \bar{x}-2 \tilde{p}+(k+1) \hat{p})-2(\bar{x}-\tilde{p}+\hat{p})^{k-2} \\
& +(k-1) \bar{x}^{n-k}(\bar{x}-\tilde{p}+\hat{p})^{k-3}(2 \bar{x}-2 \tilde{p}+k \hat{p}) \\
& =-(k-1)(\bar{x}-\tilde{p}+\hat{p})^{k-3}(2 \bar{x}-2 \tilde{p}+k \hat{p})\left(1-\bar{x}^{n-k}\right)<0
\end{aligned}
$$

We know that $\bar{x} \geq \tilde{p}$. If we evaluate $\partial G / \partial \hat{p}$ at $\bar{x}=\tilde{p}$ we obtain $\partial G / \partial \hat{p}=-k(k+1) \hat{p}^{k-1}<0$. Since $\partial G / \partial \hat{p}$ decreases in $\bar{x}$, then we conclude $\partial G / \partial \hat{p}$ is negative for all $\bar{x}$.

Compute now

$$
\begin{aligned}
\frac{\partial G}{\partial \tilde{p}} & =(k-1)(\bar{x}-\tilde{p}+\hat{p})^{k-2}(\bar{x}-\tilde{p}+(k+1) \hat{p})+(\bar{x}-\tilde{p}+\hat{p})^{k-1} \\
& +k(n-k) \int_{0}^{\bar{x}-\tilde{p}}(\varepsilon+\tilde{p})^{n-k-1}(\varepsilon+\hat{p})^{k-2}(\varepsilon+k \hat{p}) d \varepsilon \\
& -k \bar{x}^{n-k}(\bar{x}-\tilde{p}+\hat{p})^{k-2}(\bar{x}-\tilde{p}+k \hat{p}) \\
& =k(\bar{x}-\tilde{p}+\hat{p})^{k-2}(\bar{x}-\tilde{p}+k \hat{p})\left(1-\bar{x}^{n-k}\right) \\
& +k(n-k) \int_{0}^{\bar{x}-\tilde{p}}(\varepsilon+\tilde{p})^{n-k-1}(\varepsilon+\hat{p})^{k-2}(\varepsilon+k \hat{p}) d \varepsilon>0
\end{aligned}
$$

As a consequence, $v_{1}$ is increasing in $\hat{p}$.

We now observe that the solution of the equation $G(\hat{p}, \tilde{p})=0$ when $\hat{p}=0$ is negative. We establish this by contradiction. Suppose that the solution to $G(0, \tilde{p})=0$ is some non-negative number. If this is so, since we know $G$ increases in $\tilde{p}$, it should be the case that $G(0,0)<0$. However,

$$
G(0,0)=1-\bar{x}^{k}+k \int_{0}^{\bar{x}} \varepsilon^{n-1}>0
$$


which leads to a contradiction. Summarizing, we have shown that the implicit function $v_{1}$, defined on $\left[0, p_{k}^{m}\right]$, starts taking negative values and is increasing.

Consider now the second FOC $H(\hat{p}, \tilde{p})=0$ and rewrite it as

$$
\frac{1-\bar{x}^{n-k}}{(n-k)(1-\bar{x})}(1-\bar{x}-\tilde{p})+\frac{1}{(\bar{x}-\tilde{p}+\hat{p})^{k}} \int_{0}^{\bar{x}-\tilde{p}}(\varepsilon+\hat{p})^{k}(\varepsilon+\tilde{p})^{n-k-1} d \varepsilon=0
$$

Let us denote the LHS of this expression by $L(\hat{p}, \tilde{p})$. The equation $L(\hat{p}, \tilde{p})=0$ defines an implicit relationship between $\hat{p}$ and $\tilde{p}$, which we denote $\tilde{p}=v_{2}(\hat{p})$. We show next $v_{2}$ is also increasing. By the implicit function theorem we have

$$
\frac{\partial v_{2}}{\partial \hat{p}}=\frac{-\partial L / \partial \hat{p}}{\partial L / \partial \tilde{p}},
$$

We note that $L$ is increasing in $\hat{p}$ and decreasing in $\tilde{p}$. The first observation comes from

$$
\frac{\partial L}{\partial \hat{p}}=\frac{k}{(\bar{x}-\tilde{p}+\hat{p})^{k+1}} \int_{0}^{\bar{x}-\tilde{p}}(\varepsilon+\hat{p})^{k-1}(\varepsilon+\tilde{p})^{n-k-1}(\bar{x}-\tilde{p}-\varepsilon) d \varepsilon>0 .
$$

For the second, we compute

$$
\begin{aligned}
\frac{\partial L}{\partial \tilde{p}} & =-\frac{1-\bar{x}^{n-k}}{(n-k)(1-\bar{x})}+\frac{k}{(\bar{x}-\tilde{p}+\hat{p})^{k+1}} \int_{0}^{\bar{x}-\tilde{p}}(\varepsilon+\hat{p})^{k}(\varepsilon+\tilde{p})^{n-k-1} d \varepsilon \\
& +\frac{n-k-1}{(\bar{x}-\tilde{p}+\hat{p})^{k}} \int_{0}^{\bar{x}-\tilde{p}}(\varepsilon+\hat{p})^{k}(\varepsilon+\tilde{p})^{n-k-2} d \varepsilon-\bar{x}^{n-k-1}
\end{aligned}
$$

It is difficult to evaluate the sign of this derivative on inspection. To ease the evaluation, consider first the term in the second line of this derivative. We note that

$$
\begin{aligned}
& \frac{n-k-1}{(\bar{x}-\tilde{p}+\hat{p})^{k}} \int_{0}^{\bar{x}-\tilde{p}}(\varepsilon+\hat{p})^{k}(\varepsilon+\tilde{p})^{n-k-2} d \varepsilon-\bar{x}^{n-k-1} \\
& <(n-k-1) \int_{0}^{\bar{x}-\tilde{p}}(\varepsilon+\tilde{p})^{n-k-2} d \varepsilon-\bar{x}^{n-k-1}=-\tilde{p}^{n-k-1}<0
\end{aligned}
$$

Consider next the first term of (54) and note that

$$
\begin{aligned}
& \frac{k}{(\bar{x}-\tilde{p}+\hat{p})^{k+1}} \int_{0}^{\bar{x}-\tilde{p}}(\varepsilon+\hat{p})^{k}(\varepsilon+\tilde{p})^{n-k-1} d \varepsilon-\frac{1-\bar{x}^{n-k}}{(n-k)(1-\bar{x})} \\
& <\frac{k \bar{x}^{n-k-1}}{(\bar{x}-\tilde{p}+\hat{p})^{k+1}} \int_{0}^{\bar{x}-\tilde{p}}(\varepsilon+\hat{p})^{k} d \varepsilon-\frac{1-\bar{x}^{n-k}}{(n-k)(1-\bar{x})} \\
& =\frac{k \bar{x}^{n-k-1}}{k+1}-\frac{k \bar{x}^{n-k-1} \hat{p}^{k+1}}{(k+1)(\bar{x}-\tilde{p}+\hat{p})^{k+1}}-\frac{1-\bar{x}^{n-k}}{(n-k)(1-\bar{x})} \\
& <\frac{k \bar{x}^{n-k-1}}{k+1}-\frac{1-\bar{x}^{n-k}}{(n-k)(1-\bar{x})}=\frac{1}{1-\bar{x}}\left[\frac{k \bar{x}^{n-k-1}(1-\bar{x})}{k+1}-\frac{1-\bar{x}^{n-k}}{n-k}\right]
\end{aligned}
$$

We now argue that the term in square brackets in the last line of $(56)$ is negative for all $\bar{x}$. To see this, we first observe that it increases in $\bar{x}$. In fact, taking the derivative w.r.t. $\bar{x}$ we get

$$
\begin{aligned}
& \frac{k+1}{\bar{x}^{n-k-2}} \frac{\partial}{\partial \bar{x}}\left[\frac{k \bar{x}^{n-k-1}(1-\bar{x})}{k+1}-\frac{1-\bar{x}^{n-k}}{n-k}\right]=k(n-k-1)-k(n-k) \bar{x} \\
& +(k+1) \bar{x}=-k(k+1)+(k+1) \bar{x}+k^{2} \bar{x}+n k(1-\bar{x}) \\
& \geq-k(k+1)+(k+1) \bar{x}+k^{2} \bar{x}+(k+1) k(1-\bar{x})=\bar{x}>0
\end{aligned}
$$


Since for the highest possible $\bar{x}$ we have

$$
\lim _{\bar{x} \rightarrow 1} \frac{k \bar{x}^{n-k-1}(1-\bar{x})}{k+1}-\frac{1-\bar{x}^{n-k}}{n-k}=0
$$

we conclude that (56) is negative. This in turn implies that $L$ decreases in $\tilde{p}$. Since $L$ is increasing in $\hat{p}$ and decreasing in $\tilde{p}$, the function $v_{2}$, defined implicitly by the first order condition $H(\hat{p}, \tilde{p})=0$, is also increasing in $\hat{p}$.

We finally observe that the solution to $L(\hat{p}, \tilde{p})=0$ when $\hat{p}=0$ must be a positive number. By contradiction, suppose that the solution to $L(0, \tilde{p})=0$ is some negative number. If this is so, since we know $L$ decreases in $\tilde{p}$, it should be the case that $L(0,0)<0$. However,

$$
L(0,0)=\frac{1-\bar{x}^{n-k}}{n-k}+\frac{1}{\bar{x}^{k}} \int_{0}^{\bar{x}-\tilde{p}} \varepsilon^{n-1} d \varepsilon>0,
$$

which constitutes a contradiction. Summarizing, we have now shown that the implicit function $v_{2}$ defined on $\left[0, p_{k}^{m}\right]$ starts taking positive values and is increasing.

To show that $v_{1}$ and $v_{2}$ cross at least once, we now prove that $v_{1}\left(p_{k}^{m}\right)=\bar{x}>v_{2}\left(p_{k}^{m}\right)$ (since both are increasing in $\tilde{p}$ and we know that $\left.v_{1}(0)<0<v_{2}(0)\right)$. Setting $\hat{p}=p_{k}^{m}$ in the FOC for the merged entity gives

$$
\begin{aligned}
G\left(p_{k}^{m}, \tilde{p}\right) & =1-\left(\bar{x}-\tilde{p}+p_{k}^{m}\right)^{k-1}\left(\bar{x}-\tilde{p}+(k+1) p_{k}^{m}\right) \\
& +k \int_{0}^{\bar{x}-\tilde{p}}(\varepsilon+\tilde{p})^{n-k}\left(\varepsilon+p_{k}^{m}\right)^{k-2}\left(\varepsilon+k p_{k}^{m}\right) d \varepsilon=0
\end{aligned}
$$

which solution is $\tilde{p}=\bar{x}$ since $G\left(p_{k}^{m}, \bar{x}\right)=1-(k+1)\left(p_{k}^{m}\right)^{k}=0$ by definition of $p_{k}^{m}$.

Likewise setting $\hat{p}=p_{k}^{m}$ in the FOC for the non-merging firm gives

$$
\begin{aligned}
L\left(p_{k}^{m}, \tilde{p}\right) & =\frac{1-\bar{x}^{n-k}}{(n-k)(1-\bar{x})}(1-\bar{x}-\tilde{p}) \\
& +\frac{1}{\left(\bar{x}-\tilde{p}+p_{k}^{m}\right)^{k}} \int_{0}^{\bar{x}-\tilde{p}}\left(\varepsilon+p_{k}^{m}\right)^{k}(\varepsilon+\tilde{p})^{n-k-1} d \varepsilon=0
\end{aligned}
$$

Since $L\left(p_{k}^{m}, \bar{x}\right)=\left(1-\bar{x}^{n-k}\right)(1-2 \bar{x}) /(n-k)(1-\bar{x}) \leq 0$ and we know that $L$ decreases in $\tilde{p}$, it is clear that the solution to $L\left(p_{k}^{m}, \tilde{p}\right)=0$ must be some $\tilde{p}<\bar{x}$.

To complete the proof of existence, it remains to be shown that at the point(s) at which $v_{1}$ and $v_{2}$ cross we have $\tilde{p} \leq p^{m}=1 / 2$. For this, it suffices to show that $L\left(p_{k}^{m}, 1 / 2\right)<0$ because since $L$ decreases in $\tilde{p}$, this means that the solution to $L\left(p_{k}^{m}, \tilde{p}\right)=0$ must be some $\tilde{p}<1 / 2$. In fact, setting $\tilde{p}=1 / 2$, we get

$$
\begin{aligned}
L\left(p_{k}^{m}, 1 / 2\right) & =\frac{1-\bar{x}^{n-k}}{(n-k)(1-\bar{x})}\left(\frac{1}{2}-\bar{x}\right) \\
& +\frac{1}{\left(\bar{x}-\frac{1}{2}+p_{k}^{m}\right)^{k}} \int_{0}^{\bar{x}-\frac{1}{2}}\left(\varepsilon+p_{k}^{m}\right)^{k}\left(\varepsilon+\frac{1}{2}\right)^{n-k-1} d \varepsilon .
\end{aligned}
$$

We now note that $L\left(p_{k}^{m}, 1 / 2\right)$ decreases in $\bar{x}$. To see this, compute

$$
\begin{aligned}
\frac{\partial L\left(p_{k}^{m}, \frac{1}{2}\right)}{\partial \bar{x}} & =-\frac{1+(n-k-1) \bar{x}^{n-k}-(n-k) \bar{x}^{n-k-1}}{2(n-k)(1-\bar{x})^{2}} \\
& -\frac{k}{\left(\bar{x}-\frac{1}{2}+p_{k}^{m}\right)^{k+1}} \int_{0}^{\bar{x}-1 / 2}\left(\varepsilon+p_{k}^{m}\right)^{k}\left(\varepsilon+\frac{1}{2}\right)^{n-k-1} d \varepsilon
\end{aligned}
$$

and notice that $1+(n-k-1) \bar{x}^{n-k}-(n-k) \bar{x}^{n-k-1}>0$ for all $\bar{x}$ (since it decreases in $\bar{x}$ and equals zero when $\bar{x}=1)$. Therefore, if $L\left(p_{k}^{m}, 1 / 2\right) \leq 0$ for the lowest value of $\bar{x}$, then it is negative everywhere. In fact, setting $\bar{x}=1 / 2$ in (57) yields $L\left(p_{k}^{m}, 1 / 2\right)=0$. To summarize, we have now shown that $v_{1}$ and $v_{2}$ cross at least once on $\left[0, p_{k}^{m}\right] \times\left[0, p^{m}\right]$ so a candidate equilibrium exists. 
Claim 5 The pair of prices $\left\{\hat{p}^{*}, \tilde{p}^{*}\right\}$ that satisfies (19) and (20) is unique.

Proof. We start by noting that $v_{1}$ is increasing in $\hat{p}$ at a rate greater than 1 . Using the derivations above, this follows from the following remarks. First, note that

$$
\begin{aligned}
\frac{1}{k}\left(-\frac{\partial G}{\partial \hat{p}}-\frac{\partial G}{\partial \tilde{p}}\right) & =(\bar{x}-\tilde{p}+\hat{p})^{k-2}\left((\bar{x}-\tilde{p}+\hat{p})+\bar{x}^{n-k}(\bar{x}-\tilde{p}+k \hat{p})\right) \\
& -(k-1) \int_{0}^{\bar{x}-\tilde{p}}(\varepsilon+\tilde{p})^{n-k}(\varepsilon+\hat{p})^{k-3}(2 \varepsilon+k \hat{p}) d \varepsilon \\
& -(n-k) \int_{0}^{\bar{x}-\tilde{p}}(\varepsilon+\tilde{p})^{n-k-1}(\varepsilon+\hat{p})^{k-2}(\varepsilon+k \hat{p}) d \varepsilon
\end{aligned}
$$

Observe now that this expression is increasing in $\bar{x}$, as its derivative with respect to $\bar{x}$ equals $(k-$ 1) $(\bar{x}-\tilde{p}+\hat{p})^{k-2}\left(1-\bar{x}^{n-1}\right) \geq 0$. Therefore, if (59) is positive when $\bar{x}$ takes on its lowest value, then it is positive everywhere. Setting $\bar{x}=\tilde{p}$ in the RHS of (59) gives $\hat{p}^{k-2}\left(\hat{p}+k \tilde{p}^{n-k} \hat{p}\right)>0$, which proves that $v_{1}$ increases with slope greater than 1 .

We continue by noting that the rate at which $v_{2}$ increases is lower than 1 . Using the derivations above, since $\partial L / \partial \tilde{p}<0$, we need to show that

$$
\begin{aligned}
\frac{\partial L}{\partial \hat{p}}+\frac{\partial L}{\partial \tilde{p}} & =-\frac{1-\bar{x}^{n-k}}{(n-k)(1-\bar{x})}+\frac{k}{(\bar{x}-\tilde{p}+\hat{p})^{k}} \int_{0}^{\bar{x}-\tilde{p}}(\varepsilon+\hat{p})^{k-1}(\varepsilon+\tilde{p})^{n-k-1} d \varepsilon \\
& +\frac{n-k-1}{(\bar{x}-\tilde{p}+\hat{p})^{k}} \int_{0}^{\bar{x}-\tilde{p}}(\varepsilon+\hat{p})^{k}(\varepsilon+\tilde{p})^{n-k-2} d \varepsilon-\bar{x}^{n-k-1}
\end{aligned}
$$

is negative. Now notice that the last line of this expression is negative (from (55)). Moreover, regarding the first line of $(60)$ we have

$$
\begin{aligned}
& -\frac{1-\bar{x}^{n-k}}{(n-k)(1-\bar{x})}+\frac{k}{(\bar{x}-\tilde{p}+\hat{p})^{k}} \int_{0}^{\bar{x}-\tilde{p}}(\varepsilon+\hat{p})^{k-1}(\varepsilon+\tilde{p})^{n-k-1} d \varepsilon \\
& <-\frac{1-\bar{x}^{n-k}}{(n-k)(1-\bar{x})}+\frac{k \bar{x}^{n-k-1}}{(\bar{x}-\tilde{p}+\hat{p})^{k}} \int_{0}^{\bar{x}-\tilde{p}}(\varepsilon+\hat{p})^{k-1} d \varepsilon \\
& =-\frac{1-\bar{x}^{n-k}}{(n-k)(1-\bar{x})}+\frac{\bar{x}^{n-k-1}}{(\bar{x}-\tilde{p}+\hat{p})^{k}}\left[(\bar{x}-\tilde{p}+\hat{p})^{k}-\hat{p}^{k}\right] \\
& <-\frac{1-\bar{x}^{n-k}}{(n-k)(1-\bar{x})}+\bar{x}^{n-k-1}=-\frac{1+(n-k-1) \bar{x}^{n-k}-(n-k) \bar{x}^{n-k-1}}{(n-k)(1-\bar{x})}<0,
\end{aligned}
$$

where the last inequality follows from the remarks after equation (58). This implies that $v_{2}$ increases at a rate less than 1 . This, together with the arguments before shows that there exists a unique candidate equilibrium.

It remains to be shown that $\bar{x}-\hat{p}^{*}>\bar{x}-\tilde{p}^{*}$ and $\hat{p}^{*}>\tilde{p}^{*}$. Consider the case in which $s$ is sufficiently large. Since we assume that $k \leq 10, s \rightarrow 1 / 8(\bar{x} \rightarrow 1 / 2)$ suffices. It takes a few steps to check that the solution to the FOCs (19) and (20) is $\tilde{p}^{*}=p^{m}=1 / 2=\bar{x}$ and $\hat{p}^{*}=p_{m}^{k}=(1+k)^{-1 / k}$ when $s \rightarrow 1 / 8$; therefore $\hat{p}^{*}>\tilde{p}^{*}$. Given that $\bar{x}-\tilde{p}^{*}=0$ when $s \rightarrow 1 / 8$, proving that $\overline{\bar{x}}-\hat{p}^{*}>\bar{x}-\tilde{p}^{*}$ boils down to showing that $\overline{\bar{x}}-\hat{p}^{*}>0$. We know $\overline{\bar{x}}$ satisfies $\int_{x}^{1} k(\varepsilon-x) \varepsilon^{k-1} d \varepsilon-s=0$, or

$$
\frac{k(1-\overline{\bar{x}})-\overline{\bar{x}}\left(1-\overline{\bar{x}}^{k}\right)}{k+1}-s=0 .
$$

Equation (61) can be rewritten as

$$
\overline{\bar{x}}=\frac{k+\overline{\bar{x}}^{k+1}}{k+1}-s
$$




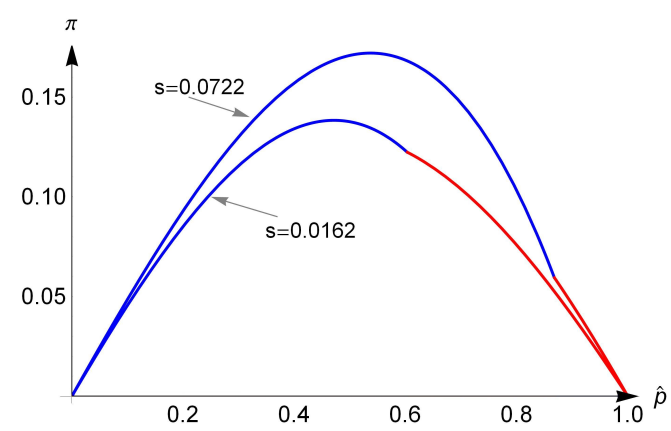

Figure 11: Payoff of the (deviating) merged entity

Deducting $\hat{p}^{*}$ on both sides of this equality gives

$$
\overline{\bar{x}}-\hat{p}^{*}=\frac{k+\overline{\bar{x}}^{k+1}}{k+1}-\hat{p}^{*}-s .
$$

When $s \rightarrow 1 / 8, \hat{p}^{*}=(1+k)^{-1 / k}$. As a result, when $s \rightarrow 1 / 8$, equation (62) writes

$$
\overline{\bar{x}}-p_{m}^{k}=\frac{k+\overline{\bar{x}}^{k+1}}{k+1}-\frac{1}{(1+k)^{\frac{1}{k}}}-\frac{1}{8}
$$

Note now that the RHS of (63) increases in $\overline{\bar{x}}$. Therefore using the lowest admissible value for $\overline{\bar{x}}$, we can write

$$
\overline{\bar{x}}-p_{m}^{k}>\frac{k+\left(\frac{1}{2}\right)^{k+1}}{k+1}-\frac{1}{(1+k)^{\frac{1}{k}}}-\frac{1}{8}>0
$$

for all $k \leq n-1$.

Finally, we check that "large" deviations are not profitable. We start with deviations by the merged entity. Consider that the merged entity deviates by charging a price $\hat{p}>1-\bar{x}+\tilde{p}^{*}$. In such a case, its payoff would be

$$
\widehat{\pi}=k \hat{p} \int_{\hat{p}}^{1}\left(\varepsilon-\hat{p}+\tilde{p}^{*}\right)^{n-k} \varepsilon^{k-1} k d \varepsilon .
$$

An analytical proof that this deviation is not profitable has proven to be very difficult so we proceed by checking it numerically. We proceed as follows. For a given search cost (or $\bar{x}$ ) we compute the putative equilibrium pair of prices $\left\{\widehat{p}^{*}, \tilde{p}^{*}\right\}$. Then we plot the payoff function of the merged entity for all possible (deviation) prices. As shown in Figure 11 for two different levels of the search cost and $n=3, k=2$, the putative equilibrium is not destabilized by large deviations. For other combinations of parameters, the shape of the payoff function is similar.

Consider now 'large' deviations by a non-merging firm, i.e. deviations to prices $\tilde{p}>1-\bar{x}+\tilde{p}^{*}$. In that case, the payoff to the deviant would be

$$
\tilde{\pi}=\tilde{p} \int_{0}^{1-\tilde{p}}\left(\varepsilon+\tilde{p}^{*}\right)^{n-k-1}\left(\varepsilon+\hat{p}^{*}\right)^{k} d \varepsilon .
$$

Taking the FOC gives

$$
\int_{0}^{1-\tilde{p}}\left(\varepsilon+\tilde{p}^{*}\right)^{n-k-1}\left(\varepsilon+\hat{p}^{*}\right)^{k} d \varepsilon-\tilde{p}\left(1-\tilde{p}+\tilde{p}^{*}\right)^{n-k-1}\left(1-\tilde{p}+\hat{p}^{*}\right)^{k}=0,
$$

which we rewrite as

$$
\int_{0}^{1-\tilde{p}} \frac{\left(\varepsilon+\tilde{p}^{*}\right)^{n-k-1}\left(\varepsilon+\hat{p}^{*}\right)^{k}}{\left(1-\tilde{p}+\tilde{p}^{*}\right)^{n-k-1}\left(1-\tilde{p}+\hat{p}^{*}\right)^{k}} d \varepsilon-\tilde{p}=0
$$

The LHS of (64) decreases in $\tilde{p}$. In fact, its derivative is 


$$
\frac{(n-k-1)\left(1-\tilde{p}+\tilde{p}^{*}\right)+k\left(1-\tilde{p}+\hat{p}^{*}\right)}{\left(1-\tilde{p}+\tilde{p}^{*}\right)^{n-k}\left(1-\tilde{p}+\hat{p}^{*}\right)^{k+1}} \int_{0}^{1-\tilde{p}}\left(\varepsilon+\tilde{p}^{*}\right)^{n-k-1}\left(\varepsilon+\hat{p}^{*}\right)^{k} d \varepsilon-2<0,
$$

where the inequality follows from

$$
\begin{aligned}
\frac{\left[(n-k-1)\left(1-\tilde{p}+\hat{p}^{*}\right)+k\left(1-\tilde{p}+\tilde{p}^{*}\right)\right] \int_{0}^{1-\tilde{p}}\left(\varepsilon+\tilde{p}^{*}\right)^{n-k-1}\left(\varepsilon+\hat{p}^{*}\right)^{k} d \varepsilon}{\left(1-\tilde{p}+\tilde{p}^{*}\right)^{n-k}\left(1-\tilde{p}+\hat{p}^{*}\right)^{k+1}} & = \\
\frac{(n-k-1) \int_{0}^{1-\tilde{p}}\left(\varepsilon+\tilde{p}^{*}\right)^{n-k-1}\left(\varepsilon+\hat{p}^{*}\right)^{k} d \varepsilon}{\left(1-\tilde{p}+\tilde{p}^{*}\right)^{n-k}\left(1-\tilde{p}+\hat{p}^{*}\right)^{k}}+\frac{k \int_{0}^{1-\tilde{p}}\left(\varepsilon+\tilde{p}^{*}\right)^{n-k-1}\left(\varepsilon+\hat{p}^{*}\right)^{k} d \varepsilon}{\left(1-\tilde{p}+\tilde{p}^{*}\right)^{n-k-1}\left(1-\tilde{p}+\hat{p}^{*}\right)^{k+1}} & < \\
\frac{(n-k-1) \int_{0}^{1-\tilde{p}}\left(\varepsilon+\tilde{p}^{*}\right)^{n-k-1} d \varepsilon}{\left(1-\tilde{p}+\tilde{p}^{*}\right)^{n-k}}+\frac{k \int_{0}^{1-\tilde{p}}\left(\varepsilon+\hat{p}^{*}\right)^{k} d \varepsilon}{\left(1-\tilde{p}+\hat{p}^{*}\right)^{k+1}} & = \\
\frac{n-k-1}{n-k}\left[1-\frac{\left(\tilde{p}^{*}\right)^{n-k}}{\left(1-\tilde{p}+\tilde{p}^{*}\right)^{n-k}}\right]+\frac{k}{k+1}\left[1-\frac{\left(\hat{p}^{*}\right)^{k+1}}{\left(1-\tilde{p}+\hat{p}^{*}\right)^{k+1}}\right] & <2
\end{aligned}
$$

Then, (64) is lower than when we set $\tilde{p}=1-\bar{x}+\tilde{p}^{*}$, that is

$$
\int_{0}^{1-\tilde{p}} \frac{\left(\varepsilon+\tilde{p}^{*}\right)^{n-k-1}\left(\varepsilon+\hat{p}^{*}\right)^{k}}{\left(1-\tilde{p}+\tilde{p}^{*}\right)^{n-k-1}\left(1-\tilde{p}+\hat{p}^{*}\right)^{k}} d \varepsilon-\tilde{p}<\int_{0}^{\bar{x}-\tilde{p}^{*}} \frac{\left(\varepsilon+\tilde{p}^{*}\right)^{n-k-1}\left(\varepsilon+\hat{p}^{*}\right)^{k}}{\bar{x}^{n-k-1}\left(\bar{x}-\tilde{p}^{*}+\hat{p}^{*}\right)^{k}} d \varepsilon-\left(1-\bar{x}+\tilde{p}^{*}\right) .
$$

Using the FOC (20), this last expression is equal to

$$
-\frac{1}{\bar{x}^{n-k-1}} \frac{1-\bar{x}^{n-k}}{(n-k)(1-\bar{x})}\left(1-\bar{x}-\tilde{p}^{*}\right)-\left(1-\bar{x}+\tilde{p}^{*}\right)=-\frac{1-\bar{x}-\tilde{p}^{*}}{1-\bar{x}} \int_{\bar{x}}^{1} \frac{\varepsilon^{n-k-1}}{\bar{x}^{n-k-1}} d \varepsilon-\left(1-\bar{x}+\tilde{p}^{*}\right)
$$

This expression increases in $k$. Therefore, it is lower than when we set $k=n-1$, which gives

$$
-\frac{1-\bar{x}-\tilde{p}^{*}}{1-\bar{x}} \int_{\bar{x}}^{1} d \varepsilon-\left(1-\bar{x}+\tilde{p}^{*}\right)=-2(1-\bar{x}) \leq 0
$$

Hence, there the deviation is not profitable.

Proof of Proposition 5. (i) We first show that the merging stores increase their profits after the merger. The difference between the profit per product of the merged entity, $\hat{\pi} / k$, and the typical pre-merger profit of a firm, $\pi^{*}$, equals:

$$
\frac{\hat{\pi}}{k}-\pi^{*}=\frac{\hat{p}^{*}}{k}\left[1-\left(\bar{x}-\tilde{p}^{*}+\hat{p}^{*}\right)^{k}+k \int_{0}^{\bar{x}-\tilde{p}^{*}}\left(\varepsilon+\hat{p}^{*}\right)^{k-1}\left(\varepsilon+\tilde{p}^{*}\right)^{n-k} d \varepsilon\right]-\frac{p^{*}}{n}\left(1-p^{* n}\right)
$$

Since $\hat{p}^{*}$ is an equilibrium price, then, given the non-merging firm's price, $\hat{\pi}\left(\hat{p}^{*}\right)$ is greater than $\hat{\pi}(\hat{p})$ for any $\hat{p} \neq \hat{p}^{*}$. Therefore, replacing $\hat{p}^{*}$ by $\tilde{p}^{*}$ gives

$$
\frac{\hat{\pi}}{k}-\pi^{*}>\tilde{p}^{*}\left[\frac{1-\bar{x}^{k}}{k}+\frac{1}{n}\left(\bar{x}^{n}-\tilde{p}^{* n}\right)\right]-\frac{p^{*}}{n}\left(1-p^{* n}\right)
$$

We now note that $\frac{1-\bar{x}^{k}}{k}=\int_{\bar{x}}^{1} \varepsilon^{k-1} d \varepsilon$ and is decreasing in $k$. Therefore, the RHS of (65) is greater than when we set $k=n-1$, which gives

$$
\begin{aligned}
& \tilde{p}^{*}\left[\frac{1-\bar{x}^{n-1}}{n-1}+\frac{1}{n}\left(\bar{x}^{n}-\tilde{p}^{* n}\right)\right]-\frac{p^{*}}{n}\left(1-p^{* n}\right) \\
= & \frac{\tilde{p}^{*}}{n(n-1)}\left[n\left(1-\bar{x}^{n-1}\right)+(n-1)\left(\bar{x}^{n}-\tilde{p}^{* n}\right)\right]-\frac{p^{*}}{n}\left(1-p^{* n}\right) .
\end{aligned}
$$


Observe next that this expression is decreasing in $\bar{x}$ since its derivative with respect to $\bar{x}$ is equal to $-\bar{x}^{n-2} n(n-1)(1-\bar{x})<0$. Therefore, (66) is larger than when we set $\bar{x}=1$, which gives

$$
\frac{\tilde{p}^{*}}{n(n-1)}\left(n-1-(n-1) \tilde{p}^{* n}\right)-\frac{p^{*}}{n}\left(1-p^{* n}\right)=\frac{\tilde{p}^{*}}{n}\left(1-\tilde{p}^{* n}\right)-\frac{p^{*}}{n}\left(1-p^{* n}\right) .
$$

Finally, note that the expression $\tilde{p}^{*}\left(1-\tilde{p}^{* n}\right)$ is increasing in $\tilde{p}^{*}$ because its derivative with respect to $\tilde{p}^{*}$ is equal to $1-(n+1) \tilde{p}^{* n}>0$. We then conclude that $\hat{\pi} / k-\pi^{*}>0$ if $\tilde{p}^{*}>p^{*}$. But, as argued in the proof of Proposition 2, the last inequality is true because $\tilde{p}^{*}$ is the price of the firms that are visited last.

(ii) It has been shown in the proof of Proposition 4 that when search cost is large $\hat{p}^{*} \rightarrow p_{k}^{m}$ and $\tilde{p}^{*} \rightarrow \frac{1}{2}$. Therefore, we have:

$$
\begin{aligned}
\lim _{\bar{x} \rightarrow 1 / 2}\left[\frac{\hat{\pi}^{*}}{k}-\tilde{\pi}^{*}\right] & =\lim _{\bar{x} \rightarrow 1 / 2}\left[\frac{\hat{p}^{*}}{k}\left(1-\left(\bar{x}-\tilde{p}^{*}+\hat{p}^{*}\right)^{k}+k \int_{0}^{\bar{x}-\tilde{p}^{*}}\left(\varepsilon+\tilde{p}^{*}\right)^{n-k}\left(\varepsilon+\hat{p}^{*}\right)^{k-1} d \varepsilon\right)\right. \\
& \left.-\tilde{p}^{*}\left(\frac{\left(\bar{x}-\tilde{p}^{*}+\hat{p}^{*}\right)^{k}}{n-k}\left(1-\bar{x}^{n-k}\right)+\int_{0}^{\bar{x}-\tilde{p}^{*}}\left(\varepsilon+\tilde{p}^{*}\right)^{n-k-1}\left(\varepsilon+\hat{p}^{*}\right)^{k} d \varepsilon\right)\right] \\
& =\frac{1}{k} p_{k}^{m}\left(1-\left(p_{k}^{m}\right)^{k}\right)-\frac{1}{2(n-k)}\left(p_{k}^{m}\right)^{k}\left(1-\frac{1}{2^{n-k}}\right) \\
& =\frac{1}{k} p_{k}^{m}\left(1-\left(p_{k}^{m}\right)^{k}\right)-\frac{\left(p_{k}^{m}\right)^{k}}{2} \int_{1 / 2}^{1} \varepsilon^{n-k-1} d \varepsilon
\end{aligned}
$$

This expression is increasing in $n$ because its derivative with respect to $n$ equals

$$
-\frac{\left(p_{k}^{m}\right)^{k}}{2} \int_{1 / 2}^{1} \varepsilon^{n-k-1} \ln \varepsilon d \varepsilon>0
$$

Then

$$
\begin{gathered}
\lim _{\bar{x} \rightarrow 1 / 2}\left[\frac{\hat{\pi}^{*}}{k}-\tilde{\pi}^{*}\right] \geq \frac{p_{k}^{m}}{k}\left(1-\left(p_{k}^{m}\right)^{k}\right)-\frac{1}{2} \frac{\left(p_{k}^{m}\right)^{k}}{k+1-k}\left(1-2^{k-k-1}\right)= \\
\frac{p_{k}^{m}}{k+1}-\frac{\left(p_{k}^{m}\right)^{k}}{2}\left(1-\frac{1}{2}\right)=\frac{p_{k}^{m}}{k+1}-\frac{1}{4(k+1)}=\frac{1}{4(k+1)}\left[4 p_{k}^{m}-1\right]>0
\end{gathered}
$$

where the first inequality follows form replacing $n$ by $k+1$.

Proof of Proposition 6. (i) We first note that the equilibrium of Proposition 4 has $\hat{p}^{*}>\tilde{p}^{*}$ when the search cost is sufficiently high. The difference between post- and pre-merger total industry profits is $\Delta \Pi \equiv \hat{\pi}^{*}+(n-k) \tilde{\pi}^{*}-n \pi^{*}$. Using the expressions for profits above, we have

$$
\begin{aligned}
\Delta \Pi & =\hat{p}^{*}\left(1-\left(\bar{x}-\tilde{p}^{*}+\hat{p}^{*}\right)^{k}+k \int_{0}^{\bar{x}-\tilde{p}^{*}}\left(\varepsilon+\tilde{p}^{*}\right)^{n-k}\left(\varepsilon+\hat{p}^{*}\right)^{k-1} d \varepsilon\right)+ \\
& \tilde{p}^{*}\left(\left(\bar{x}-\tilde{p}^{*}+\hat{p}^{*}\right)^{k}\left(1-\bar{x}^{n-k}\right)+(n-k) \int_{0}^{\bar{x}-\tilde{p}^{*}}\left(\varepsilon+\tilde{p}^{*}\right)^{n-k-1}\left(\varepsilon+\hat{p}^{*}\right)^{k} d \varepsilon\right)-p^{*}\left(1-p^{* n}\right)
\end{aligned}
$$

Note now that this expression is clearly increasing in $\hat{p}^{*}$ (the derivative of the first line, by the FOC, is zero and that of the second line is positive). Hence,

$$
\Delta \Pi>\left.\Delta \Pi\right|_{\hat{p}^{*}=\tilde{p}^{*}}=\tilde{p}^{*}\left(1-\tilde{p}^{* n}\right)-p^{*}\left(1-p^{* n}\right)>0
$$

as shown in the proof of Proposition 5. 
(ii) In the pre-merger market, consumer surplus is given by

$$
\begin{aligned}
C S^{*} & =\frac{1-\bar{x}^{n}}{1-\bar{x}} \int_{\bar{x}}^{1}\left(\varepsilon-p^{*}\right) d \varepsilon+n \int_{p^{*}}^{\bar{x}} \varepsilon^{n-1}\left(\varepsilon-p^{*}\right) d \varepsilon-\frac{1-\bar{x}^{n}}{1-\bar{x}} s \\
& =\frac{1-\bar{x}^{n}}{1-\bar{x}} \int_{\bar{x}}^{1}\left(\varepsilon-p^{*}\right) d \varepsilon+n \int_{p^{*}}^{\bar{x}} \varepsilon^{n-1}\left(\varepsilon-p^{*}\right) d \varepsilon-\frac{\left(1-\bar{x}^{n}\right)(1-\bar{x})}{2}
\end{aligned}
$$

In the post-merger market, consumer surplus is given by $C S=\widehat{C S}+\widetilde{C S}-S c$ where $\widehat{C S}, \widetilde{C S}$ and $S c$ are given by (21), (22) and (23), respectively.

When $s \rightarrow 1 / 8, \bar{x} \rightarrow 1 / 2, p^{*} \rightarrow 1 / 2$ and $\hat{p}^{*} \rightarrow p_{k}^{m}$. Then, we can establish the comparison

$$
\lim _{s \rightarrow 1 / 8}\left[\widehat{C S}+\widetilde{C S}-S c-C S^{*}\right]=\int_{p_{k}^{m}}^{1} k\left(\varepsilon-p_{k}^{m}\right) \varepsilon^{k-1} d \varepsilon-\frac{1}{8}>0
$$

The proof is now complete.

Proof of Proposition 7. The first order conditions of the merger and a non-merged firm are

$$
\begin{gathered}
1-\left(\bar{x}-\tilde{p}^{*}+\hat{p}^{*}\right)^{k-1}\left(\bar{x}-\tilde{p}^{*}+(k+1) \hat{p}^{*}\right)+k \int_{0}^{\bar{x}-\tilde{p}^{*}}\left(\varepsilon+\tilde{p}^{*}\right)^{n-k}\left(\varepsilon+\hat{p}^{*}\right)^{k-2}\left(\varepsilon+k \hat{p}^{*}\right) d \varepsilon=0 \\
\frac{\left(\bar{x}-\tilde{p}^{*}+\hat{p}^{*}\right)^{k}}{n-k} \frac{1-\bar{x}^{n-k}}{1-\bar{x}}\left(1-\bar{x}-\tilde{p}^{*}\right)+\int_{0}^{\bar{x}-\tilde{p}^{*}}\left(\varepsilon+\tilde{p}^{*}\right)^{n-k-1}\left(\varepsilon+\hat{p}^{*}\right)^{k} d \varepsilon=0
\end{gathered}
$$

(a) We now prove that when search cost is sufficiently high then $\hat{p}^{*}>\tilde{p}^{*}$ and therefore consumer expectations are violated. We start by noting that, because the price of the non-merging firms is less than or equal to $1 / 2<p_{k}^{m}$ for all $\bar{x} \in\left[p_{k}^{m} ; 1\right]$, the integral in (68) is positive. As a result, for an equilibrium to exist, the rest of the LHS of $(68), 1-\left(\bar{x}-\tilde{p}^{*}+\hat{p}^{*}\right)^{k}-k\left(\bar{x}-\tilde{p}^{*}+\hat{p}^{*}\right)^{k} \hat{p}^{*}$, must be negative. Note that this expression decreases in $\hat{p}^{*}$. Then, it must be higher than when we set $\hat{p}^{*}=\tilde{p}^{*}$ because $\hat{p}^{*}<\tilde{p}^{*}$ by assumption. That is, it must be the case that

$$
1-\left(\bar{x}-\tilde{p}^{*}+\hat{p}^{*}\right)^{k}-k\left(\bar{x}-\tilde{p}^{*}+\hat{p}^{*}\right)^{k} \hat{p}^{*}>1-\bar{x}^{k}-k \bar{x}^{k-1} \tilde{p}^{*}
$$

We now note that when $\bar{x} \rightarrow p_{k}^{m}$ the expression $1-\bar{x}^{k}-k \bar{x}^{k-1} p_{k}^{m}$ is equal to zero. Since $\tilde{p}^{*} \leq 1 / 2<p_{k}^{m}$, it is clear that $1-\bar{x}^{k}-k \bar{x}^{k-1} p_{k}^{m}>0$ when $\bar{x} \rightarrow p_{k}^{m}$. But this constitutes a contradiction because then the LHS of (68) cannot be negative. As a result, there is no such pair of prices $\hat{p}^{*}$ and $\tilde{p}^{*}$ that satisfy (68) and (69) when $\bar{x} \rightarrow p_{k}^{m}$ and $\hat{p}^{*}<\tilde{p}^{*}$.

(b) We prove now that when search cost goes to zero again we obtain $\hat{p}^{*}>\tilde{p}^{*}$, which violates consumer expectations. To show this we use again the equality

$$
Y\left(\tilde{p}^{*}, \hat{p}^{*}\right) \equiv Q-\hat{q}^{*}-(n-k) \tilde{q}^{*}=0
$$

where $Q=1-\hat{p}^{* k} \tilde{p}^{* n-k}$ denotes the aggregate quantity sold in the market and $\hat{q}^{*}$ and $\tilde{q}^{*}$ denote the equilibrium quantities of the merged entity and the non-merging firms. From the FOCs, these quantities are given by

$$
\begin{aligned}
& \hat{q}^{*}=k\left(\bar{x}-\tilde{p}^{*}+\hat{p}^{*}\right)^{k-1} \hat{p}^{*}-k(k-1) \hat{p}^{*} \int_{0}^{\bar{x}-\tilde{p}^{*}}\left(\varepsilon+\hat{p}^{*}\right)^{k-2}\left(\varepsilon+\tilde{p}^{*}\right)^{n-k} d \varepsilon \\
& \tilde{q}^{*}=\frac{\left(\bar{x}-\tilde{p}^{*}+\hat{p}^{*}\right)^{k-1}}{n-k} \frac{1-\bar{x}^{n-k}}{1-\bar{x}} \tilde{p}^{*}
\end{aligned}
$$


The partial derivative of $Y$ with respect to $\hat{p}^{*}$ is negative because $\tilde{q}^{*}$ increases with $\hat{p}^{*}$ and the derivative of $\hat{q}^{*}$ with respect to $\hat{p}^{*}$ is positive:

$$
\begin{aligned}
\frac{\partial \hat{q}^{*}}{\partial \hat{p}^{*}} & =k\left(\bar{x}-\tilde{p}^{*}+\hat{p}^{*}\right)^{k-1}+k(k-1)\left(\bar{x}-\tilde{p}^{*}+\hat{p}^{*}\right)^{k-2} \hat{p}^{*}-k(k-1) \int_{0}^{\bar{x}-\tilde{p}^{*}}\left(\varepsilon+\hat{p}^{*}\right)^{k-2}\left(\varepsilon+\tilde{p}^{*}\right)^{n-k} d \varepsilon \\
& -k(k-1)(k-2) \hat{p}^{*} \int_{0}^{\bar{x}-\tilde{p}^{*}}\left(\varepsilon+\hat{p}^{*}\right)^{k-3}\left(\varepsilon+\tilde{p}^{*}\right)^{n-k} d \varepsilon \\
& >k\left(\bar{x}-\tilde{p}^{*}+\hat{p}^{*}\right)^{k-1}+k(k-1)\left(\bar{x}-\tilde{p}^{*}+\hat{p}^{*}\right)^{k-2} \hat{p}^{*}-k(k-1) \bar{x}^{n-k} \int_{0}^{\bar{x}-\tilde{p}^{*}}\left(\varepsilon+\hat{p}^{*}\right)^{k-2} d \varepsilon \\
& -k(k-1)(k-2) \hat{p}^{*} \bar{x}^{n-k} \int_{0}^{\bar{x}-\tilde{p}^{*}}\left(\varepsilon+\hat{p}^{*}\right)^{k-3} d \varepsilon \\
& =k\left(\bar{x}-\tilde{p}^{*}+\hat{p}^{*}\right)^{k-2}\left(\bar{x}-\tilde{p}^{*}+k \hat{p}^{*}\right)\left(1-\bar{x}^{n-k}\right)>0 .
\end{aligned}
$$

Therefore, given that $\hat{p}^{*}<\tilde{p}^{*}$, if we set $\hat{p}^{*}=\tilde{p}^{*}$ then $Y$ must be negative when $\bar{x} \rightarrow 1$. That is, it must be the case that

$$
\begin{aligned}
\left.\lim _{\bar{x} \rightarrow 1} Y\right|_{\hat{p}^{*}=\tilde{p}^{*}} & =\lim _{\bar{x} \rightarrow 1}\left[1-\tilde{p}^{* n}-k \tilde{p}^{*}+k(k-1) \tilde{p}^{*} \int_{0}^{1-\tilde{p}^{*}}\left(\varepsilon+\tilde{p}^{*}\right)^{n-2} d \varepsilon-(n-k) \tilde{p}^{*}\right] \\
& =\lim _{\bar{x} \rightarrow 1}\left[1-\tilde{p}^{* n}-n \tilde{p}^{*}+\frac{k(k-1) \tilde{p}^{*}}{n-1}\left(1-\tilde{p}^{* n-1}\right)\right]<0 .
\end{aligned}
$$

The FOC (69) may be rearranged as

$$
1-\bar{x}-\tilde{p}^{*}+\frac{(n-k)(1-\bar{x})}{1-\bar{x}^{n-k}} \frac{1}{\left(\bar{x}-\tilde{p}^{*}+\hat{p}^{*}\right)^{k}} \int_{0}^{\bar{x}-\tilde{p}^{*}}\left(\varepsilon+\tilde{p}^{*}\right)^{n-k-1}\left(\varepsilon+\hat{p}^{*}\right)^{k} d \varepsilon=0
$$

The LHS of $(72)$ increases in $\hat{p}^{*}$ because

$$
\begin{aligned}
& \frac{k\left(\bar{x}-\tilde{p}^{*}+\hat{p}^{*}\right)^{k} \int_{0}^{\bar{x}-\tilde{p}^{*}}\left(\varepsilon+\tilde{p}^{*}\right)^{n-k-1}\left(\varepsilon+\hat{p}^{*}\right)^{k-1} d \varepsilon-k\left(\bar{x}-\tilde{p}^{*}+\hat{p}^{*}\right)^{k-1} \int_{0}^{\bar{x}-\tilde{p}^{*}}\left(\varepsilon+\tilde{p}^{*}\right)^{n-k-1}\left(\varepsilon+\hat{p}^{*}\right)^{k} d \varepsilon}{\left(\bar{x}-\tilde{p}^{*}+\hat{p}^{*}\right)^{2 k}} \\
& =\frac{k\left(\bar{x}-\tilde{p}^{*}+\hat{p}^{*}\right) \int_{0}^{\bar{x}-\tilde{p}^{*}}\left(\varepsilon+\tilde{p}^{*}\right)^{n-k-1}\left(\varepsilon+\hat{p}^{*}\right)^{k-1} d \varepsilon-k \int_{0}^{\bar{x}-\tilde{p}^{*}}\left(\varepsilon+\tilde{p}^{*}\right)^{n-k-1}\left(\varepsilon+\hat{p}^{*}\right)^{k} d \varepsilon}{\left(\bar{x}-\tilde{p}^{*}+\hat{p}^{*}\right)^{k+1}} \\
& =\frac{k \int_{0}^{\bar{x}-\tilde{p}^{*}}\left(\varepsilon+\tilde{p}^{*}\right)^{n-k-1}\left(\varepsilon+\hat{p}^{*}\right)^{k-1}\left(\bar{x}-\tilde{p}^{*}-\varepsilon\right) d \varepsilon}{\left(\bar{x}-\tilde{p}^{*}+\hat{p}^{*}\right)^{k+1}}>0
\end{aligned}
$$

Therefore, given that $\hat{p}^{*}<\tilde{p}^{*}$, if we set $\hat{p}^{*}=\tilde{p}^{*}$ then the LHS of (72) must be positive, that is,

$$
1-\bar{x}-\tilde{p}^{*}+\frac{(n-k)(1-\bar{x})}{1-\bar{x}^{n-k}} \frac{1}{\bar{x}^{k}} \frac{1}{n}\left(\bar{x}^{n}-\tilde{p}^{* n}\right)>0
$$

If we take the limit of the LHS of (73) when $\bar{x} \rightarrow 1$, then we get the following inequality:

$$
\lim _{\bar{x} \rightarrow 1}\left[-\tilde{p}^{*}+\frac{1}{n}\left(1-\tilde{p}^{* n}\right)\right]>0
$$

This inequality implies that $1-\tilde{p}^{* n}-n \tilde{p}^{*}>0$ in the limit when $\bar{x} \rightarrow 1$. As a result, (71) is positive. But this constitutes a contradiction and therefore it cannot be the case that $\hat{p}^{*}>\tilde{p}^{*}$ when $\bar{x} \rightarrow 1$.

(c) Now we prove that $\hat{p}^{*}>\tilde{p}^{*}$ if $n=3$. We will use the results from the proof of part (b) of this proposition. If $n=3$,

$$
Y(\cdot)_{\hat{p}^{*}=\tilde{p}^{*}}=1-\tilde{p}^{* 3}-2 \bar{x} \tilde{p}^{*}+\tilde{p}^{*}\left(\bar{x}^{2}-\tilde{p}^{* 2}\right)-\bar{x} \tilde{p}^{*}=1-2 \tilde{p}^{* 3}+\left(\bar{x}^{2}-3 \bar{x}\right) \tilde{p}^{*}
$$


while condition (73) reduces to $\tilde{p}^{*}<1-\bar{x}+\frac{1}{3 \bar{x}^{2}}\left(\bar{x}^{3}-\tilde{p}^{* 3}\right)$.

Then,

$$
\begin{aligned}
Y(\cdot)_{\hat{p}^{*}=\tilde{p}^{*}} & >1-2 \tilde{p}^{* 3}+\left(\bar{x}^{2}-3 \bar{x}\right)\left(1-\bar{x}+\frac{\bar{x}^{3}-\tilde{p}^{* 3}}{3 \bar{x}^{2}}\right)=1+\tilde{p}^{* 3} \frac{3-7 \bar{x}}{3 \bar{x}}-\frac{\bar{x}}{3}(3-\bar{x})(3-2 \bar{x}) \\
& >1+\left(\frac{1}{2}\right)^{3} \frac{3-7 \bar{x}}{3 \bar{x}}-\frac{\bar{x}}{3}(3-\bar{x})(3-2 \bar{x})=\frac{1}{24 \bar{x}}\left(3+17 \bar{x}-72 \bar{x}^{2}+72 \bar{x}^{3}-16 \bar{x}^{4}\right)
\end{aligned}
$$

which is always positive. Therefore, $Y_{\hat{p}^{*}=\tilde{p}^{*}}>0$ and $\hat{p}^{*}>\tilde{p}^{*}$ if $n=3$.

(d) Finally, in the limit when $n \rightarrow \infty$ the FOC of the merged entity becomes

$$
1-\left(\bar{x}-\tilde{p}^{*}+\hat{p}^{*}\right)^{k}-k\left(\bar{x}-\tilde{p}^{*}+\hat{p}^{*}\right)^{k-1} \hat{p}^{*}=0
$$

while that of a non-merging firm becomes

$$
\frac{1}{1-\bar{x}}\left(\bar{x}-\hat{p}^{*}+\tilde{p}^{*}\right)^{k}\left(1-\bar{x}-\tilde{p}^{*}\right)=0 .
$$

This implies that $\lim _{n \rightarrow \infty} \tilde{p}^{*}=1-\bar{x}$.

The LHS of (75) decreases in $\hat{p}^{*}$. Then, if $\hat{p}^{*}<\tilde{p}^{*}$, the LHS of (75) must be negative if we replace $\hat{p}^{*}$ by $\tilde{p}^{*}=1-\bar{x}$. However,

$$
1-\bar{x}^{k}-k \bar{x}^{k-1}(1-\bar{x})=1+(k-1) \bar{x}^{k}-k \bar{x}^{k-1} \geq 0
$$

where the inequality follows from setting $\bar{x}=1$. This establishes a contradiction so $\hat{p}^{*}<\tilde{p}^{*}$ cannot hold in the limit when $n \rightarrow \infty$.

Proof of Proposition 8. Taking the FOCs, imposing the condition that and $\tilde{p}=\tilde{p}^{*}$ and $\hat{p}=\hat{p}^{*}$ and simplifying gives:

$$
\begin{gathered}
\frac{1}{n-k} \frac{1-\bar{x}^{n-k}}{1-\bar{x}}\left(1-\bar{x}-\tilde{p}^{*}\right)+\frac{1}{n-k}\left[\bar{x}^{n-k}-\left(\overline{\bar{x}}-\hat{p}^{*}+\tilde{p}^{*}\right)^{n-k}\right]+\int_{0}^{\overline{\bar{x}}-\hat{p}^{*}}\left(\varepsilon+\tilde{p}^{*}\right)^{n-k-1}\left(\varepsilon+\hat{p}^{*}\right)^{k} d \varepsilon=0 \\
\left(\overline{\bar{x}}-\hat{p}^{*}+\tilde{p}^{*}\right)^{n-k}\left(1-\overline{\bar{x}}^{k}-k \overline{\bar{x}}^{k-1} \hat{p}^{*}\right)+k \int_{0}^{\overline{\bar{x}}-\hat{p}^{*}}\left(\varepsilon+\tilde{p}^{*}\right)^{n-k}\left(\varepsilon+\hat{p}^{*}\right)^{k-2}\left(\varepsilon+k \hat{p}^{*}\right) d \varepsilon=0
\end{gathered}
$$

Assume that there is a pair of non-negative prices $\hat{p}^{*}$ and $\tilde{p}^{*}$ that satisfy the system of equations (76) and (77). For these prices to be consistent with equilibrium, first, they must be lower than or equal to the monopoly prices $p_{k}^{m}$ and $p^{m}$, respectively; moreover, the reservation utility at the merged entity must be lower than the reservation utility at a non-merging firm.

Take the LHS of the FOC of a non-merging firm, equation (76). Note that the integral in this equation is positive. Observe now that the second summand is also positive because the assumption $\bar{x}-\tilde{p}^{*}>\overline{\bar{x}}-\hat{p}^{*}$ implies that $\bar{x}>\overline{\bar{x}}-\hat{p}^{*}+\tilde{p}^{*}$. As a consequence, if an equilibrium exists, the first term of the FOC (76) must be negative. This implies that in equilibrium, it must be the case that $\tilde{p}^{*}>1-\bar{x}$.

Take now the limiting case where search cost is high so that $\bar{x} \rightarrow 1 / 2$. If this is so, for an equilibrium to exist, it must be the case that $\tilde{p}^{*}>1 / 2$. But this is a contradiction because $\tilde{p}^{*} \leq p^{m}=1 / 2$. 


\section{References}

[1] Anderson, S. P. and Renault, R.: "Pricing, Product Diversity, and Search Costs: a BertrandChamberlin-Diamond Model," RAND Journal of Economics 30, 719-35, 1999.

[2] Arbatskaya, M.: "Ordered Search," RAND Journal of Economics 38, 119-127, 2007.

[3] Armstrong, M., Vickers J. and Zhou, J.: "Prominence and Consumer Search," RAND Journal of Economics, 40-2, 209-33, 2009.

[4] Armstrong, M. and Zhou, J.: "Paying for Prominence," The Economic Journal, 121, F368-F395, 2011.

[5] Bar-Isaac, H., Caruana, G. and Cuñat, V.: "Search, Design and Market Structure," American Economic Review, forthcoming, 2011.

[6] Diamond, P.: "A Model of Price Adjustment," Journal of Economic Theory 3, 156-168, 1971.

[7] Deneckere, R. and Davidson, C.: "Incentives to Form Coalitions with Bertrand Competition," RAND Journal of Economics 16, 473-86, 1985.

[8] Farrell, J. and Shapiro, C.: "Horizontal Mergers: An Equilibrium Analysis," American Economic Review 1, 107-126, 1990.

[9] Fischer, J.H. and Harrington, J.E.: "Product Variety and Firm Agglomeration," The RAND Journal of Economics 27-2, 281-309, 1996.

[10] Haan, M. A. and J. L. Moraga-González: "Advertising for Attention in a Consumer Search Model," The Economic Journal, 121, 552-579, 2011.

[11] Janssen, M. C. W. and J. L. Moraga-González: "On Mergers in Consumer Search Markets," Tinbergen Institute Discussion Paper \# 2007-054/1, The Netherlands, 2007.

[12] Klemperer, P.: "Equilibrium Product Lines: Competing Head-to-Head May be Less Competitive," American Economic Review 82-4, 740-755, 1992.

[13] Klemperer, P. and Padilla A.J.: "Do Firms' Product Lines Inlcude Too Many Varieties," RAND Journal of Economics 28-3, 472-488, 1997.

[14] Kohn, M. and Shavell, S.: "The theory of search," Journal of Economic Theory, 9, 93-123, 1974.

[15] McAfee, R.P. and Williams, M.A.: "Horizontal Mergers and Antitrust Policy," Journal of Industrial Economics 40, 181-186, 1992.

[16] Moraga-González, J. L. and Petrikaitè, V.: "Mergers, Consumer Search and Product Differentiation," Tinbergen Institute Discussion Paper \# TI 2011-099/1, The Netherlands, June, 2011.

[17] Perloff, J. M. and Salop, S. C.: "Equilibrium with Product Differentiation" Review of Economic Studies, 52: 107-120, 1985

[18] Perry, M. K. and Porter, R. H.: "Oligopoly and the Incentive for Horizontal Merger," American Economic Review, 75: 219-227, 1985

[19] Salant, S. W., Switzer, S. and Reynolds, R. J.: "Losses from Horizontal Mergers: The Effects of Exogenous Change in Industry Structure on Cournot-Nash Equililibrium," Quarterly Journal of Economics, 98: 185-99, 1983. 
[20] Schulz, N. and Stahl, K.: "Do Consumers Search for the Highest Price? Oligopoly Equilibrium and Monopoly Optimum in Differentiated-Products Markets," RAND Journal of Economics 27-3, 542-562, 1996.

[21] Stahl, K.: "Differentiated Products, Consumer Search and Locational Oligopoly," Journal of Industrial Economics 31, 97-114, 1982.

[22] Weitzman, M. L.: "Optimal Search for the Best Alternative," Econometrica 47-3, 641-654, 1979.

[23] Whinston, M.D.:Lectures on Antitrust Economics, MIT Press, Cambridge, 2006.

[24] Williamson, O.E.: "Economies as an Antitrust Defence: The Welfare Tradeoffs," American Economic Review 58, 407-426, 1968

[25] Wolinsky, A.: "Retail Trade Concentration Due to Consumers' Imperfect Information," Bell Journal of Economics 101-3, 493-511, 1983.

[26] Wolinsky, A.: "True Monopolistic Competition as a Result of Imperfect Information," Quarterly Journal of Economics 101-3, 493-511, 1986.

[27] Wolinsky, A.: "Procurement via Sequential Search," Journal of Political Economy 113-4, 785-810, 2005.

[28] Zhou, J.: "Ordered Search in Differentiated Markets," International Journal of Industrial Organization 29-2, 253-262, 2011.

[29] Zhou, J.: "Prominence and Consumer Search: The Case of Multiple Prominent Firms," MPRA paper No. 12.554, 2009b. 